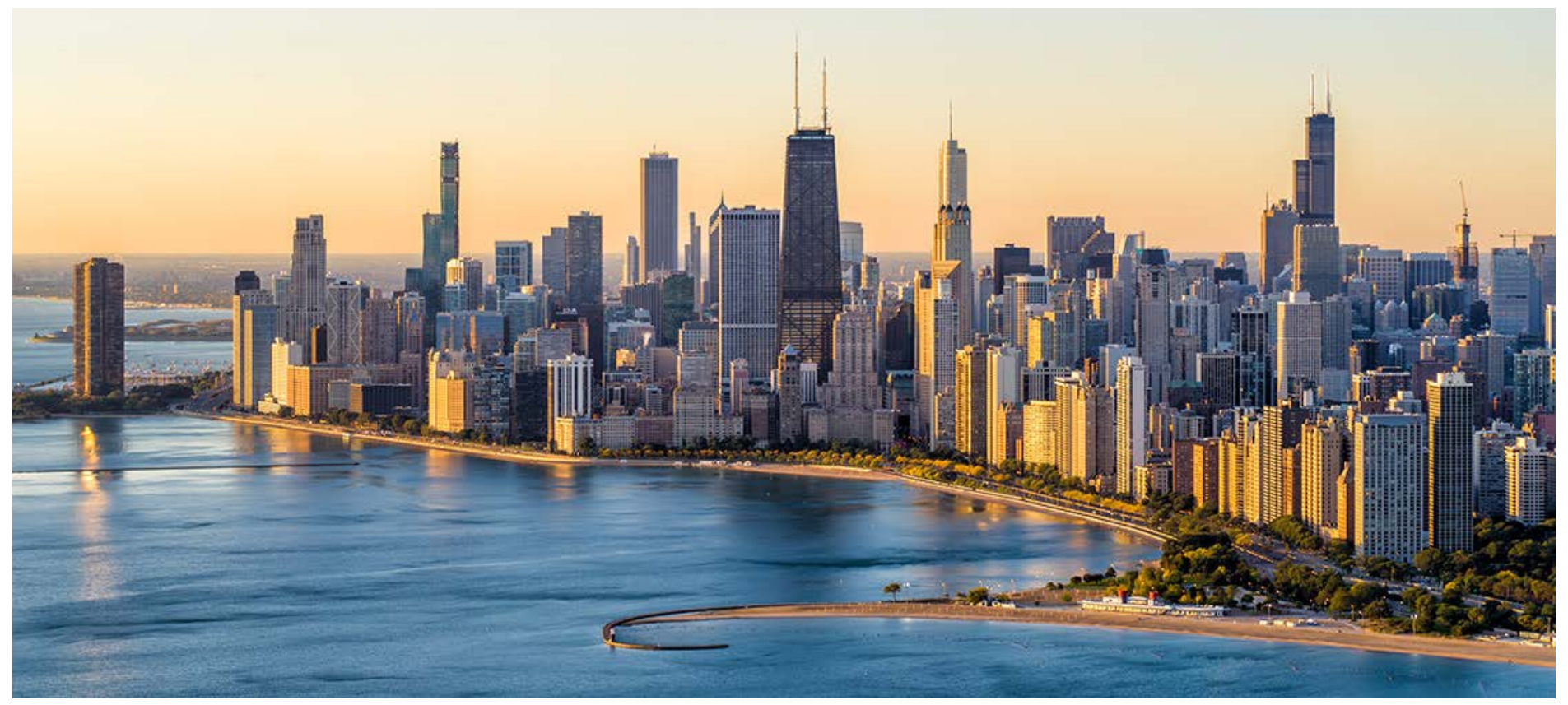

\title{
Industrial Conveyor Motor Performance Evaluation
}

Alex Bulk, Greg Shoukas, and Ramin Faramarzi

National Renewable Energy Laboratory

Produced under direction of ComEd by the National Renewable Energy Laboratory (NREL) under Technical Services Agreement TSA-19-01159

NREL is a national laboratory of the U.S. Department of Energy Office of Energy Efficiency \& Renewable Energy

Operated by the Alliance for Sustainable Energy, LLC

This report is available at no cost from the National Renewable Energy Laboratory (NREL) at www.nrel.gov/publications.
Strategic Partnership Project Report NREL/TP-5500-80051

September 2021 


\title{
Industrial Conveyor Motor Performance Evaluation
}

\author{
Alex Bulk, Greg Shoukas, and Ramin Faramarzi
}

National Renewable Energy Laboratory

\section{Suggested Citation}

Bulk, Alex, Greg Shoukas, and Ramin Faramarzi. 2021. Industrial Conveyor Motor Performance Evaluation. Golden, CO: National Renewable Energy Laboratory. NREL/TP-5500-80051. https://www.nrel.gov/docs/fy21osti/80051.pdf.

NREL is a national laboratory of the U.S. Department of Energy Office of Energy Efficiency \& Renewable Energy Operated by the Alliance for Sustainable Energy, LLC

This report is available at no cost from the National Renewable Energy Laboratory (NREL) at www.nrel.gov/publications.

Contract No. DE-AC36-08GO28308
Strategic Partnership Project Report NREL/TP-5500-80051

September 2021

National Renewable Energy Laboratory 15013 Denver West Parkway Golden, CO 80401

303-275-3000 • www.nrel.gov 


\section{NOTICE}

This work was authored by the National Renewable Energy Laboratory, operated by Alliance for Sustainable Energy, LLC, for the U.S. Department of Energy (DOE) under Contract No. DE-AC36-08GO28308. Support for the work was also provided by ComEd through CLEAResult under TSA-19-01159. The views expressed in the article do not necessarily represent the views of the DOE or the U.S. Government.

The ComEd Energy Efficiency Program is funded in compliance with state law.

This report is available at no cost from the National Renewable Energy Laboratory (NREL) at www.nrel.gov/publications.

U.S. Department of Energy (DOE) reports produced after 1991 and a growing number of pre-1991 documents are available free via www.OSTI.gov.

Cover photo from iStock 1180689542.

NREL prints on paper that contains recycled content. 


\section{Acknowledgments}

The authors would like to thank the ComEd Energy Efficiency Program and CLEAResult for supporting this research. This report was prepared by the National Renewable Energy Laboratory (NREL) Building Technologies and Science Center.

The authors would also like to express their sincere gratitude to the North Carolina Advanced Energy Corporation for their detailed motor characterization analysis and contribution to this report, and to Turntide Technologies for performing the physical dynamometer testing and providing equipment and labor at their Sunnyvale, California, location. From NREL, the authors would like to thank Lauren Klun for managing the project, and both Ian Doebber and Omkar Ghatpande for providing motor and dynamometer expertise. Finally, the authors would like to thank Stephen Labarge of ComEd, and Leah Scull and Gabriel Duarte of CLEAResult for their in-depth report review.

For more information, contact:

Alex Bulk

National Renewable Energy Laboratory

Email: alexander.bulk@nrel.gov 


\section{List of Acronyms}

AC

AHRI

ANSI

ComEd

DC

DOE

HRSRM

NEMA

NREL

SRM

VFD

$\Delta \mathrm{kWh}$

$\mathrm{HP}$

$\mathrm{Hz}$

$\mathrm{kg}$

$\mathrm{kW}$

$\mathrm{kWh} /$ day

$\mathrm{MHz}$

$\mathrm{m} / \mathrm{s}$

$\mathrm{mL}$

$\mathrm{Ph}$

RPM alternating current

Air Conditioning, Heating, and Refrigeration Institute: a North American trade association of air-conditioning, heating, and commercial refrigeration equipment manufacturers

American National Standards Institute: a private nonprofit organization that oversees consensus standards for products, services, processes, systems, and personnel

The Commonwealth Edison Company: the sole electric utility provider for Chicago and Northern Illinois

direct current

U.S. Department of Energy

high rotor pole switched-reluctance motor

National Electrical Manufacturers' Association

National Renewable Energy Laboratory

switched-reluctance motor

variable frequency drives

delta kilowatt hours: the difference in measured energy used to define savings horsepower: a unit of measurement of power

hertz: a unit of electrical frequency

kilogram: a unit of measurement of mass

kilowatt: a unit of measurement of power

kilowatt-hours per day: a unit of measurement of energy consumed over one 24hour period

megahertz: a unit of electrical frequency; equal to one million hertz

meters per second: a unit of measurement of velocity

milliliter: a unit of measurement of volume

phase: the number of distinct electrical wave cycles

revolutions per minute: a unit of motor speed 


\section{Executive Summary}

This project is part of an effort by the Commonwealth Edison Company (ComEd) to evaluate the energy saving potential of emerging technologies for inclusion in their energy efficiency incentive portfolio. The objective of this project is to evaluate the energy efficiency potential of high-efficiency motor and drive system retrofits in industrial conveyor belt applications. The project is composed of two phases:

1. Laboratory performance characterization of a high-efficiency and baseline motor/drive under various torque and frequency scenarios

2. Development of an engineering tool to estimate the daily and annual energy and demand savings of high-efficiency motors in a representative conveyor belt system.

In phase 1, the performance of a high-efficiency high rotor pole switched-reluctance motor (HRSRM) operating in a 1- to 3-horsepower (HP) range was evaluated. The efficiency and power consumption of the HRSRM were assessed on a benchtop dynamometer along with a 2-HP baseline premium-efficiency alternating current (AC) induction motor equipped with a variable frequency drive (VFD) from a selected conveyor section in a ComEd customer facility. The performance characterization of the two motor/drive systems was outsourced to Advanced Energy, an ISO 17025-accredited laboratory. Because of the high-frequency torque ripple characteristic of switched-reluctance motors (SRMs), Advanced Energy was not able to adequately average measurements due to a low sampling frequency of their torque transducer. Therefore, a second assessment was conducted at Turntide's laboratory, which was equipped with a dynamometer utilizing a higher-frequency torque transducer. The baseline motor/drive was evaluated at both locations to ensure the different test instruments had no other effect on results. All tests were conducted in accordance with ANSI/ASHRAE 222-2018 [1], and under close supervision of engineers from the National Renewable Energy Laboratory (NREL).

In phase 2, an engineering calculation tool was developed using models based on guidelines according to ANSI/ISO standard 5048-1989 [2]. This tool was developed to estimate energy savings of the HRSRM in a selected conveyor system application. The tool allows any user to calculate energy consumption/savings in any straight belt conveyor. The tool is provided with a motor performance library from the U.S. Department of Energy's (DOE's) MotorMaster-Plus database of 16,359 motors [3]. This library enables users to compare performance of a wide variety of motors in existing conveyor applications, and/or to optimize conveyor design. Detailed instructions for using the tool are provided in this report in Appendix A.

Using conveyor structural and operational parameters provided by ComEd's customer, energy consumption was calculated for a 10-hour and 24-hour operation day, which yielded 1.65 and 3.96 $\mathrm{kWh}$ /day for the baseline induction motor/VFD and $1.14 \mathrm{kWh}$ and $2.73 \mathrm{kWh} /$ day for the SRM, respectively. This corresponded to $0.51 \Delta \mathrm{kWh}$ /day savings across a 10-hour operation period and 1.23 $\Delta \mathrm{kWh}$ /day across 24 hours, which constituted a $31.0 \%$ reduction in total daily energy consumption. If integrated yearly, including weekends but excluding holidays, annual energy consumption in the baseline motor and VFD was $587 \mathrm{kWh}$ and 1,408 kWh, and the SRM was $405 \mathrm{kWh}$ and $972 \mathrm{kWh}$ for 10 - and 24-hour operation days, respectively. This yielded annual savings of $182 \Delta \mathrm{kWh}$ and $436 \Delta \mathrm{kWh}$.

The speed and torque demand at which the selected conveyor belt would operate was very low for the baseline motor and drive systems' operational range. This resulted in low operational efficiency in the baseline motor and drive. The SRM yielded significant savings compared to the induction motor/VFD 
due to the higher efficiencies at the low speeds and torques. The higher part-load efficiency of the SRM also reduced the estimated mean power by $31 \%$ or $53 \mathrm{~W}(165 \mathrm{~W}$ to $114 \mathrm{~W})$. Results from dynamometer characterization revealed that the SRM maintained significantly higher efficiency across a wide operational range. The SRM efficiency was $6.4 \%$ to $18.5 \%$ higher than the baseline scenario across varying torques at 1,800 RPM. The higher efficiencies of the SRM were even more pronounced at lower frequencies. At a $20-\mathrm{Hz}$ frequency (600 RPM), the SRM efficiency was $21.2 \%$ to $34.3 \%$ higher than the baseline motor/drive.

A sensitivity analysis unveiled that the mass of the idlers was the most influential parameter impacting the system torque. The belt's mass, conveyed material, and combined frictional resistances had considerably less impact on the torque. Overall, the SRM performed more efficiently under various scenarios where all operational parameters were changed. 


\section{Table of Contents}

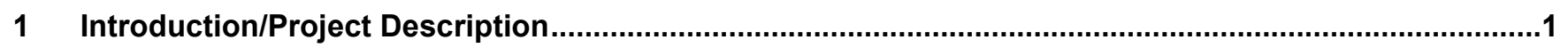

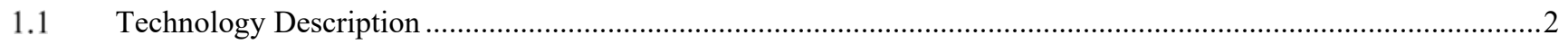

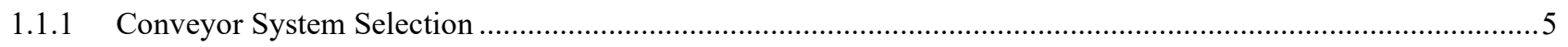

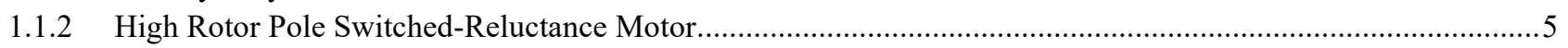

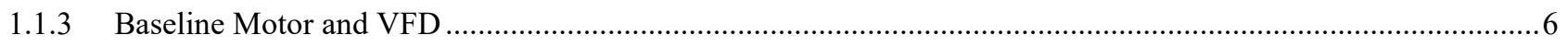

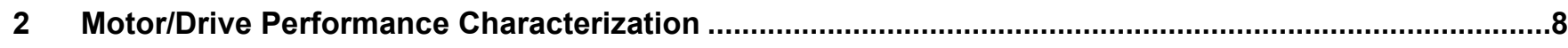

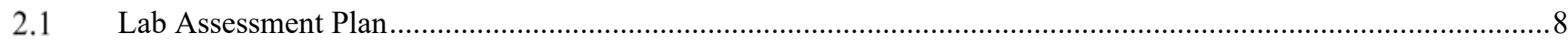

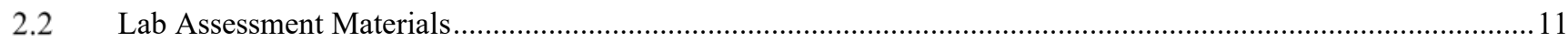

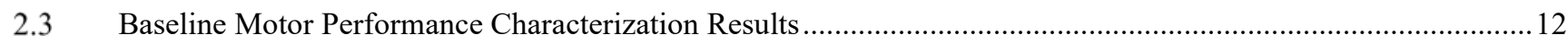

$2.4 \quad$ Switch-Reluctance Motor Performance Characterization Results..................................................................... 14

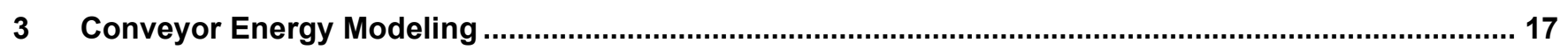

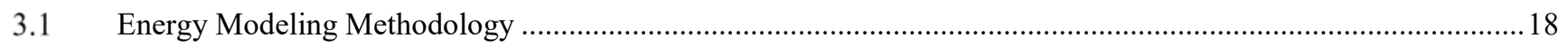

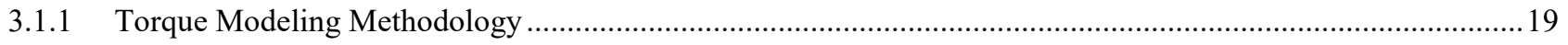

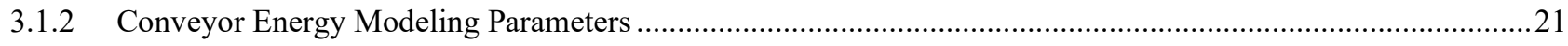

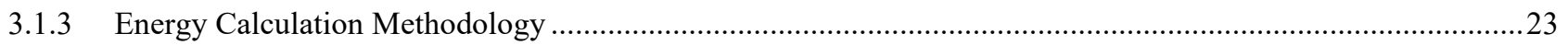

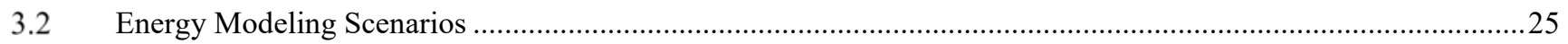

3.2.1 Peak Demand; Daily and Yearly Savings Assessments ...........................................................................25

3.2.2 Assessment of Energy Sensitivity to Conveyor Parameters ..........................................................................27

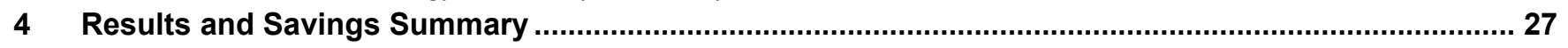

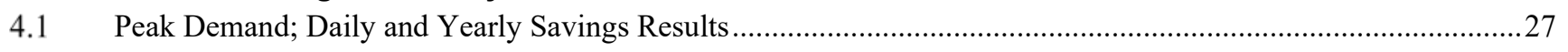

4.2 Effect of Conveyor Parameters on Energy Consumption and Savings ……......................................................... 31

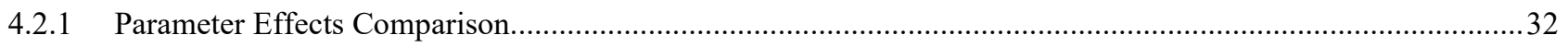

4.2.2 Effect of Full Parameter Variation, Discussion ................................................................................... 37

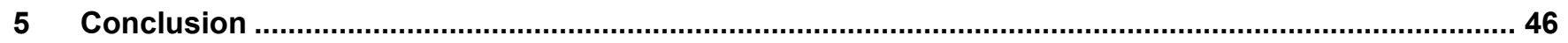

Appendix A. Instructions for Conveyor Modeling Calculation Tool................................................... 50

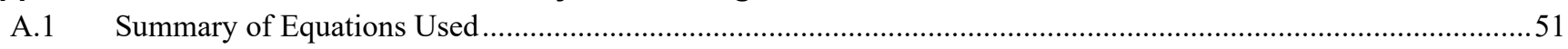

A.2 Sheets 1-2: Baseline/Proposed Motor Characterization Inputs Sheet................................................................52

A.3 Sheet 3: Conveyor Structural Parameter Inputs Sheet..................................................................................5

A.4 Sheet 4: Conveyor Operational Parameter Inputs Sheet...................................................................................5

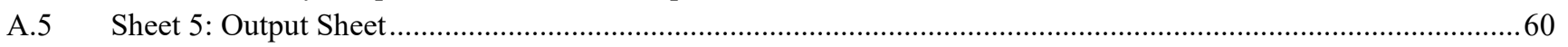

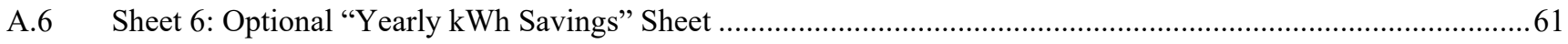

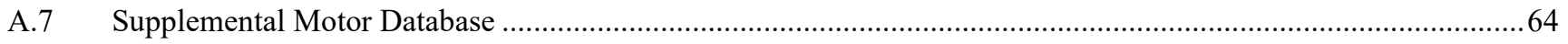

Appendix B. Tabulated Motor/Drive System Performance Characterization Data ................................67

Appendix C. Sensitivity Analysis Full Result Data......................................................................... 70 


\section{List of Tables}

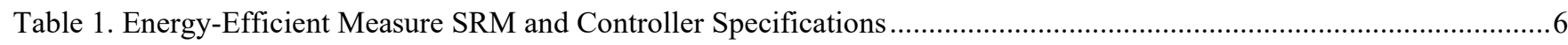

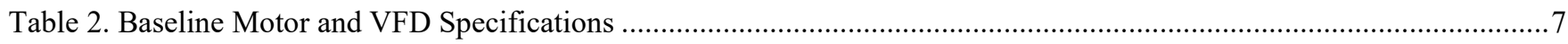

Table 3. List of Dynamometer Characterization Torque and Frequency Setpoints ..........................................................9

Table 4. Summary of Measurement Equipment Used to Conduct Motor/Drive Performance Characterization at Turntide's

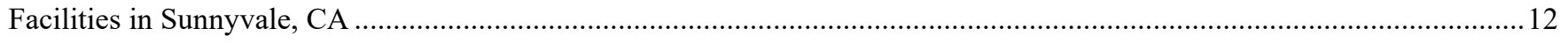

Table 5. Baseline ABB Motor and Allen-Bradley VFD Noise Level Testing Results .....................................................14

Table 6. Energy-Efficient SRM Noise Level Testing Results ................................................................................17

Table 7. Assumption-Based Requirements for Using the ISO 5048 Standard-Based Conveyor Energy Modeling Tool

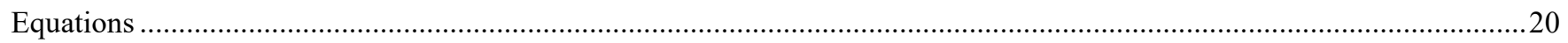

Table 8. List of Conveyor Energy Modeling Tool Structural Parameter Inputs and Descriptions ........................................21

Table 9. List of Conveyor Energy Modeling Tool Operational Parameter Inputs and Descriptions .....................................23

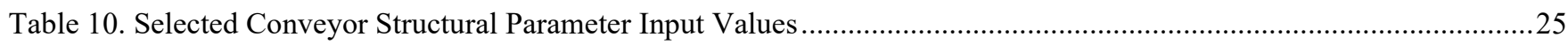

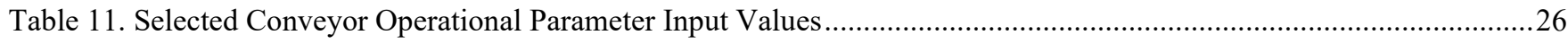

Table 12. Total Estimated Daily Conveyor Motor Energy Consumption and Savings by SRM .........................................27

Table 13. Total Estimated Yearly Conveyor Motor Energy Consumption and Savings by SRM ......................................28

Table 14. Baseline ABB Motor and Allen-Bradley VFD Performance Characterization Results .........................................67

Table 15. Energy-Efficient Switch-Reluctance Motor Performance Characterization Results ..............................................69

\section{List of Figures}

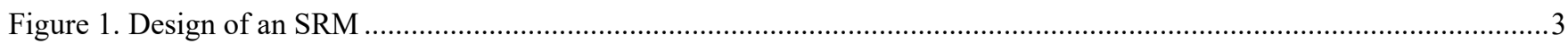

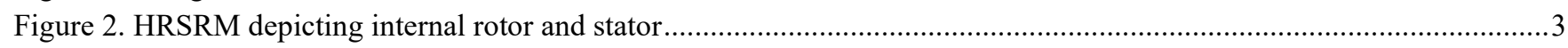

Figure 3. Diagram of generated magnetic field in an AC induction motor (left) and SRM (right) .....................................4

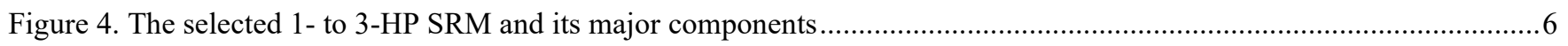

Figure 5. Baseline 2-HP induction motor (left), and VFD (right).........................................................................

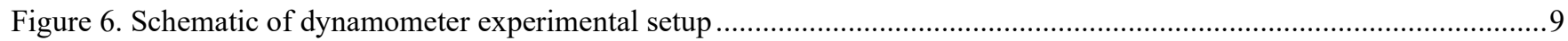

Figure 7. Relationship between torque ripple and frequency

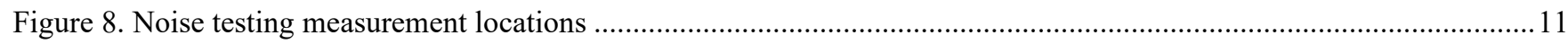

Figure 9. Image of baseline ABB motor on test dynamometer and Allen-Bradley VFD module .......................................12

Figure 10. Baseline induction motor/VFD efficiency performance characterization curve with respect to torque ...................13

Figure 11. Baseline induction motor/VFD efficiency performance characterization curve with respect to rotational velocity 13

Figure 12. Image of energy-efficient SRM on test dynamometer and controller module.................................................... 14

Figure 13. Energy-efficient switch-reluctance motor efficiency performance characterization curve with respect to torque ...15

Figure 14. Energy-efficient switch-reluctance motor efficiency performance characterization curve with respect to torque...15

Figure 15. Comparison of motor and drive system efficiency between the SRM and baseline induction motor/VFD with

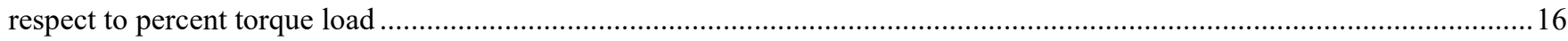

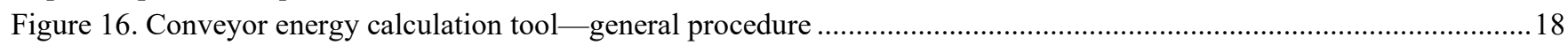

Figure 17. Calculator tool output conveyor drive system efficiency at estimated torque (10-hour operation) .........................29

Figure 18. Calculator tool output conveyor estimated daily power consumption (10-hour operation)...................................29

Figure 19. Calculator tool output total conveyor estimated torque demand and belt speed (10-hour operation) .....................30

Figure 20. Sensitivity of baseline ABB motor/Allen-Bradley VFD energy consumption to conveyor structural and operational

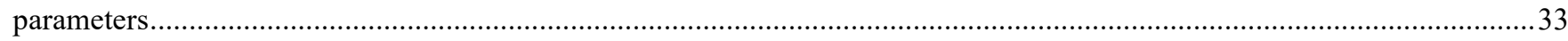

Figure 21. Sensitivity of SRM energy consumption to conveyor structural and operational parameters ...............................34

Figure 22. Sensitivity of SRM energy savings to conveyor structural and operational parameters........................................36

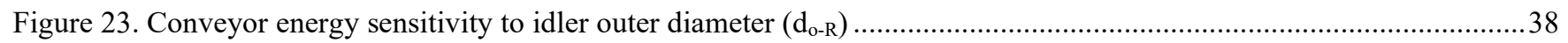

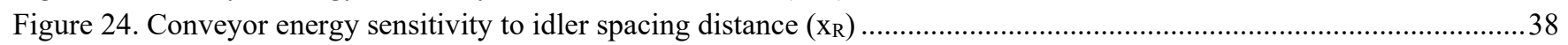




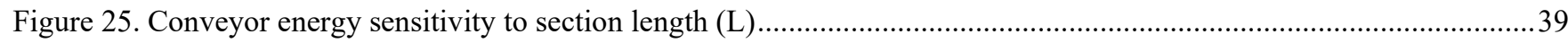

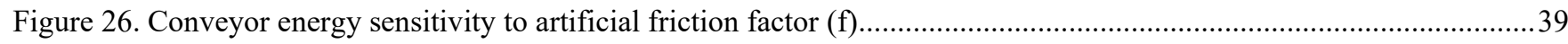

Figure 27. Conveyor energy sensitivity to idler width $\left(b_{R}\right.$, top), and density of the rotating parts $\left(\rho_{\mathrm{R}}\right.$, bottom) ...................40

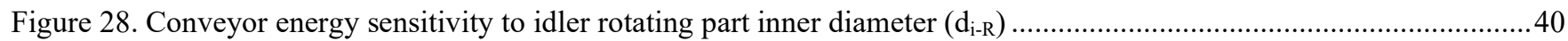

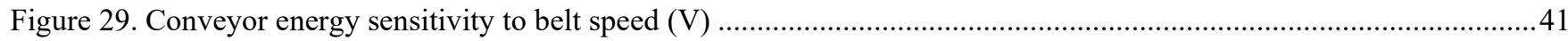

Figure 30. Conveyor energy sensitivity to section guide board width $\left(b_{1}\right.$, top), and density of the conveyed product material

$(\rho$, bottom)

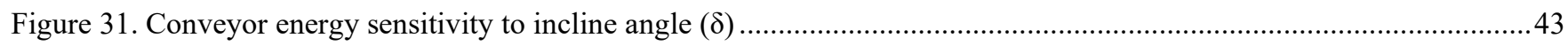

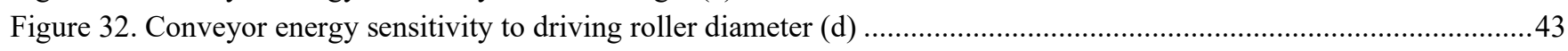

Figure 33. Conveyor energy sensitivity to belt width ( $b_{0}$, top), belt thickness $\left(t_{b}\right.$, middle), and belt material density ( $\rho_{b}$,

bottom)

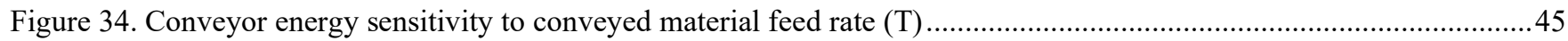

Figure 35. Conveyor energy sensitivity to material-guide board friction coefficient $(\mu)$.......................................................45

Figure 36. Conveyor energy sensitivity to idler coating thickness ( $\mathrm{t}_{\mathrm{c}-\mathrm{R}}$, top), and coating material density ( $\rho_{\mathrm{c}-\mathrm{R}}$, bottom) .......46

Figure 37. Baseline or proposed motor performance characterization data input sheet....................................................53

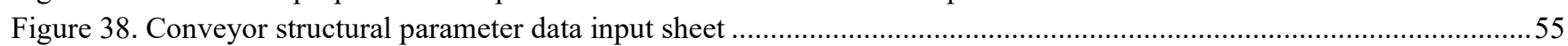

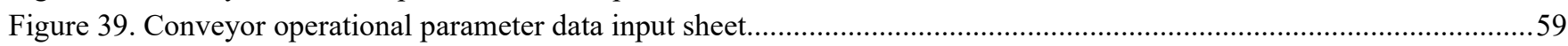

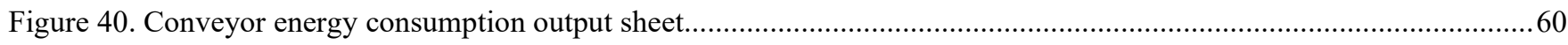

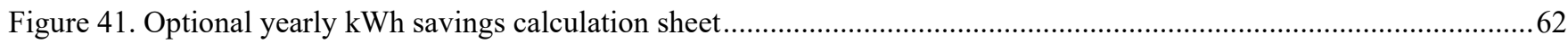

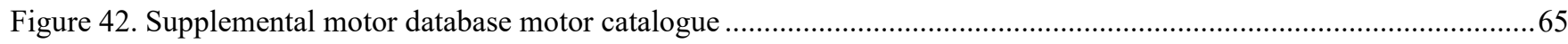

Figure 43. Supplemental motor database - performance curve data input sheet .............................................................66

Figure 44. Sensitivity of motor/drive system energy consumption and savings to variation in conveyor structural parameters: section length $(\mathrm{L})$, incline angle $(\delta)$, guide friction coefficient $(\mu)$, driving roller diameter $(\mathrm{d})$, and belt width $\left(\mathrm{b}_{0}\right) \ldots \ldots \ldots \ldots \ldots . . . .71$ Figure 45. Sensitivity of motor/drive system energy consumption and savings to variation in conveyor structural parameters: belt thickness $\left(t_{b}\right)$, belt density $\left(\rho_{b}\right)$, artificial friction factor $(f)$, idler spacing $\left(x_{R}\right)$, and idler width $\left(b_{R}\right) \ldots \ldots \ldots \ldots \ldots \ldots \ldots \ldots \ldots \ldots . . .72$ Figure 46. Sensitivity of motor/drive system energy consumption and savings to variation in conveyor structural parameters: idler rotating part inner diameter $\left(\mathrm{d}_{\mathrm{i}-\mathrm{R}}\right)$, outer diameter $\left(\mathrm{d}_{\mathrm{o}-\mathrm{R}}\right)$, idler rotating part material density $\left(\rho_{\mathrm{R}}\right)$, idler coating thickness

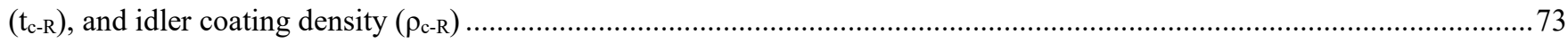

Figure 47. Sensitivity of motor/drive system energy consumption and savings to variation in conveyor operational parameters: belt speed $(\mathrm{V})$, section width $\left(b_{1}\right)$, conveyed product material density $\left(\rho_{R}\right)$, material mass feed rate $(T)$ .74 


\section{Introduction/Project Description}

The purpose of this project is to estimate the energy savings potential from a switched-reluctance motor (SRM) compared to an induction motor equipped with variable frequency drive (VFD) in a straight belt conveyor application. To experimentally evaluate savings in a realistic scenario, a baseline motor and VFD were selected from one of ComEd's manufacturing customers' conveyor systems. It was desired to not only estimate savings in the selected conveyor system, but to evaluate potential savings from using the SRM in any straight belt conveyor. Therefore, NREL developed a conveyor system energy calculation tool to supplement the experimental results of this assessment. The project was divided into two segments:

1. Experimental performance characterization of the high-efficiency SRM and baseline induction motor and drive systems (Section 2 of this report).

2. Development of an engineering tool to estimate the daily and annual energy and demand savings of high-efficiency motors in a representative conveyor belt system (Section 3 of this report).

The experimental assessment involved characterizing the performance of both the high-efficiency SRM and baseline drive systems according to ANSI/ASHRAE 222-2018 [1]. The performance characterization involved mapping the torque, speed, input/output power, and efficiency of each motor/drive using a dynamometer and power analyzer. A dynamometer is a device that supplies a controlled braking torque to the motor and is fitted with a torque and speed transducer to measure torque and rotational speed in RPM, respectively. The power analyzer measures the input power to the drive system, and the output from the motor is used to calculate overall system efficiency.

Advanced Energy initially characterized the performance of both motor/drive systems at their ISO 17025-accredited laboratory. During this evaluation, however, the low sampling frequency of the torque transducer used was not able to sufficiently average measurements of the SRM due to high-frequency torque ripple characteristic of the motor design. Therefore, a second assessment using a higherfrequency torque transducer was conducted at Turntide's laboratory. The entire assessment was remotely overseen by Advanced Energy and NREL engineers, which included both the baseline and SRM motor/drives to ensure consistency between tests.

Subsequent to laboratory performance characterization, a conveyor energy calculation tool was developed to estimate daily and annual demand and energy savings. The framework of the tool is based on ANSI/ISO standard 5048-1989 [2]. It allows the user to input conveyor parameters into an Excel file that outputs daily torque, power, energy use, and efficiency, as well as daily and annual energy savings. The tool requires the following input parameters to calculate torque and speed, which will be used to estimate the electric power and efficiency of a motor/drive system:

- Structural parameters (e.g., section length, incline angle, belt/idler dimensions)

- Operational parameters (e.g., belt speed, feed rate of conveyed material onto the belt)

- Daily and yearly operational schedule.

Conveyor system efficiency and power consumption are calculated by interpolating the torque and speed demand to the characterized performance map of the baseline and energy-efficient drive systems. Power 
consumption is then integrated across the operation timeline to calculate daily and yearly consumption and $\Delta \mathrm{kWh}$ savings. If using the calculator tool to evaluate energy consumption by a conveyor with a different motor/drive system, the user is able to select motor manufacturing data provided in a supplemental catalogue collected from the U.S. Department of Energy's (DOE's) MotorMaster-Plus tool [3]. In this case, VFD efficiency losses at reduced speeds are estimated by the tool based on theory reported in literature $[4,5]$ to generate a motor/drive performance map. Speed and torque demand by the conveyor are then interpolated to the performance map as was done using the motor/drives evaluated here.

The estimated energy savings results from using the SRM in the selected conveyor section is provided in Section 4.1. Because the conveyor energy calculator tool can be used with any straight belt conveyor, it can also be used to optimize energy-efficient conveyor system design. Therefore, a "sensitivity" analysis was conducted to assess the effect of each conveyor parameter on the resulting energy consumption. The results of this analysis are provided in Section 4.2. Appendix A provides detailed instructions for using the tool.

\subsection{Technology Description}

The primary benefit of an SRM is that it can be operated below its rated speed without using a VFD. Therefore, it is not subjected to the losses incurred by a VFD. This is because unlike a VFD, an SRM does not require switching internal transistors at the high frequency needed to produce a sinusoidal AC voltage to rotate the motor. Rather, DC current is converted from AC using an inverter controller and supplied directly to stationary stator poles. Each pole is individually excited and de-excited by this DC current at a specified frequency successively around the circumference of the motor. Therefore, the frequency can be adjusted manually through the controller to change the motor speed without generating losses that would be seen in an induction motor and VFD.

An example of an SRM rotor-stator pole configuration is shown in Figure 1. As with a typical induction motor, it is composed of a stationary stator and a rotor that is unfixed to rotate internally to the stator. The rotors are made of ferrous laminate material and have no windings, as current is not generated in them [6]. Here, stator poles A would be energized such that rotor poles 1 and 4 line up to generate a low-reluctance magnetic circuit [7]. Stator poles A would then be de-energized once stator poles B are energized. To maintain the low-reluctance magnetic circuit, the rotor would rotate clockwise such that rotor poles 3 and 6 would then align with stator pole B. Rotor poles 2 and 5 would then align with stator poles $\mathrm{C}$, and so on. The frequency adjusted by the controller would specify the frequency at which the stator poles are energized on and off, thereby switching the low-reluctance magnetic circuit about the circumference of the motor at a controlled speed. 


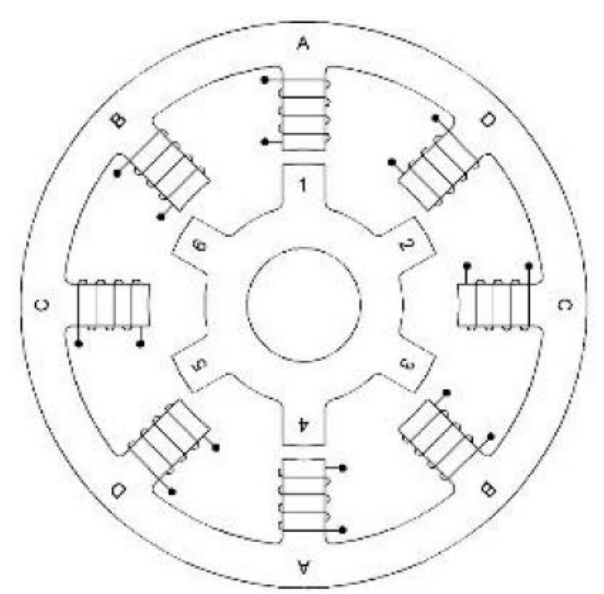

Figure 1. Design of an SRM

Image from [7]

An SRM requires an unequal number of stator poles and rotor poles to prevent each pole from aligning and causing the rotor to remain stationary [7]. Traditional SRMs, which contain only a few rotor and stator poles, previously did not operate as efficiently as NEMA Premium Efficiency induction motors (NEMA is the National Electrical Manufacturers' Association). The frequency at which the stator poles are switched on and off is dependent on the ratio of rotor poles to stator poles. Therefore, SRMs evolved to use a large number of rotor poles (HRSRMs) to reduce the switching frequencies required to operate the SRM at the same rotational velocities. When the stator poles of an SRM are energized and deenergized, there becomes a "pull and release" that causes torque ripple, such that there is a brief reduction in torque at the switching frequency of the SRM. Using a larger ratio of rotor poles than stator poles not only improves efficiency by reducing the switching frequency, but also reduces the effect of torque ripple [8]. A cut-away diagram of a typical HRSRM is shown in Figure 2.

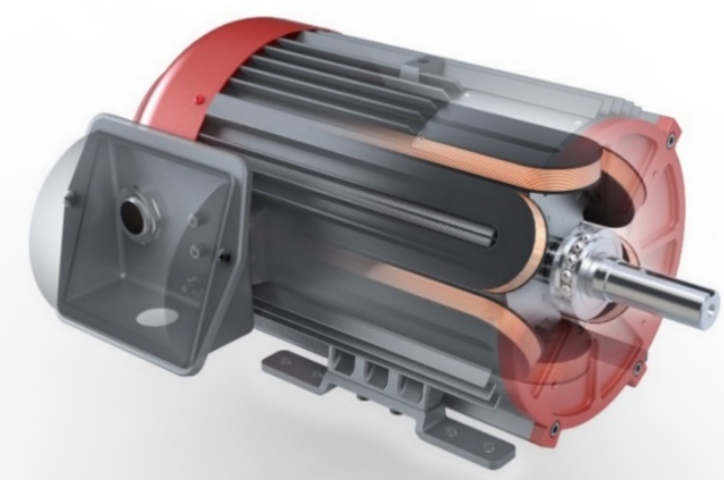

Figure 2. HRSRM depicting internal rotor and stator

Figure courtesy of Turntide Technologies

SRMs use a DC current in the stator poles to reduce the circuitry in the drive system design [6]. This is possible because the closest rotor pole is pulled toward an energized stator pole, and therefore the direction of rotation is not affected by the direction of the magnetic field [6]. For this reason, SRMs 
operate on a square electric current that is switched at the respective frequency to regulate rotational velocity. Generating a square current signal with the stator coil at the proper frequency requires feedback measurement of the motor velocity, which is determined by encoders that monitor rotor orientation [9].

Unlike an SRM, an asynchronous AC induction motor uses metal bars wrapped in electrically conductive windings as both the stator and rotor poles. The most common AC induction motors are composed of a "squirrel cage" design, in which the stator poles are situated evenly around the circumference of the motor [10]. When a three-phase AC current is passed through the stator windings, a rotating magnetic field is generated that moves about the circumference of the motor according to the frequency of the AC current $[10,11]$. The speed of this rotating magnetic field is defined as the synchronous speed, which is equivalent to double the ratio of frequency to the number of magnetic poles [10].

Through induction, current is generated through the rotor windings by the rotating magnetic field generated by the AC current in the stator windings. This current also induces its own magnetic field, which opposes the rotating stator magnetic field. The current in the rotor windings will try to adjust to the opposing magnetic fields based on Lenz's law [11]. However, because the current is generated by the stator magnetic field, the rotor will rotate to "catch up" to the rotating magnetic field. The torque generated by the motor is governed by the "slip," or the difference between the rotor speed and synchronous speed [6]. When a load is applied to a motor, the rotor speed is reduced, which increases the slip. The rotating magnetic field compensates, which causes more current to pass through the windings, thereby increasing torque [12]. A diagram showing the different magnetic fields generated in the $\mathrm{AC}$ induction motor versus an SRM is shown in Figure 3.
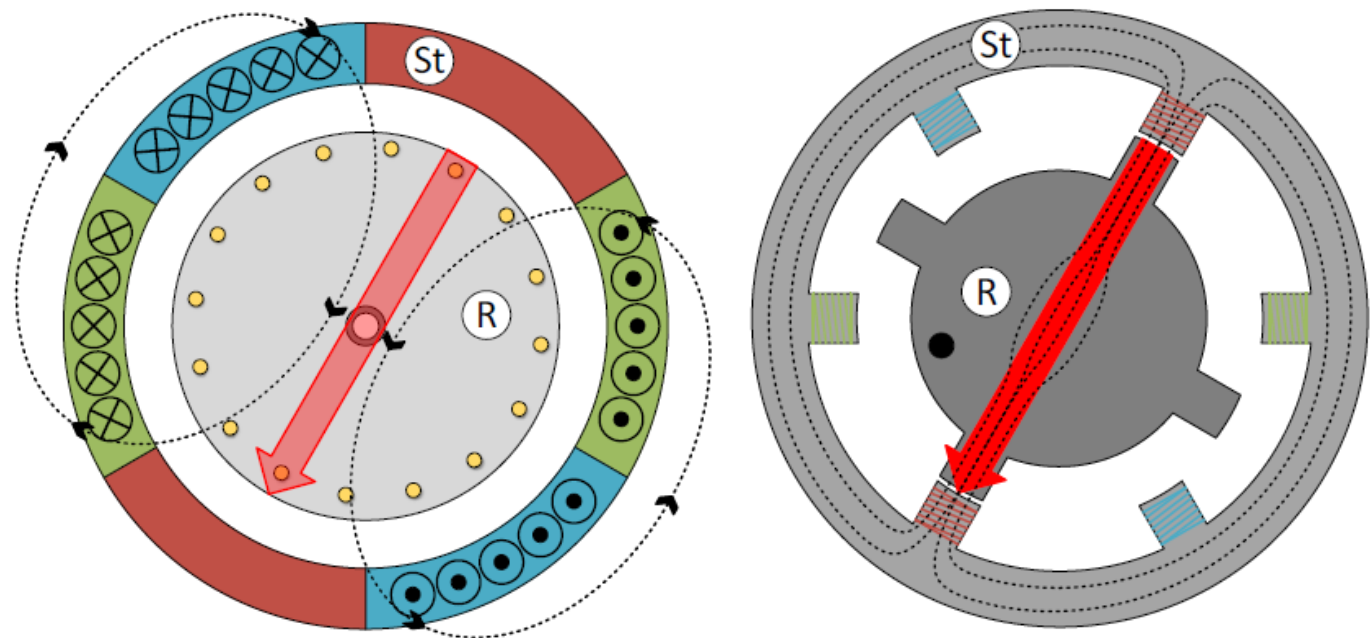

Figure 3. Diagram of generated magnetic field in an AC induction motor (left) and SRM (right)

Figure from [6]

An induction motor can only operate at a single speed, according to the input AC frequency. A VFD, however, can be coupled with an induction motor to adjust the frequency and thereby control the speed. To maintain a voltage/frequency ratio that does not saturate the magnetic circuit between rotor and stator, the VFD also controls the output voltage to the motor [13]. First, AC voltage is converted to DC and smoothed using a rectifier and filter capacitors [13]. Power transistors then convert the DC voltage 
to AC using pulse-width modulation, which involves controlling the time that the voltage is rapidly switched on and off to produce a sinusoidal waveform. The frequency at which a VFD switches the voltage on and off to produce a sinusoid is referred to as the "carrier frequency," which often is extremely high. The power required by the VFD to change transistor states at such a high frequency generates losses that ultimately lower the efficiency of the VFD and motor overall. A VFD is typically supplied with a digital user interface to control and monitor speed. Alternatively, a VFD can be linked to external software so that a manufacturer can schedule the motor to rotate at particular speeds throughout a varied operation timeline.

The selection of the baseline motor and VFD in this project was based on the most representative equipment specification at one of ComEd's industrial customers' facilities. The selected SRM was rated at the same horsepower, rated speed, and input power requirements as the baseline motor/drive. A description of the motor selection process and selected technologies is provided in the following sections.

\subsubsection{Conveyor System Selection}

Motor/drive system energy and power consumption is dictated by rotational speed and torque load, which depend on the motor/drive's specific application. In this project, the power and energy consumed by the baseline and SRM were evaluated based on a selected conveyor system configuration at a major industrial customer facility in ComEd's service territory. The selected facility is a large plant for a multinational snack food, candy, and beverage manufacturing corporation.

The ComEd customer facility contains 25 motor/drive systems used to operate various conveyor sections. Of the motors used with a VFD, a 2-HP motor was observed to be configured into more sections than any other motor-VFD used at this facility. Therefore, the 2-HP motor and VFD was selected as the baseline technology for this study to maximize energy savings. This baseline motor was an ABB model EM3774T 60-Hz induction motor, and the VFD was an Allen-Bradley PowerFlex 525 model 25B-D4P0N114.

Of the four conveyor sections driven by the selected baseline motor and VFD, one conveyor section was selected to compare estimated energy consumption between the SRM and baseline motor/VFD. It was desired to select a conveyor section that operated for the longest period of time and that conveyed the highest amount of material. The ComEd customer identified a representative section exhibiting the longest operational duration and material throughput. The conveyed material on this selected section was boxes of candy.

\subsubsection{High Rotor Pole Switched-Reluctance Motor}

To match the load requirements of the conveyor section selected at the ComEd customer's facility, an SRM rated to the same horsepower and speed as the selected baseline motor was used. This motor was a Turntide HRSRM (Figure 4) that operates at a range of 1 to 3 HP. The SRM controller was set to operate on a $460-\mathrm{V}$ input to match the baseline. The specifications of the SRM and controller are shown in Table 1. 
Table 1. Energy-Efficient Measure SRM and Controller Specifications

\begin{tabular}{|l|c|l|c|}
\hline Motor Model \#: & V01-0300-4-D00 & Controller Model \#: & SMC-P04W \\
\hline Motor Output Rating: & $1.0-3.0 \mathrm{HP}$ & Controller Input Voltage (V): & 460 \\
\hline Motor Voltage (V): & $680 \mathrm{VDC}$ & Controller Input Current (A): & $3.8-5.7$ \\
\hline Motor Rated Current (A): & 3.6 & Controller Input Frequency (Hz): & 60 \\
\hline Motor Rated Speed (RPM): & 1,800 & Controller Output Voltage (V): & $280-680$ VDC \\
\hline Motor Frequency (Hz): & - & Controller Output Current (A): & - \\
\hline Motor Service Factor: & 1.15 & Controller Output Frequency (Hz): & - \\
\hline Motor Frame: & $143 T / 145 T$ & & \\
\hline Motor Enclosure: & TEFC & & \\
\hline Motor Insulation Class: & F & & \\
\hline Motor Duty: & Continuous & & \\
\hline Motor Rated Efficiency: & $92 \%$ & & \\
\hline
\end{tabular}
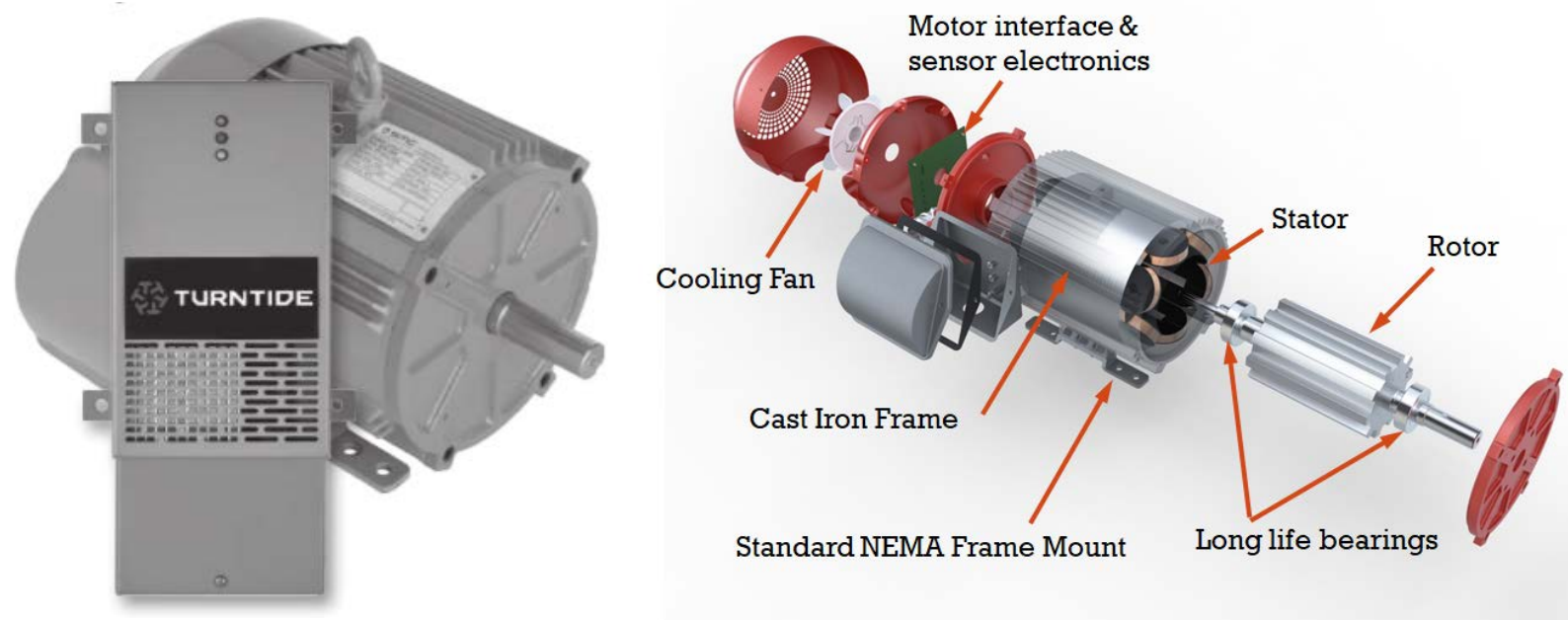

Figure 4. The selected 1- to 3-HP SRM and its major components

Figures courtesy of Turntide Technologies

\subsubsection{Baseline Motor and VFD}

An ABB NEMA Premium Efficiency induction motor and an Allen-Bradley PowerFlex 525 VFD matching the models used in the selected conveyor section were acquired as the baseline motor/drive (Figure 5). The induction motor was a three-phase NEMA B squirrel cage motor. NEMA ratings are designated based on the speed-torque-slip performance characteristics of the motor. A NEMA design B motor is often used in conveyor systems with low starting torque requirements. The baseline motor model is capable of operating with an input voltage of $208-230 \mathrm{~V}$ or $460 \mathrm{~V}$; however, it was operated at $460 \mathrm{~V}$ at the customer's facility. The specifications of the baseline motor and VFD are shown in Table 2. 
Table 2. Baseline Motor and VFD Specifications

\begin{tabular}{|l|c|l|c|}
\hline Motor Model \#: & EM3774T & VFD Model \#: & 25B-D4P0N114 \\
\hline Motor Output Rating: & $2.0 \mathrm{HP}$ & VFD Input Voltage (V): & $380-480$ \\
\hline Motor Voltage (V): & $208-230 / 460$ & VFD Input Current (A): & $2.9-5.7$ \\
\hline Motor Rated Current (A): & $6.6-5.8 / 2.9$ & VFD Input Frequency (Hz): & $47-63$ \\
\hline Motor Rated Speed (RPM): & 1,755 & VFD Output Voltage (V): & $0-480$ \\
\hline Motor Frequency (Hz): & 60 & VFD Output Current (A): & 4.0 \\
\hline Motor Service Factor: & 1.15 & VFD Output Frequency (Hz): & $0-500$ \\
\hline Motor Frame: & $145 T$ & & \\
\hline Motor Enclosure: & TEFC & & \\
\hline Motor Insulation Class: & F & & \\
\hline Motor Duty: & Continuous & & \\
\hline Motor Rated Efficiency: & $86.5 \%$ & & \\
\hline
\end{tabular}

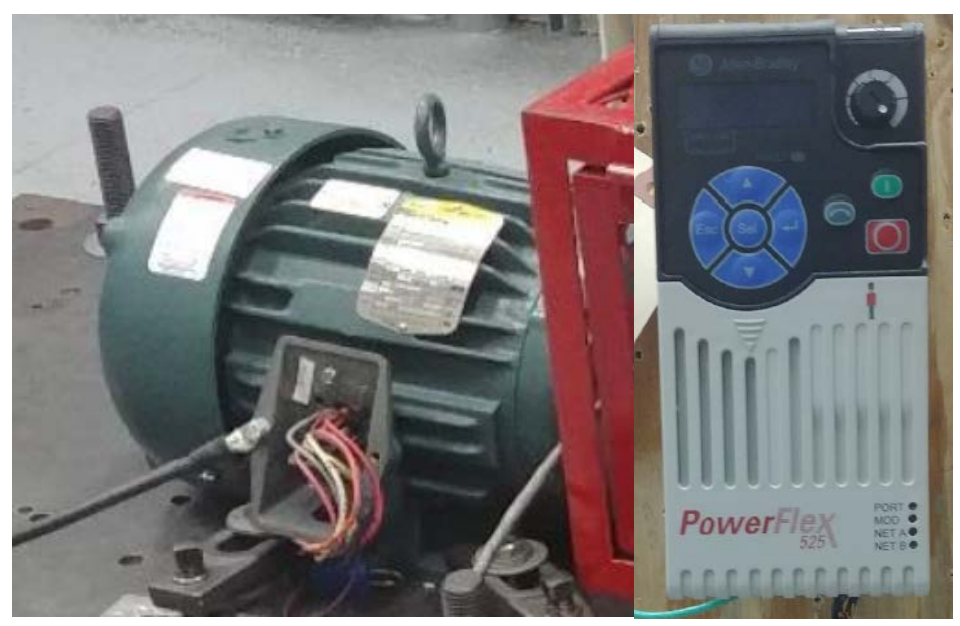

Figure 5. Baseline 2-HP induction motor (left), and VFD (right) 


\section{Motor/Drive Performance Characterization}

This section provides details pertaining to the experimental setup, evaluation, and results of the motor/drive performance characterizations. The energy efficiency assessment of the two motor/drive systems was guided by and references practices published in ANSI/ASHRAE standard 222-2018 Section 7 [1]. NREL is not a rating entity; however, the test procedure and guidelines for measurement outlined in this standard were closely followed where applicable. In circumstances that required strict adherence to these standard guidelines, calibration certificates were validated to ensure that measurement uncertainty fell within the range specified by the standard.

NREL asked Advanced Energy, an outside subcontractor, to perform motor and drive system characterization via dynamometer, which imposes a braking force on the motor shaft such that the torque, speed, and power consumption can be evaluated. Advanced Energy is an ISO 17025-accredited laboratory for efficiency testing of electric motors through the National Voluntary Laboratory Accreditation Program.

The baseline motor and SRM were initially evaluated at Advanced Energy's facilities in Raleigh, North Carolina. SRM results, however, were not consistent with the manufacturer because the torque transducer used was not able to account for the impact of "torque ripple" inherent to the design of an SRM. Due to the COVID-19 pandemic, Advanced Energy then virtually oversaw testing conducted by the SRM manufacturer's team at their facilities in Sunnyvale, California. It was determined that Advanced Energy's standard torque sampling rate requirements generated variable and inconsistent results with the SRM. At the manufacturer's lab, using a torque transducer with a denser sampling rate generated more accurate and consistent results. This was confirmed by evaluating the baseline induction motor at both facilities and acquiring performance characterization curves within an expected margin of error. Because of this, only the results generated using the higher sampling rate torque transducer are provided here.

\subsection{Lab Assessment Plan}

Each motor/drive system was mounted to a dynamometer, which was connected to a power analyzer and torque and speed transducer, as shown in the Figure 6 test schematic. A Yokogawa WT1806 precision power analyzer was used to measure input electrical power. To ensure synchronization of data, the torque and speed transducers were connected to the power analyzer. Output power was measured through the product of the values measured by the torque and speed transducer.

The baseline motor was first evaluated across a range of torque load setpoints at the rated frequency of the motor $(60 \mathrm{~Hz})$. The same range of torque loads was then evaluated at lower frequencies down to 5 $\mathrm{Hz}$. The torque and speed of the baseline motor/drive at each of these setpoints was then used as the setpoints for characterizing the energy-efficient SRM. Table 3 shows the torque and frequency setpoints used to evaluate both motor/drive systems. 


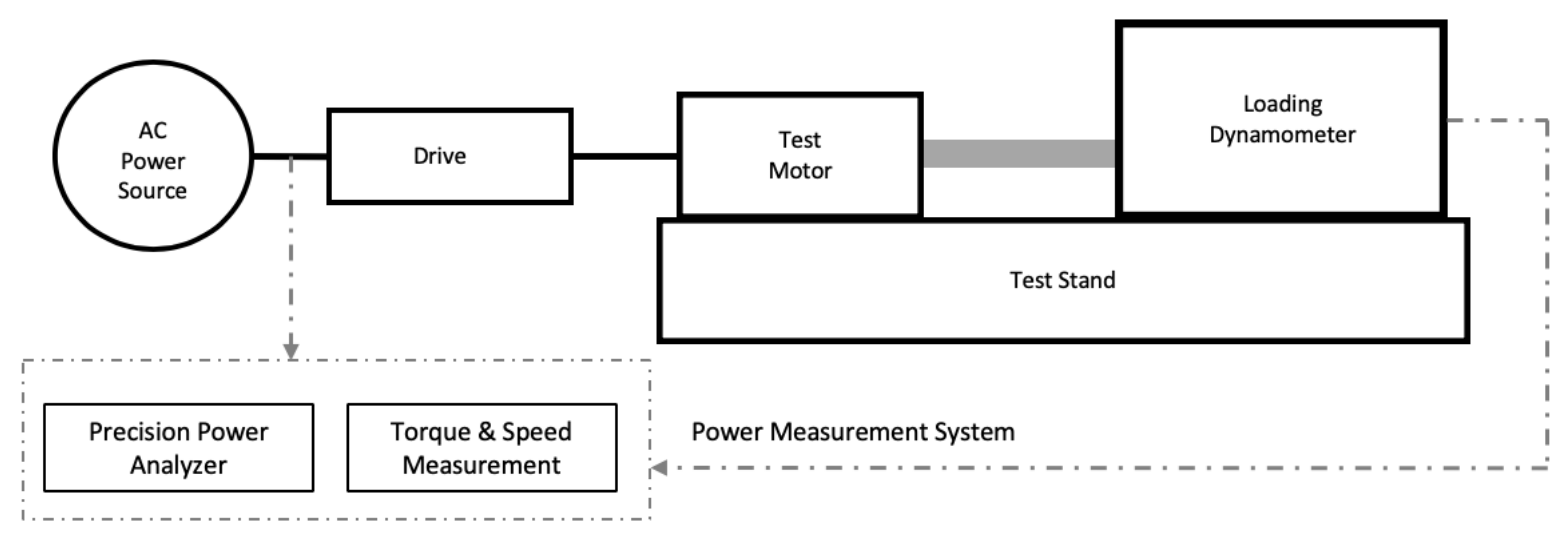

Figure 6. Schematic of dynamometer experimental setup

Prior to collecting measurements at the first setpoint (110\% torque load at the highest speed), each motor was thermally stabilized. This involved operating the motor/drive at the highest speed and $100 \%$ torque load until temperature would no longer rise by more than $2^{\circ} \mathrm{C}$ over a 30 -minute period. A surface temperature thermocouple was placed on the motor casing at the 12:00-location on the drive end of the motor and connected to a multimeter to monitor temperature stability.

To reach each setpoint, a speed control loop was used. The drive was set to rotate the motor at a target frequency and then the dynamometer frequency was matched to the motor. A target torque was then obtained by ramping down through torque setpoints in a "catch on the fly" method. At both Turntide and Advanced Energy's facilities, the dynamometer was unable to sufficiently load the SRM to higher torques at the lowest frequencies of 5 and $10 \mathrm{~Hz}$ using the speed control loop. Advanced Energy was able to reach these torques using an open-loop torque control method, but this capability was not available at Turntide's facility where the high-sampling rate torque transducer was used. Because the torque demand and rotational velocity of the selected conveyor were not within these data points, they were ignored for this evaluation.

Table 3. List of Dynamometer Characterization Torque and Frequency Setpoints

\begin{tabular}{|c|c|c|c|c|c|c|c|}
\hline \multirow{3}{*}{$\begin{array}{l}\text { Torque } \\
(\%, \mathrm{Nm})\end{array}$} & \multicolumn{7}{|c|}{ Motor Speed (Hz) } \\
\hline & \multicolumn{7}{|c|}{ Approximate Motor Speed (RPM) } \\
\hline & 1,800 & 1,500 & 1,200 & 900 & 600 & 300 & 150 \\
\hline \multirow{2}{*}{$\begin{array}{l}110,8.9 \\
100,8.1\end{array}$} & $x$ & $x$ & $x$ & $x$ & $x$ & $x$ & $x$ \\
\hline & $\mathrm{x}$ & $x$ & $x$ & $x$ & $x$ & $x$ & $x$ \\
\hline \multirow{4}{*}{$\begin{array}{l}90,7.3 \\
75,6.1 \\
50,4.1 \\
25,2.0\end{array}$} & $\mathrm{x}$ & $x$ & $\mathrm{x}$ & $x$ & $x$ & $x$ & $x$ \\
\hline & $x$ & $x$ & $x$ & $x$ & $x$ & $x$ & $x$ \\
\hline & $x$ & $x$ & $x$ & $x$ & $x$ & $x$ & $\mathrm{x}$ \\
\hline & $\mathrm{x}$ & $\mathrm{x}$ & $x$ & $x$ & $x$ & $x$ & $x$ \\
\hline
\end{tabular}


At each torque and speed setpoint, the following data were recorded as an average across a minimum 5minute period: speed (RPM), torque (Nm, \% full-load), efficiency, input/output power (W), current (A), voltage $(\mathrm{V})$, frequency $(\mathrm{Hz})$, and total harmonic distortion $(\% \mathrm{~V}$ and $\% \mathrm{~A})$. Advanced Energy initially sampled data every 3 seconds across a 90 -second averaging period. It was later found that this sampling rate was too infrequent to consistently measure data accurately with the SRM due to the variation in current (and therefore torque) caused by torque ripple. The sampling rate appeared to have no effect on the baseline induction motor, of which results were consistent between tests with different sampling rates within an expected margin of error. Each measurement was sampled by the Yokogawa power analyzer at a rate of $2 \mathrm{MHz}$. Averaged values across this sampling rate were then supplied to a Turntide in-house data acquisition system at a 30 -second rate, such that at least 10 values were averaged for each data point measured.

Torque ripple is caused by the "pull and release" induced by the energized stator poles, and therefore occurs at a frequency proportional to the rotational frequency and ratio of rotor to stator poles. For the SRM evaluated in this study, this frequency was 15 times the motor/drive frequency. Figure 7 shows the effect of rotational velocity on the torque ripple in an example Turntide SRM. To effectively capture an accurate average of torque across each ripple period, Turntide requested the use of more than two measurement points per period. Because the rated speed of the baseline motor is just under 1,800 RPM, the SRM ripple period would be $900 \mathrm{~Hz}$ at this speed $(60 \mathrm{~Hz})$. Therefore, a sampling frequency higher than $1.8 \mathrm{MHz}$ was required, so a 2-MHz rate was used. So, dynamometer testing was conducted at Turntide's facilities because a torque transducer capable of sampling at this frequency was not available at Advanced Energy's facilities.

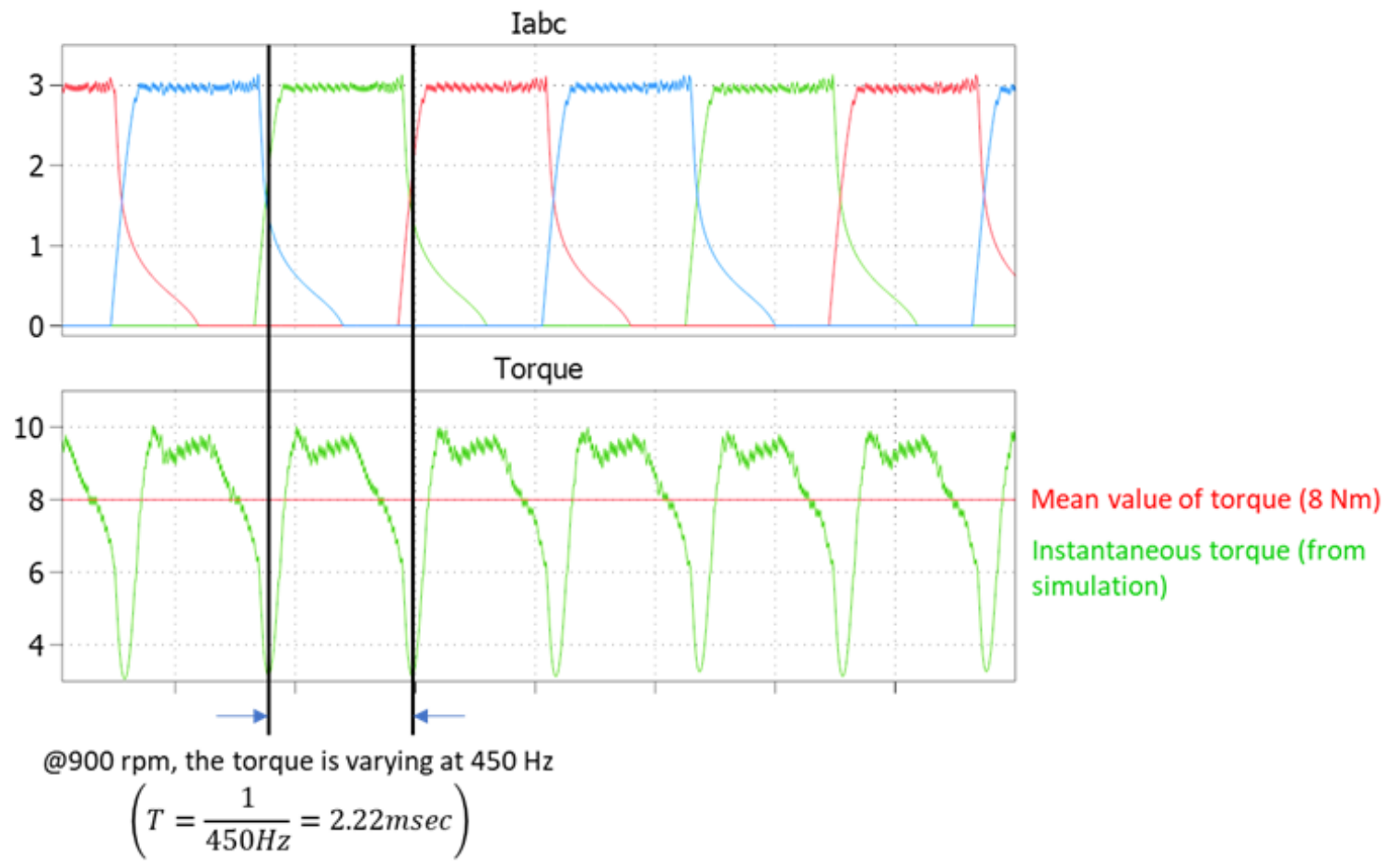

Figure 7. Relationship between torque ripple and frequency Image courtesy of Turntide Technologies 
The full-scale capacity of the dynamometer used was within double the maximum measured torque in accordance with ANSI/ASHRAE standard 222-2018 [1]. Measurement accuracy was also within requirements of the standard such that:

- $\quad$ Electrical measurements were within $\pm 0.2 \%$

- Temporal measurements were within $\pm 0.5 \%$

- Rotational velocity measurements were within \pm 1 RPM

- Torque measurements were within $\pm 0.2 \%$

- Temperature measurements were within $\pm 1.1^{\circ} \mathrm{C}$.

Standard 600-V shielded cables 6 feet in length were used to reduce any potential electrical noise, so VFD cables supplied with the baseline motor were not used. Three single-phase variable AC transformers at the power supply were used for manual balancing. The power source voltage supplied to both the baseline drive and SRM controller was maintained at the rated RMS voltage and rated frequency within $\pm 0.5 \%$, also according to ANSI/ASHRAE 222-2018 [1]. The max deviation of a particular RMS phase voltage from the average across all phases was maintained at less than $\pm 0.5 \%$, the power supply source impedance was maintained within $\pm 1 \%$, and the total harmonic distortion at no load was less than 3\% [1].

Advanced Energy performed noise testing with the two motor/drive systems per NEMA MG-1-2016 Part 9 requirements [14], but an anechoic chamber was not used. Rather, ambient noise from the motor and dynamometer were dissipated using other methods that were controlled for both motors. Decibel levels were measured at five positions on all sides of the motor except the bottom. A diagram of these noise measurement locations is shown in Figure 8. Noise level was recorded using a RION model NA24 sound level meter with a UC52 microphone, which was placed $1 \mathrm{~m}$ from the geometric center of the motor at each location.

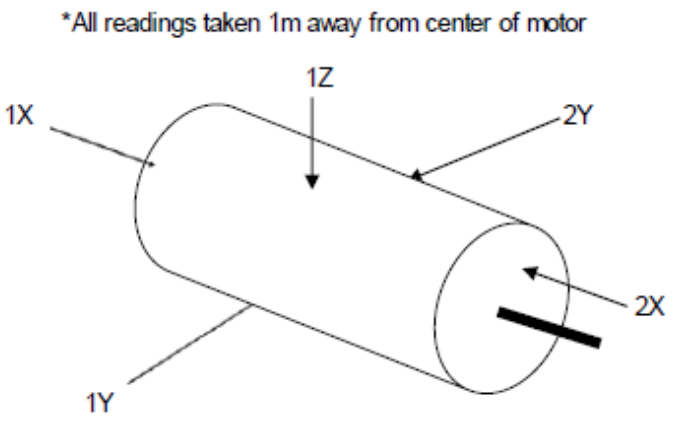

Figure 8. Noise testing measurement locations

\subsection{Lab Assessment Materials}

Turntide Technologies supplied all measurement equipment for this evaluation except for noise testing. Noise testing was conducted only at Advanced Energy's facilities, so the noise level meter and microphone were provided by Advanced Energy. Because Advanced Energy is an ISO 17025-accredited laboratory for electric motor efficiency testing, their review and approval of calibration certificates was required for all equipment. Each equipment item used was calibrated within the last calendar year by recognized certified calibration testing entities. NREL and Advanced Energy have access to calibration certificates, which can be provided upon request. 
Turntide used a custom AC dynamometer to load the motor and a Yokogawa WT1806 precision power analyzer to record electrical measurements. A Himmelstein Ultra-Precise 48800V digital torquemeter was paired with the dynamometer that measured both speed and torque. A summary of the measurement equipment, their accuracies, and their calibration statuses are shown below in Table 4.

Table 4. Summary of Measurement Equipment Used to Conduct Motor/Drive Performance Characterization at Turntide's Facilities in Sunnyvale, CA

\begin{tabular}{|l|c|c|c|c|c|c|}
\hline Measurement & Metric & Make & Model & Serial Number & Accuracy & $\begin{array}{c}\text { Calibration } \\
\text { Due }\end{array}$ \\
\hline Power Out & Torque & Himmelstein & $48803 \mathrm{~V}$ & 48803 V50170108 & $\pm 0.05 \%$ & $5 / 4 / 2020$ \\
\hline Power Out & Speed & Himmelstein & $48803 \mathrm{~V}$ & $48803 V 50170108$ & $\pm 0.05 \%$ & $5 / 4 / 2020$ \\
\hline Power In & $\begin{array}{l}\text { Voltage/ } \\
\text { Current }\end{array}$ & Yokogawa & WT1806 & C3QK23018E & $\pm 0.05 \%$ & $2 / 25 / 2021$ \\
\hline Sound Level & N/A & Rion & NA-24 & $20952-10$ & $\pm 0.5 \mathrm{~dB}$ & $3 / 10 / 2021$ \\
\hline
\end{tabular}

\subsection{Baseline Motor Performance Characterization Results}

The baseline ABB motor is shown mounted to the custom AC dynamometer at Turntide's facilities in the left image in Figure 9. The black-colored custom dynamometer is on the left side of the casing near the wall, and the dark, blue-colored ABB motor is on the right, closer to the camera. The right image in Figure 9 shows the Allen-Bradley VFD module.

The speed and torque setpoints were controlled via the keypad of the Allen-Bradley VFD. The VFD was operated using default parameters with sensorless vector control and no auto-tuning. Other than inputting the nameplate parameters associated with the baseline motor, Advanced Energy and Turntide technicians did not alter any settings from the manufacturers' default configuration. No attempt was made to determine the most efficient control method for operating the ABB motor.

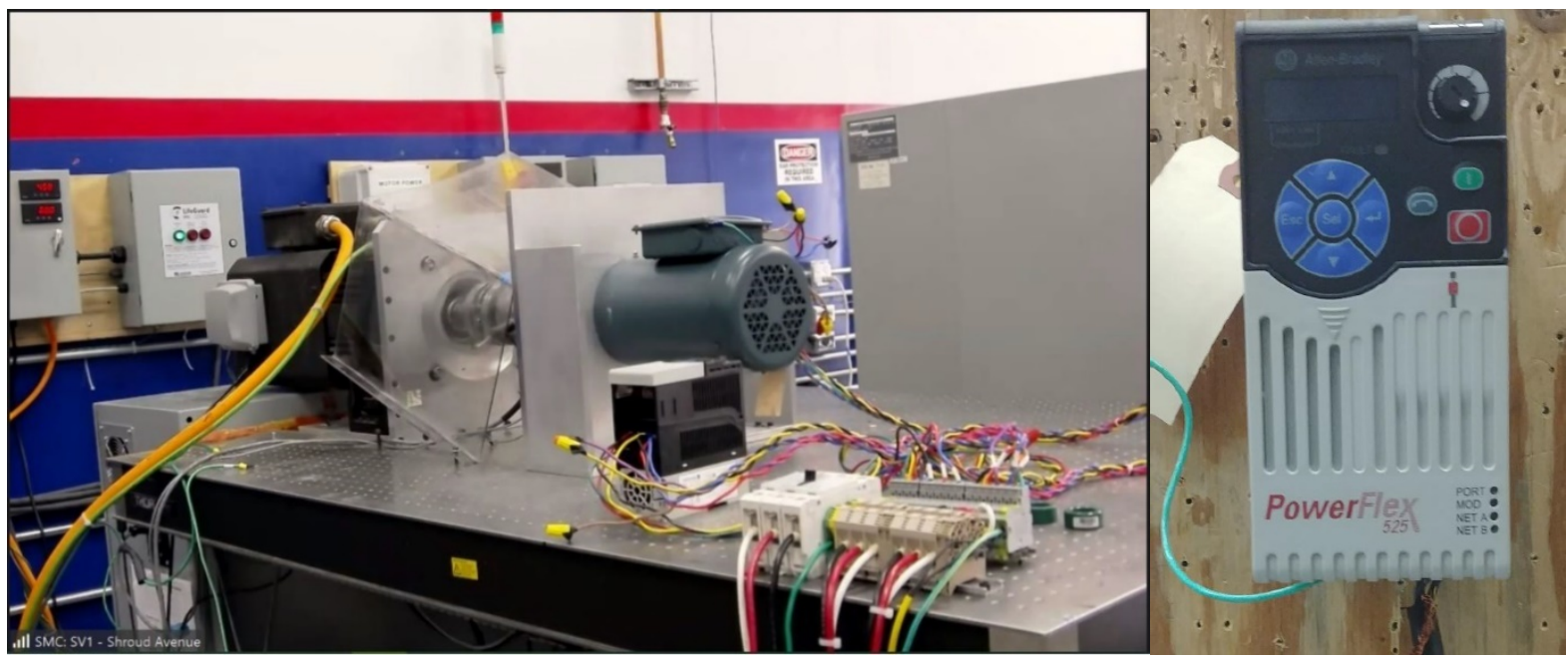

Figure 9. Image of baseline ABB motor on test dynamometer and Allen-Bradley VFD module

The baseline induction motor and VFD dynamometer characterization results are provided in Figures 10 and 11. Tabulated data recorded for each of the parameters listed in Section 2.1 is provided in Appendix B. The uncertainty in each direct measurement is equivalent to the accuracies specified in Table 4. Efficiency was calculated from the ratio of shaft output power (the product of torque and speed) to the electrical input power. This generated a propagated uncertainty of $\pm 0.238 \%$ in efficiency. 


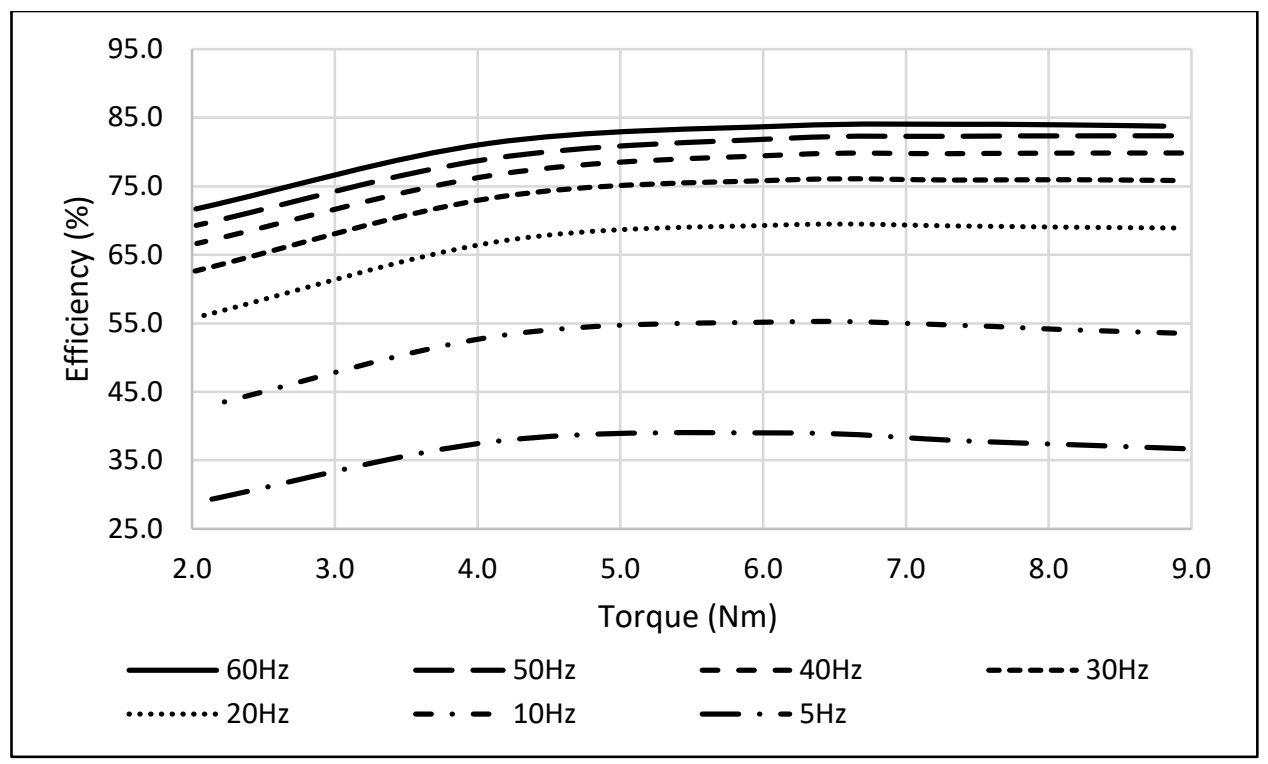

Figure 10. Baseline induction motor/VFD efficiency performance characterization curve with respect to torque (Nm)

The efficiency performance curves shown in Figures 10 and 11 were as expected for this induction motor. At the rated frequency $(60 \mathrm{~Hz})$, the efficiency curve was slightly offset from the curve reported by the original equipment manufacturer (OEM) spec sheet by an expected degree. This observed difference was in-line with the manufacturer-reported efficiency of the VFD.

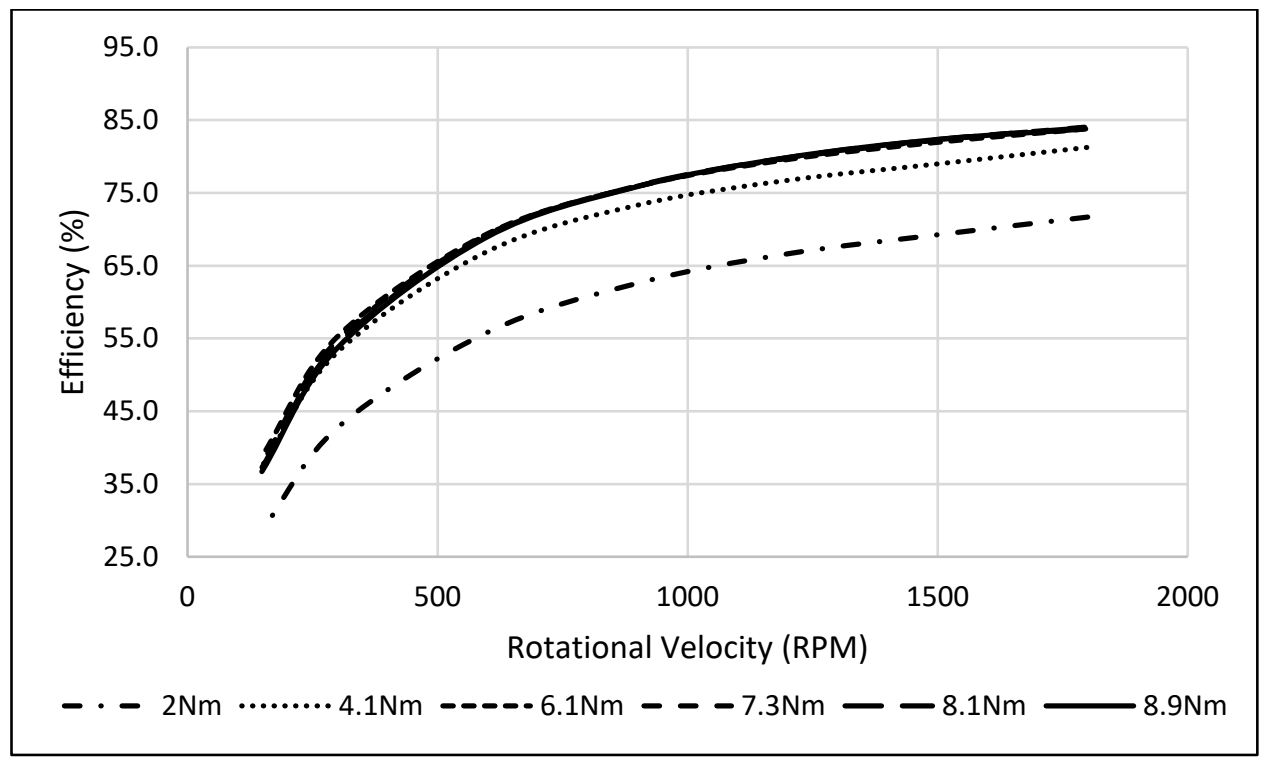

Figure 11. Baseline induction motor/VFD efficiency performance characterization curve with respect to rotational velocity (RPM)

There was a large reduction in efficiency at torque loads below approximately $4 \mathrm{Nm}$. This was not as significant as the effect on efficiency of reducing frequency, which appeared to induce an approximately exponential loss. As frequency was reduced below $10 \mathrm{~Hz}$, the efficiency was reduced to nearly half of its value at $60 \mathrm{~Hz}$. These reductions in efficiency were expected for this induction motor and in relative 
agreement with literature. Burt et al. derived an idealized VFD efficiency at reduced frequencies, which if applied to the OEM-reported efficiency curve for the induction motor alone, would generate partfrequency curves largely similar to those measured here [4].

Advanced Energy performs standard noise testing due to noise concerns in many industrial applications. At each location specified in Figure 8, a UC-52 microphone was used with the Rion sound level meter to record decibel levels. Measurements were recorded at $60 \mathrm{~Hz}$ frequency and $100 \%$ torque load as shown in Table 5. Decibel levels were typical for a standard induction motor of this size.

Table 5. Baseline ABB Motor and Allen-Bradley VFD Noise Level Testing Results

\begin{tabular}{|l|c|c|c|c|c|}
\hline Location: & $\mathbf{1 X}$ & $\mathbf{2 X}$ & $\mathbf{1 Y}$ & $\mathbf{2 Y}$ & $\mathbf{1 Z}$ \\
\hline Motor Off & $44.5 \mathrm{~dB}$ & $44.2 \mathrm{~dB}$ & $44.7 \mathrm{~dB}$ & $45.2 \mathrm{~dB}$ & $45.5 \mathrm{~dB}$ \\
\hline Motor On & $76.2 \mathrm{~dB}$ & $74.3 \mathrm{~dB}$ & $76.0 \mathrm{~dB}$ & $75.2 \mathrm{~dB}$ & $73.4 \mathrm{~dB}$ \\
\hline
\end{tabular}

\subsection{Switch-Reluctance Motor Performance Characterization Results}

The energy-efficient SRM is shown mounted to the custom AC dynamometer at Turntide's facilities in the top-left corner of the left image in Figure 12. The custom dynamometer is on the left side of the motor shaft off-screen, and the Yokogawa power analyzer is shown labeled below the test bench. The top of the image was removed to protect Turntide intellectual property in their facility. The right image in Figure 12 shows the SRM controller.

The SRM controller was provided with its own software, which was installed to a lab computer. The speed and torque setpoints were then controlled via the software's user interface. As with the baseline motor, Advanced Energy and Turntide did not alter any settings from the default configuration, which was preprogrammed at Turntide's facilities prior to shipping to Advanced Energy using the most updated firmware version 2.3.15.

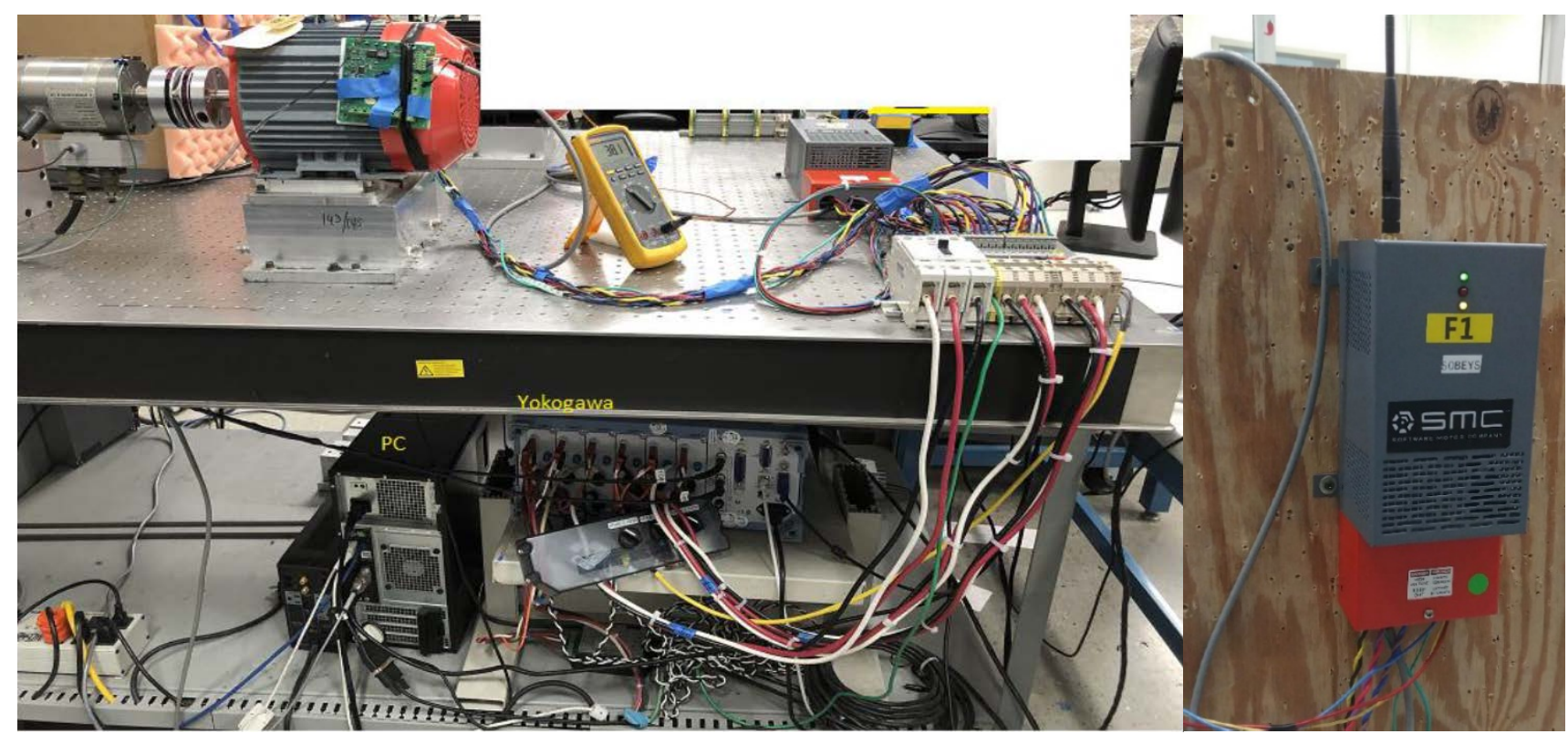

Figure 12. Image of energy-efficient SRM on test dynamometer and controller module 
Figures 13 and 14 show the resultant performance characterization data from the SRM at the specified torque and frequency setpoints. Tabulated data recorded for each of the parameters listed in Section 2.1 are provided in Appendix B. The uncertainty in each base measurement is equivalent to the accuracies specified in Table 4, which generated a propagated uncertainty of $\pm 0.238 \%$ in efficiency. The open-loop torque control method was unable to load the SRM to higher torques at the lowest frequencies. Because this method was the only loading method available at Turntide's facility, $90 \%-110 \%$ torque load measurements are not provided at $10 \mathrm{~Hz}$, and $75 \%-110 \%$ torque load measurements are not provided at $5 \mathrm{~Hz}$.

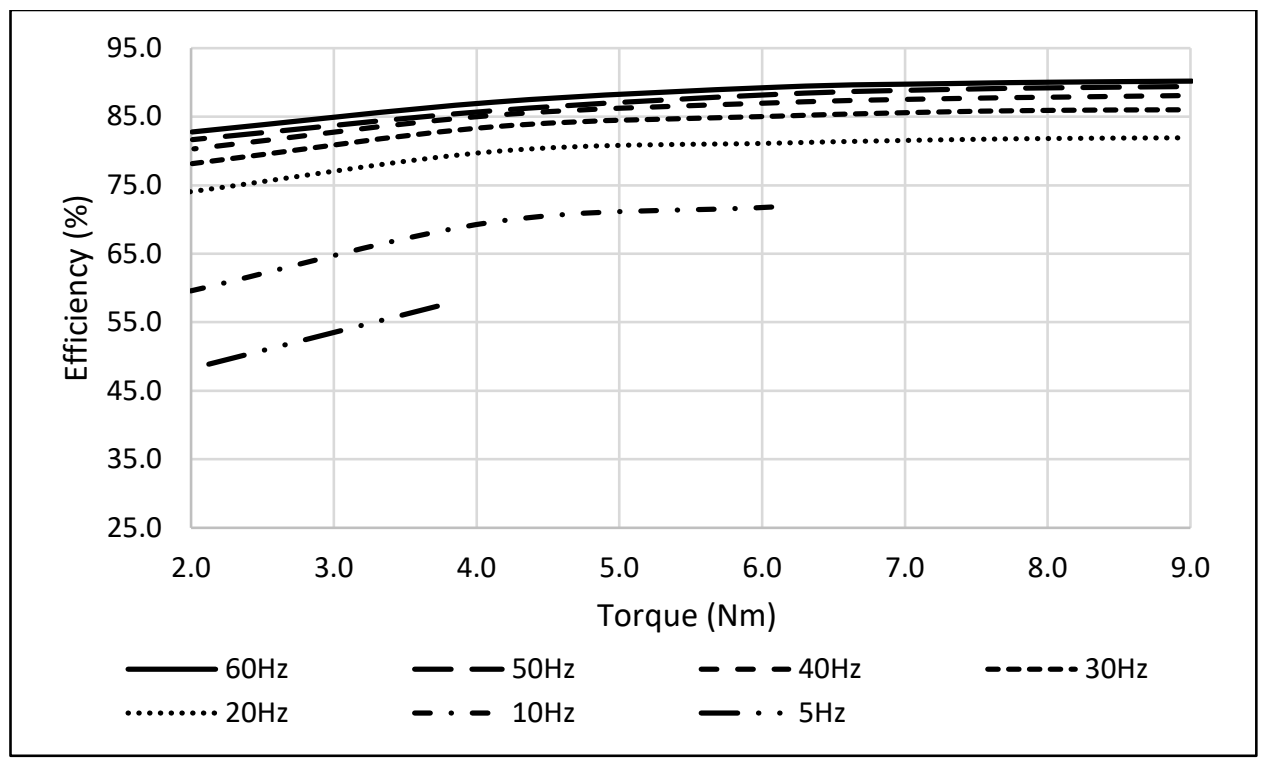

Figure 13. Energy-efficient switch-reluctance motor efficiency performance characterization curve with respect to torque $(\mathrm{Nm})$

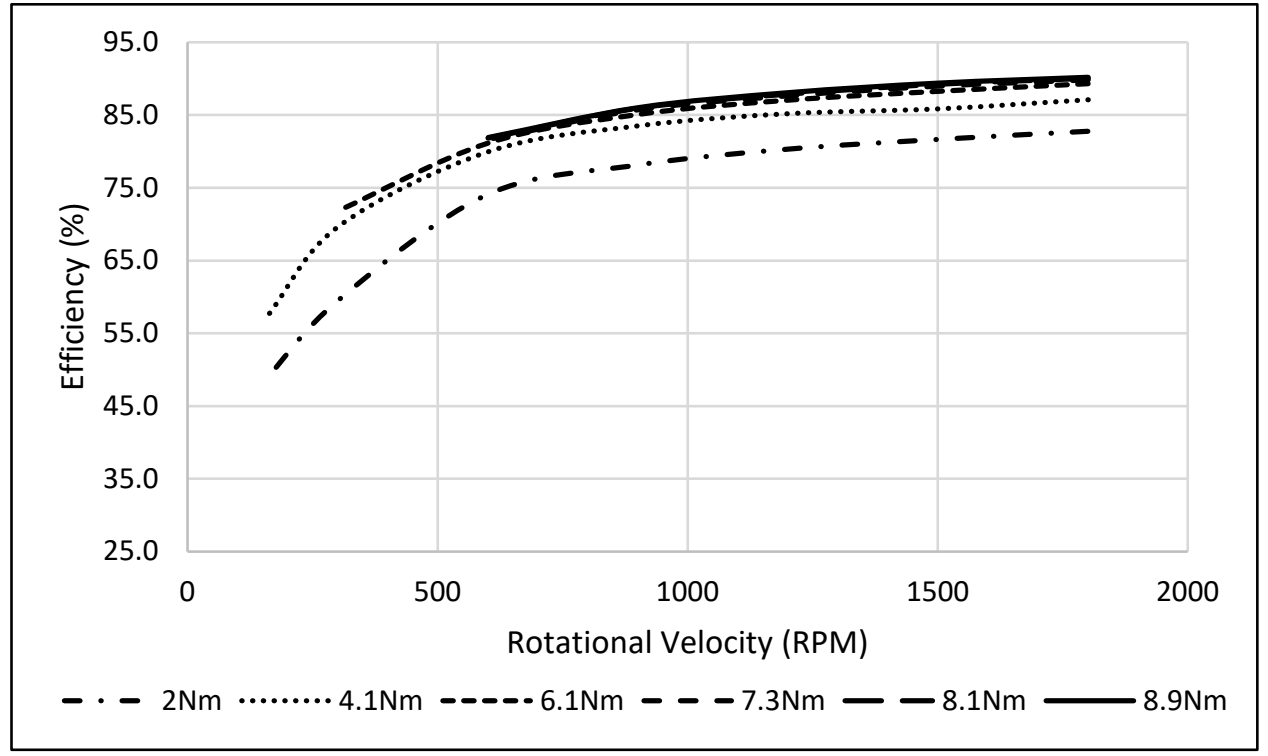

Figure 14. Energy-efficient switch-reluctance motor efficiency performance characterization curve with respect to torque $(\mathrm{Nm})$ 
Figures 13 and 14 show that the SRM performed far more efficiently than the baseline induction motor and VFD at every torque load and rotational velocity setpoint. The SRM particularly outperformed the baseline motor at lower torque loads and frequencies, where losses were far less significant than seen in the baseline motor and drive. At 110\% torque load operating at the rated frequency (60 Hz, 1,800 RPM), the SRM efficiency was $6.4 \%$ higher than the baseline motor. As the torque load was dropped to $25 \%$ at that speed, the difference in efficiency increased to $18.5 \%$.

Lower speeds revealed further benefits of the SRM. At a 20-Hz frequency (600 RPM), the SRM efficiency was $21.2 \%$ higher than the baseline motor and VFD at full torque load, and as high as $34.3 \%$ at $25 \%$ load. Figure 15 shows a comparison of the total system efficiency of both motor and drive systems with respect to torque at frequencies between 10-60 Hz.
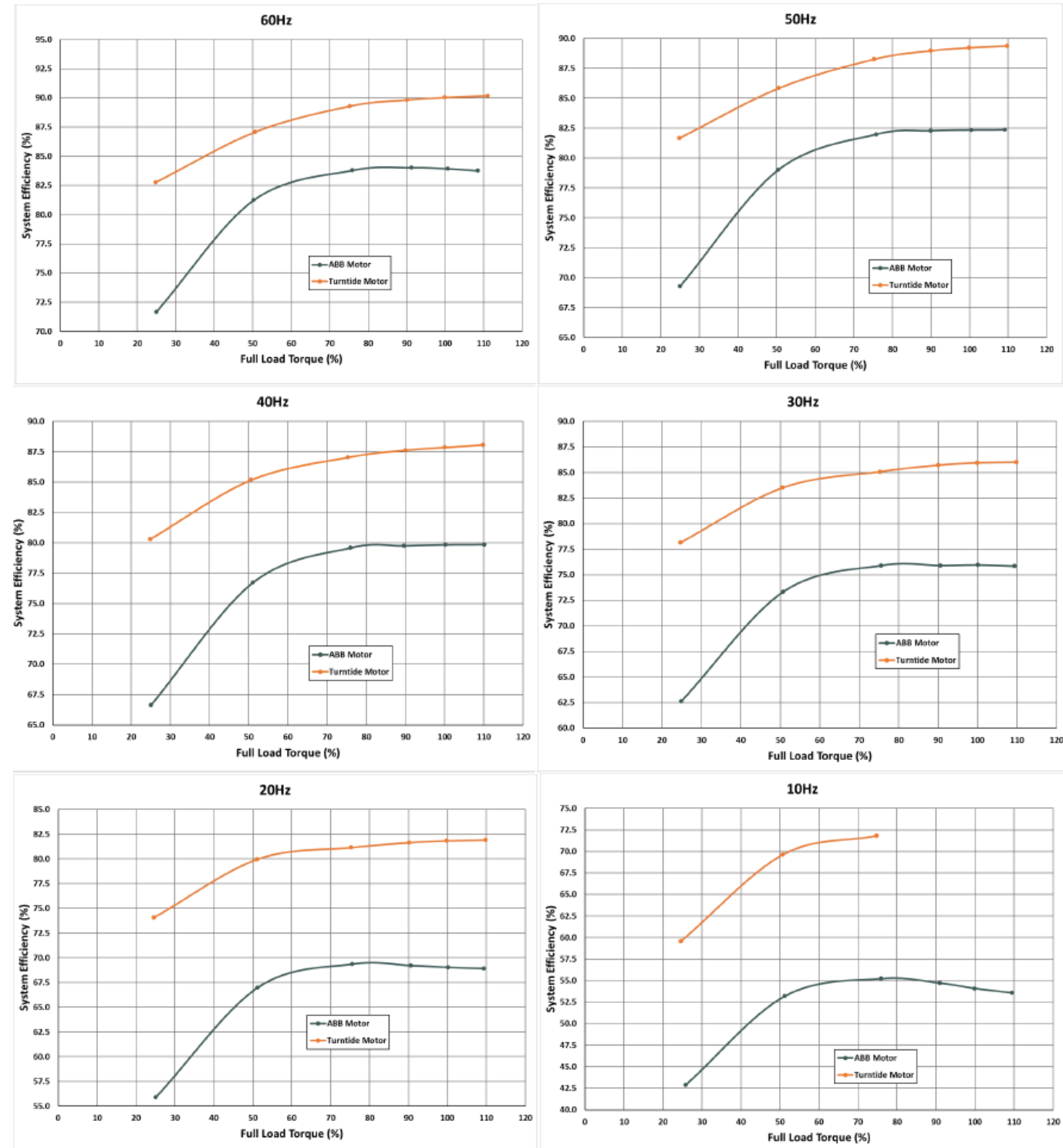

Figure 15. Comparison of motor and drive system efficiency between the SRM and baseline induction motor/VFD with respect to percent torque load 
A torque-speed contour map of the efficiency for each motor can be found in the copy of Advanced Energy's report provided in Appendix D. Because conveyor system operation often requires varying torque and rotational velocity, these improvements are expected to generate significant savings if these induction motor/VFDs are replaced in a wide variety of types of conveyor systems.

Advanced Energy performs standard noise testing due to noise concerns in many industrial applications. At each location specified in Figure 8, a UC-52 microphone was used with the Rion sound level meter to record decibel levels. Measurements were recorded at $60-\mathrm{Hz}$ frequency and $100 \%$ torque load shown in Table 6. One drawback to the SRM is that it produces much more audible noise than the baseline induction motor. This can be a limiting factor in some applications where volume levels are a concern.

Table 6. Energy-Efficient SRM Noise Level Testing Results

\begin{tabular}{|l|c|c|c|c|c|}
\hline Location: & $\mathbf{1 X}$ & $\mathbf{2 X}$ & $\mathbf{1 Y}$ & $\mathbf{2 Y}$ & $\mathbf{1 Z}$ \\
\hline Motor Off & $44.5 \mathrm{~dB}$ & $44.2 \mathrm{~dB}$ & $44.7 \mathrm{~dB}$ & $45.2 \mathrm{~dB}$ & $45.5 \mathrm{~dB}$ \\
\hline Motor On & $88.1 \mathrm{~dB}$ & $88.2 \mathrm{~dB}$ & $89.1 \mathrm{~dB}$ & $85.3 \mathrm{~dB}$ & $90.0 \mathrm{~dB}$ \\
\hline
\end{tabular}

\section{Conveyor Energy Modeling}

In order to evaluate energy savings of the SRM compared to the baseline motor/VFD, the power consumed by each motor/drive was estimated in the selected conveyor system. This would be done by calculating the power consumed by each motor and drive corresponding to a specific torque and belt speed of the conveyor. A conveyor energy modeling tool was therefore developed to calculate energy consumption based on characterized motor/drive system performance curves from dynamometer evaluation. Although the performance of the conveyor system selected at the ComEd customer facility is evaluated here, development of the modeling tool was driven by a need to be able to evaluate other conveyor sections.

Conveyor sections are designed based on their manufacturing needs, and no two conveyor sections at the same facility, let alone across manufacturing industries, are the same. Structural and operational differences will affect the speed and torque demand on the motor. Therefore, energy consumption will vary widely between any two conveyors using the same motor/drive system. To satisfy the need to evaluate the energy consumed by any type of straight belt conveyor, developing an easy-to-use tool was necessary. This would also provide the benefit that any other motor/drive characterization data could be input to the tool to estimate savings from its retrofit. For this reason, the developed tool is also provided with motor performance data from the DOE MotorMaster-Plus tool [3], allowing a user to evaluate a conveyor energy consumption from thousands of other different motors. Detailed instructions on using the energy calculation tool are provided in Appendix A.

To estimate conveyor torque demand and rotational velocity, the conveyor energy modeling tool requires user-input conveyor structural and operational parameters described below. These parameters are then interpolated to a motor performance curve to calculate estimated efficiency and power consumption:

- Structural parameters: associated with the physical structure of the belt that do not change throughout daily industrial operations (e.g., belt and idler mass, section width) 
- Operational parameters: can change throughout daily operation, (e.g., belt speed, conveyed product material densities), or dictate operation (the daily/weekly operation schedule).

At each time point in operation, consumed power is calculated from the torque load, rotational velocity, and efficiency of the motor/drive system. This procedure is outlined in Figure 16. Input power is then integrated across a daily (and/or yearly) operation period to calculate total $\mathrm{kWh}$ consumption for either a single motor or both a baseline and energy-efficient measure as was done here.

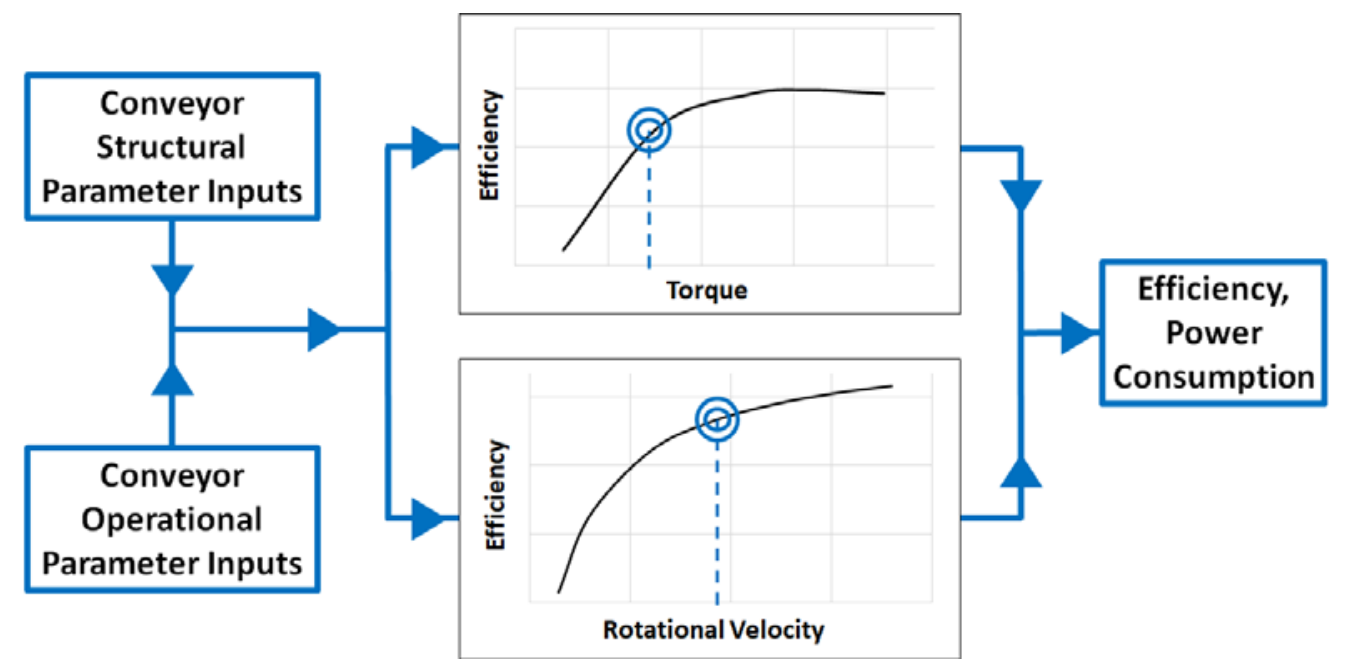

Figure 16. Conveyor energy calculation tool-general procedure

The calculation of torque from conveyor structural parameters was derived from equations used in ANSI/ISO standard 5048 for calculating the operating power and tensile forces of belt conveyors with carrying idlers [2]. This standard only applies to conveyors in which a motor/drive system works to rotate a driving roller that is connected to an array of idler rollers via a belt (the most common conveyor type). This could consist of a standard belt conveyor, in which the product load sits atop the belt above the idlers. Or this could consist of a "live roller" conveyor, in which the rotation of the idlers is driven by a belt, but the product load makes contact with the idlers and not the belt. This does not include pneumatic, screw, gravity roller, towline, spinning tube, or any oscillating conveyors. This does, however, include conveyors with angled surfaces such as trough belt conveyors used in mining applications.

A detailed overview of the calculations used in the conveyor modeling tool is provided in the following subsections. A sensitivity analysis was conducted to evaluate the effect of conveyor modeling parameters on total energy consumption and savings of the selected motor/drive systems, which will also be described in the following section.

\subsection{Energy Modeling Methodology}

As stated, the calculations used to develop the conveyor energy calculation tool were derived from equations used in ANSI/ISO standard 5048-1989 [2]. This standard can be used for any belt-type conveyor, although the modeling tool developed here is not able to be used for curved conveyor sections. The calculations per ISO 5048 that are required to estimate the power and tensile forces within a curved conveyor section would require knowledge of obscure structural parameters that most users of the modeling tool would not likely be readily able to obtain. 
Users of the conveyor energy calculation tool are able to input conveyor structural parameters on one user interface, select the appropriate units, and specify conditions. For certain parameters, the user will have the option to select from a list of materials and specify dimensions to calculate unit masses if the user is unable to determine those parameters on their own. Then, a separate interface is used to define a daily operation schedule. Operational parameters are entered separately for each unique operation period specified and the user can select desired units.

Two additional interfaces allow the user to input baseline and proposed motor/drive performance data; the user is only required to input data for a single motor/drive if not comparing between two. The user can either enter their own dynamometer test data or select from a motor in a supplemental motor list from DOE's MotorMaster-Plus database. An output page on the modeling tool shows the total daily $\mathrm{kWh}$ consumption for the motor/drive system(s) and $\Delta \mathrm{kWh}$ savings between the baseline and proposed motor and drives. A final optional interface page is also included so that the user can input unique operation days into a yearly schedule to calculate yearly consumption and/or savings. Detailed instructions on the use of this modeling tool are provided in Appendix A.

\subsubsection{Torque Modeling Methodology}

Conveyor operating power is calculated from the product of the torque required to pull the conveyor belt, and the rotational velocity of the motor. The ISO 5048 standard states that the required torque is calculated based on the sum of internal frictional resistances along the conveyor section as described in equation 1:

$$
T_{M}=\frac{d}{2}\left(F_{H}+F_{N}+F_{s t}+F_{S}\right)
$$

where $d$ is the outer diameter of the driving roller (connected to the motor shaft), $F_{H}$ is the "main resistance," $F_{\mathrm{N}}$ is the "secondary resistance," $\mathrm{F}_{\mathrm{st}}$ is the "slope resistance," and $\mathrm{F}_{\mathrm{S}}$ is the "special resistance." The main resistance, which is defined as the sum of resistances within the idlers, belts, and pulleys within the "carry-through region" of the belt (main region between loading and unloading), is calculated based on Coulomb's friction law according to the following equation:

$$
F_{H}=f L g\left[Q_{R}+2 Q_{B}+\frac{T(t)}{V(t)}\right] \cos (\delta)
$$

where $\mathrm{f}$ is the "artificial friction factor," $\mathrm{L}$ is the section length, $\mathrm{Q}_{\mathrm{R}}$ is the unit mass of the rotating parts of the idlers, $\mathrm{Q}_{\mathrm{B}}$ is the unit mass of the belt, $\mathrm{T}(\mathrm{t})$ is the feed rate of material (conveyed product) onto the belt, $\mathrm{V}(\mathrm{t})$ is the belt speed, and $\delta$ is the belt incline angle, where $0^{\circ}$ is defined as horizontal. The accuracy of the main resistance equation is restricted to belt lengths of up to 80 meters. The unit masses are defined as mass per unit length of the conveyor section. Therefore, the unit mass of the rotating parts of the idlers is affected by the spacing between the idlers along the conveyor section. The feed rate of material onto the belt is calculated in mass per time so that the ratio of feed rate to belt velocity yields the unit mass of conveyed product material. The "artificial friction factor" is associated with the rolling resistance of the carrying idlers and belt advancement resistance, and is determined based on qualitative descriptions of the idler bearing conditions according to ISO 5048 [2]. The developed modeling tool allows the user to select from these descriptions to calculate $f$.

The secondary resistance is defined as the sum of the frictional resistances between the material and belt and material and any guide/skirt boards in the loading/unloading region. If we assume that frictional 
resistances between the material and belt and material and any guide/skirt boards are relatively the same, and that the belt-pulley wrap resistance is negligibly low, the secondary resistance can be calculated as:

$$
F_{N}=T(t) V(t)+\frac{T(t)^{2}}{\rho(t) b_{t}(t)^{2}}
$$

where $\rho(t)$ is the material density and $b_{1}(t)$ is the width of the conveyor section, or width between guide/skirt boards if any are present. The section width is given as a function of time due to circumstances in which pneumatic-controlled guide boards are used to reduce the section width at different periods of operation.

The slope resistance is the resistance caused by any incline or decline of the conveyor section due to gravitational force of the material load, and is specified as:

$$
F_{s t}=\frac{g L T(t) \sin (\delta)}{V(t)}
$$

where $\mathrm{g}$ is acceleration due to gravity.

Finally, the special resistance is defined as the frictional resistance between the material and guide/skirt boards in the carry-through region as well as other various resistances. If the friction due to any belt cleaners, ploughs, or aprons overhanging the belt can be considered negligibly low, as well as if there is no tilting of the idlers, then the special resistance is simplified to the following equation:

$$
F_{S}=\frac{\mu g L T(t)}{\rho(t) b_{1}(t)^{2} V(t)}
$$

where $\mu$ is the kinetic friction coefficient between the material and guide boards.

Because these equations were simplified to a form that uses only parameters that are readily available and known to a regular user of the calculation tool, various assumptions must be made. These assumptions require a list of conveyor specifications that must be confirmed in order to use the developed conveyor energy modeling tool. In addition to assumptions that are required to use the general ISO 5048 model, the requirements for using the derived equations in the developed calculation tool are listed in Table 7.

Table 7. Assumption-Based Requirements for Using the ISO 5048 Standard-Based Conveyor Energy Modeling Tool Equations

\begin{tabular}{|l|l|}
\hline $\begin{array}{l}\text { Associated Function } \\
\text { (Equation) }\end{array}$ & Requirement: \\
\hline Full Model & Conveyor section must be a belt-driven conveyor with a single drive \\
\hline Full Model & Conveyor section must be straight with no turns or curves \\
\hline Main Resistance (2) & Conveyor section length must be less than 80 meters \\
\hline Secondary Resistance (3) & $\begin{array}{l}\text { The frictional resistances between the material and belt and } \\
\text { material and any guide/skirt boards are relatively the same in the } \\
\text { loading/unloading region, if guide/skirt boards are present }\end{array}$ \\
\hline Secondary Resistance (3) & The belt-pulley wrap resistance, if applicable, is negligibly low \\
\hline Special Resistance (5) & $\begin{array}{l}\text { There is no tilt to the idlers with respect to the belt surface plane, or } \\
\text { resistance due to any idler tilt is negligibly low }\end{array}$ \\
\hline
\end{tabular}




\begin{tabular}{|l|l|}
\hline $\begin{array}{l}\text { Associated Function } \\
\text { (Equation) }\end{array}$ & Requirement: \\
\hline Special Resistance (5) & $\begin{array}{l}\text { There are no belt cleaners, or any friction caused by belt cleaners is } \\
\text { negligibly low }\end{array}$ \\
\hline Special Resistance (5) & $\begin{array}{l}\text { There are no ploughs or aprons, or any friction caused by any } \\
\text { ploughs or aprons is negligibly low }\end{array}$ \\
\hline
\end{tabular}

\subsubsection{Conveyor Energy Modeling Parameters}

A list of the structural (constant) parameters that can be entered into the modeling tool are shown in Table 8 . Some parameters, such as section length $(L)$, incline angle $(\delta)$, guide friction coefficient $(\mu)$, and the driving roller diameter (d) are required as-is because they cannot be calculated using other methods. The user is able to input these parameters using any units, which can be selected from a dropdown list and converted automatically. Other parameters, such as the belt unit mass $\left(\mathrm{Q}_{\mathrm{B}}\right)$, and forward and return idler unit masses ( $\mathrm{Q}_{\mathrm{RO}}$ and $\left.\mathrm{Q}_{\mathrm{RU}}\right)$ are typically provided by belt and idler manufacturers. They can be calculated using the other available parameter inputs if not known. Table 8 specifies which parameters are required based on the knowledge of other optional parameters in the right column.

Table 8. List of Conveyor Energy Modeling Tool Structural Parameter Inputs and Descriptions

\begin{tabular}{|c|c|c|c|}
\hline Parameter & Symbol & Description & Required? \\
\hline Section Length & $\mathrm{L}$ & Length of conveyor section (driven by one motor) & YES \\
\hline Incline Angle & $\delta$ & $\begin{array}{c}\text { Incline angle of section belt (horizontal }=0^{\circ} \\
\text { negative if decline) }\end{array}$ & YES \\
\hline $\begin{array}{l}\text { Guide Friction } \\
\text { Coefficient }\end{array}$ & $\mu$ & $\begin{array}{l}\text { Kinetic friction coefficient of the skirt plates/guide } \\
\text { boards ( } 0 \text { if none) }\end{array}$ & YES \\
\hline $\begin{array}{l}\text { Driving Roller (pulley) } \\
\text { Diameter }\end{array}$ & d & $\begin{array}{c}\begin{array}{c}\text { Outer diameter of the driving roller (mounted to } \\
\text { motor) }\end{array} \\
\text { ( }\end{array}$ & YES \\
\hline Belt Unit Mass & $Q_{B}$ & Unit mass of the belt & $\begin{array}{c}\mathrm{NO} \\
\text { if } \mathrm{b}_{0}, \mathrm{t}_{\mathrm{b}} \text {, and } \rho_{\mathrm{b}} \text { available }\end{array}$ \\
\hline Belt Width & $\mathrm{b}_{0}$ & Width of the belt & $\begin{array}{c}\mathrm{NO} \\
\text { if } \mathrm{Q}_{\mathrm{B}} \text { available }\end{array}$ \\
\hline Belt Thickness & $t_{b}$ & Thickness of the belt & $\begin{array}{c}\mathrm{NO} \\
\text { if } \mathrm{Q}_{\mathrm{B}} \text { available }\end{array}$ \\
\hline Belt Density & $\rho_{b}$ & Density of the belt material & $\begin{array}{c}\mathrm{NO} \\
\text { if } \mathrm{Q}_{\mathrm{B}} \text { available or belt } \\
\text { material }\end{array}$ \\
\hline Belt Material & -- & Material of the belt & $\begin{array}{c}\mathrm{NO} \\
\text { if } \mathrm{QB}_{\mathrm{B}} \text { or } \rho_{\mathrm{b}} \text { available }\end{array}$ \\
\hline $\begin{array}{l}\text { Artificial Friction } \\
\text { Factor }\end{array}$ & $f$ & $\begin{array}{c}\text { Rolling resistance of the carrying idlers and the } \\
\text { belt advancement resistance (conditional based } \\
\text { on belt speed, idler/roller diameter, and idler/roller } \\
\text { spacing) }\end{array}$ & $\begin{array}{l}\text { YES - chosen from } \\
\text { qualitative description } \\
\text { list }\end{array}$ \\
\hline $\begin{array}{l}\text { Forward Idler Unit } \\
\text { Mass }\end{array}$ & QRO & $\begin{array}{l}\text { Unit mass of only the rotating parts of the forward } \\
\text { idlers/rollers (idlers driving the top of the belt) } \\
\text { (total mass per unit length of conveyor) }\end{array}$ & $\begin{array}{l}\mathrm{NO} \\
\text { if } \mathrm{XRO}_{\mathrm{RO}}, \mathrm{b}_{\mathrm{RO}}, \mathrm{d}_{\mathrm{i}-\mathrm{RO}}, \mathrm{d}_{\mathrm{o}-\mathrm{RO}} \\
\rho_{\mathrm{RO}}, \mathrm{t}_{\mathrm{c}-\mathrm{RO}} \text {, and } \rho_{\mathrm{c}-\mathrm{RO}} \\
\text { available }\end{array}$ \\
\hline $\begin{array}{l}\text { Return Idler Unit } \\
\text { Mass }\end{array}$ & QRU & $\begin{array}{c}\text { Unit mass of only the rotating parts of the } \\
\text { idlers/rollers (idlers driving the bottom of the belt, } \\
0 \text { if top idlers driving both belts) (total mass per } \\
\text { unit length of conveyor) }\end{array}$ & $\begin{array}{l}\mathrm{NO} \\
\text { if } \mathrm{XRU}_{\mathrm{RU}}, \mathrm{b}_{\mathrm{RU}}, \mathrm{d}_{\mathrm{i}-\mathrm{RU}}, \mathrm{d}_{\mathrm{o}-\mathrm{RU}} \\
\rho_{\mathrm{RU}}, \mathrm{t}_{\mathrm{c}-\mathrm{RU}} \text {, and } \rho_{\mathrm{c}-\mathrm{RU}} \\
\text { available }\end{array}$ \\
\hline $\begin{array}{l}\text { Forward Idler } \\
\text { Spacing }\end{array}$ & $\mathrm{X}_{\mathrm{RO}}$ & $\begin{array}{c}\text { Distance between the center of each forward } \\
\text { idler/roller }\end{array}$ & $\begin{array}{c}\mathrm{NO} \\
\text { if } \mathrm{QRO}_{\mathrm{RO}} \text { available } \\
\end{array}$ \\
\hline
\end{tabular}




\begin{tabular}{|c|c|c|c|}
\hline Parameter & Symbol & Description & Required? \\
\hline Return Idler Spacing & $\mathrm{XRU}$ & $\begin{array}{l}\text { Distance between the center of each return } \\
\text { idler/roller (enter } 0 \text { if top idlers drive both forward } \\
\text { and return belts) }\end{array}$ & $\begin{array}{l}\mathrm{NO} \\
\text { if QRu available }\end{array}$ \\
\hline Forward Idler Width & $b_{\text {RO }}$ & Width of the forward idlers/rollers & $\begin{array}{c}\text { NO } \\
\text { if } Q_{R O} \text { available }\end{array}$ \\
\hline Return Idler Width & $b_{R U}$ & $\begin{array}{l}\text { Width of the return idlers/rollers ( } 0 \text { if top idlers } \\
\text { driving both forward and return belts) }\end{array}$ & $\begin{array}{c}\mathrm{NO} \\
\text { if } \mathrm{QRU}_{\mathrm{R}} \text { available }\end{array}$ \\
\hline $\begin{array}{l}\text { Forward Idler Inner } \\
\text { Diameter }\end{array}$ & $d_{i-R O}$ & $\begin{array}{l}\text { Inner diameter of the rotating part of the forward } \\
\text { idlers/rollers }\end{array}$ & $\begin{array}{c}\mathrm{NO} \\
\text { if } \mathrm{QRO}_{\mathrm{RO}} \text { available }\end{array}$ \\
\hline $\begin{array}{l}\text { Forward Idler Outer } \\
\text { Diameter }\end{array}$ & do-RO & $\begin{array}{c}\text { Outer diameter of the rotating part of the forward } \\
\text { idlers/rollers }\end{array}$ & $\begin{array}{c}\mathrm{NO} \\
\text { if QRO available }\end{array}$ \\
\hline $\begin{array}{l}\text { Return Idler Inner } \\
\text { Diameter }\end{array}$ & $d_{i-R U}$ & $\begin{array}{l}\text { Inner diameter of the rotating part of the return } \\
\text { idlers/rollers ( } 0 \text { if top idlers driving both forward } \\
\text { and return belts) }\end{array}$ & $\begin{array}{l}\mathrm{NO} \\
\text { if QRu available }\end{array}$ \\
\hline $\begin{array}{l}\text { Return Idler Outer } \\
\text { Diameter }\end{array}$ & $d_{0-R U}$ & $\begin{array}{c}\text { Outer diameter of the rotating part of the return } \\
\text { idlers/rollers ( } 0 \text { if top idlers driving both forward } \\
\text { and return belts) }\end{array}$ & $\begin{array}{c}\mathrm{NO} \\
\text { if } \mathrm{QRU}_{\mathrm{R}} \text { available }\end{array}$ \\
\hline Forward Idler Density & $\rho_{\mathrm{RO}}$ & $\begin{array}{l}\text { Density of material used in rotating part of } \\
\text { forward idlers/rollers }\end{array}$ & $\begin{array}{c}\mathrm{NO} \\
\text { if } \mathrm{QRO}_{\mathrm{RO}} \text { or material } \\
\text { available }\end{array}$ \\
\hline Return Idler Density & $\rho \mathrm{RU}$ & $\begin{array}{c}\text { Density of material used in rotating part of return } \\
\text { idlers/rollers ( } 0 \text { if top idlers driving both forward } \\
\text { and return belts) }\end{array}$ & $\begin{array}{l}\mathrm{NO} \\
\text { if QRu or material } \\
\text { available }\end{array}$ \\
\hline $\begin{array}{l}\text { Forward Idler } \\
\text { Material }\end{array}$ & -- & $\begin{array}{l}\text { Material used in rotating part of forward } \\
\text { idlers/rollers }\end{array}$ & $\begin{array}{c}\mathrm{NO} \\
\text { if } Q_{\mathrm{RO}} \text { or } \rho_{\mathrm{RO}} \text { available }\end{array}$ \\
\hline Return Idler Material & -- & $\begin{array}{c}\text { Material used in rotating part of return } \\
\text { idlers/rollers }\end{array}$ & $\begin{array}{c}\mathrm{NO} \\
\text { if } \mathrm{QRU}_{\mathrm{R}} \text { or } \rho_{\mathrm{R} U} \text { available }\end{array}$ \\
\hline $\begin{array}{l}\text { Forward Idler } \\
\text { Coating Thickness }\end{array}$ & $t_{c-R O}$ & $\begin{array}{c}\text { Thickness of coating/secondary layer on forward } \\
\text { idlers/rollers ( } 0 \text { if none) }\end{array}$ & $\begin{array}{c}\mathrm{NO} \\
\text { if } \mathrm{QRO}_{\mathrm{R}} \text { available } \\
\end{array}$ \\
\hline $\begin{array}{l}\text { Return Idler Coating } \\
\text { Thickness }\end{array}$ & $t_{c-R U}$ & $\begin{array}{c}\text { Thickness of coating/secondary layer on return } \\
\text { idlers/rollers ( } 0 \text { if none, } 0 \text { if top idlers driving both } \\
\text { forward and return belts) }\end{array}$ & $\begin{array}{l}\mathrm{NO} \\
\text { if QRu available }\end{array}$ \\
\hline $\begin{array}{l}\text { Forward Idler } \\
\text { Coating Density }\end{array}$ & $\rho_{c-R O}$ & $\begin{array}{l}\text { Density of material used in forward idler/roller } \\
\text { coating }\end{array}$ & $\begin{array}{c}\mathrm{NO} \\
\text { if } \mathrm{QRO}_{\mathrm{RO}} \text { or material } \\
\text { available }\end{array}$ \\
\hline $\begin{array}{l}\text { Return Idler Coating } \\
\text { Density }\end{array}$ & $\rho_{c-R U}$ & $\begin{array}{l}\text { Density of material in return idler/roller coating ( } 0 \\
\text { if top idlers driving both forward and return belts) }\end{array}$ & $\begin{array}{l}\text { NO } \\
\text { if QRu or material } \\
\text { available }\end{array}$ \\
\hline $\begin{array}{l}\text { Forward Idler } \\
\text { Coating Material }\end{array}$ & & Material used for forward idler/roller coating & $\begin{array}{c}\mathrm{NO} \\
\text { if } \mathrm{QRO}_{\mathrm{RO}} \text { or } \rho_{\mathrm{c}-\mathrm{RO}} \text { available }\end{array}$ \\
\hline $\begin{array}{l}\text { Return Idler Coating } \\
\text { Material }\end{array}$ & & Material used for return idler/roller coating & $\begin{array}{c}\mathrm{NO} \\
\text { if } \mathrm{QRU}_{\mathrm{R}} \text { or } \rho_{\mathrm{c}-\mathrm{RU}} \text { available }\end{array}$ \\
\hline
\end{tabular}

If the unit mass of the conveyor belt $\left(\mathrm{Q}_{\mathrm{B}}\right)$ is unknown, the belt width $\left(\mathrm{b}_{0}\right)$, belt thickness $\left(\mathrm{t}_{\mathrm{b}}\right)$, and belt material density $\left(\rho_{\mathrm{b}}\right)$ can be used to alternatively calculate $\mathrm{Q}_{\text {в }}$ according to:

$$
Q_{B}=b_{0} t_{b} \rho_{b}
$$

Material density, if unknown, can also be determined by selecting a common conveyor belt material from a user-selected dropdown menu. The densities associated with each material in the user-selected dropdown were collected from the Engineering Toolbox database [15]. 
In addition to the belt unit mass, the idler unit masses ( $\mathrm{Q}_{\mathrm{RO}}$ or $\left.\mathrm{Q}_{\mathrm{RU}}\right)$ can also both be calculated from the idler spacing $\left(\mathrm{x}_{R O}\right.$ or $\left.\mathrm{x}_{\mathrm{RU}}\right)$, width $\left(\mathrm{b}_{\mathrm{RO}}\right.$ or $\left.\mathrm{b}_{\mathrm{RU}}\right)$, inner and outer diameters $\left(\mathrm{d}_{\mathrm{i}-\mathrm{RO}}, \mathrm{d}_{\mathrm{o}-\mathrm{RO}}\right.$ or $\left.\mathrm{d}_{\mathrm{i}-\mathrm{RU}}, \mathrm{d}_{\mathrm{o}-\mathrm{RU}}\right)$, density $\left(\rho_{R O}\right.$ or $\left.\rho_{R U}\right)$, coating thickness $\left(t_{c-R O}\right.$ or $\left.t_{c-R U}\right)$, and coating density $\left(\rho_{c-R O}\right.$ or $\left.\rho_{c-R U}\right)$. If return idlers are present, the unit mass can be calculated the same as the forward idlers according to:

$$
\frac{\pi b_{R}}{4 x_{R}}\left(\rho_{R}\left(d_{o-R}^{2}-d_{i-R}^{2}\right)+\rho_{c-R}\left(\left(d_{o-R}+2 t_{c-R}\right)^{2}-d_{o-R}^{2}\right)\right)
$$

If only one set of idlers are driven by both the forward and return of the belt (that is, the belt makes contact with the top and bottom of one set of idlers and there are no return idlers), then the return idler unit mass can simply be set to zero. Idlers are typically also coated in a wrapping material to increase friction between the idler and the belt. However, if no coating material is present around the idler, then the coating thickness can also be set to zero to not affect the calculation. As with the belt material, the idler density can also be selected from a drop-down list of common idler materials [15].

To input operational (varying) parameters in the modeling tool, the user is required to specify a number of unique operation periods in a day. Unique operation periods are defined such that operational parameters are constant for the duration of each period. The user will enter the number of periods and then be required to specify the start and end time for each operation period. The user will then designate the value and units for each operational parameter for every unique period across an operation day. Operation periods are limited to a minimum time of one minute in the tool. A list of the operational parameters that can be entered into the tool is shown in Table 9.

As with certain structural parameters, the belt speed, $\mathrm{V}(\mathrm{t})$, the section width, $\mathrm{b}_{1}(\mathrm{t})$, and material (product) density, $\rho(t)$, cannot be calculated using other methods and are required as-is. If the feed rate of material onto the belt, $\mathrm{T}(\mathrm{t})$, is not known, then the material unit mass, $\mathrm{Q}_{\mathrm{G}}(\mathrm{t})$, can be entered instead because unit mass is equivalent to the ratio of feed rate to belt speed. The section width, $b_{1}(t)$, can sometimes be altered by pneumatic-controlled guides to reduce the section width and is therefore considered an operational parameter here.

Table 9. List of Conveyor Energy Modeling Tool Operational Parameter Inputs and Descriptions

\begin{tabular}{|l|c|c|c|}
\hline Parameter & Symbol & Description & Required? \\
\hline Belt Speed & $\mathrm{V}$ & Belt velocity & YES \\
\hline Section Width & $\mathrm{b}_{1}$ & $\begin{array}{c}\text { Width of conveyor section, or just belt width if no } \\
\text { guide boards. Changes with time if pneumatic- } \\
\text { controlled guides. }\end{array}$ & YES \\
\hline Material Feed Rate & $\mathrm{T}$ & $\begin{array}{c}\text { Feed rate of material mass onto the conveyor } \\
\text { section }\end{array}$ & $\begin{array}{c}\text { NO } \\
\text { If QG available }\end{array}$ \\
\hline Material Unit Mass & $\mathrm{Q}_{\mathrm{G}}$ & $\begin{array}{c}\text { Unit mass per length of material on the conveyor } \\
\text { section }\end{array}$ & $\begin{array}{c}\text { NO } \\
\text { If T available }\end{array}$ \\
\hline Material Density & $\rho$ & $\begin{array}{c}\text { Density of material (changes with time if different } \\
\text { materials fed) }\end{array}$ & YES \\
\hline
\end{tabular}

\subsubsection{Energy Calculation Methodology}

The conveyor energy modeling tool outputs each of the conveyor parameters to a table at each minutetimestep of the specified operation timeline. The torque is calculated at each timestep according to equations $1-7$, and the rotational velocity (in RPM) is calculated from the belt speed, $V(t)$, and driving roller diameter, $\mathrm{d}$, according to: 


$$
V_{R P M}(t)=\frac{60 V(t)}{\pi d}
$$

The efficiency at each time step is then calculated by interpolating the rotational velocity $V_{\text {RPM }}(t)$ and the torque $\mathrm{T}_{\mathrm{M}}(\mathrm{t})$ to the characterized motor/drive system performance curve. The conveyor energy modeling tool does this by fitting a quartic, two-dimensional regression surface to the motor performance data to estimate efficiency on an axis orthogonal to $V_{\text {RPM }}$ and $T_{M}$. Quartic least-squares regression is a standard and reliable method used for curve-fitting dynamometer performance data in most regular motor/drive systems. Input power is also interpolated at each timestep, or alternatively could be calculated according to:

$$
P_{M}(t)=\frac{T_{M}(t) V(t)}{\pi d \eta(t)}
$$

where $\eta(t)$ is the efficiency of both the motor and drive system. By integrating the calculated power across a day of operation, the total daily $\mathrm{kWh} /$ day of energy use is calculated. Likewise, the $\Delta \mathrm{kWh} /$ day savings between a baseline and energy-efficient motor/drive system measure can be calculated. The total estimated energy consumption and savings is reported on the output page of the conveyor energy modeling tool. Additionally, the daily power consumption in watts, daily drive system efficiency, daily drive torque (in Nm) and daily belt speed (in $\mathrm{m} / \mathrm{s}$ ) are all plotted automatically across a 24-hour operation day starting at the start time specified for the first operation period.

To estimate yearly energy consumption and/or savings, an additional optional interface page within the calculation tool can be used to define a schedule similarly to the method used to specify a daily operation schedule. The number of unique weeks (weeks containing holidays) is entered, and the number of unique days in a typical week (and each holiday week) can be specified as well. A table is generated for each unique week that allows the user to enter the number of times a unique operation day is repeated that week, such as " 5 " for an operation day that is the same between Monday through Friday. The user is then able to enter the kWh consumption calculated from the output sheet to this table for the specified operation day. This requires the user of the tool to specify different operational parameters and operation period schedules for the different days. The energy consumption and/or savings is then again integrated across a year to calculate total yearly $\mathrm{kWh}$ consumption and $\Delta \mathrm{kWh}$ savings.

For users of the conveyor energy modeling tool who are not conducting motor/drive dynamometer characterization, a supplementary motor database was developed to be provided with the modeling tool. The motor database generates a data table of the estimated performance curve when a selected motor is coupled with a VFD. On one page, the user can sort through a list of 16,359 motors based on manufacturer, model number, rated HP, RPM, efficiency, voltage, amperage, cost, weight, NEMA design, frame size, or even warranty. Not all of these parameters are listed for every motor. The motor catalogue was extracted from the MotorMaster-Plus software tool developed by DOE's Office of Energy Efficiency and Renewable Energy Industrial Technologies Program [3]. The performance data available from this catalogue were collected from spec sheets acquired across 14 manufacturers. Because these data were obtained from manufacturers and not from standard performance testing, it should be noted that the data contained in this catalogue may not be indicative of the actual performance of these models.

When coupled with a VFD, the performance of the catalogued motors is estimated at reduced velocities using the idealized VFD efficiency factors at those velocities [4]. The idealized VFD efficiency factors 
were calculated by Burt et al. based on the Wallbom-Carlson theory, which accounts for losses in the motor caused by a VFD, as well as losses in the VFD $[4,5]$. When these idealized efficiency factors were applied to the manufacturer-reported performance curve for the baseline motor evaluated in this study, calculated efficiencies were nearly the same as those measured via dynamometer testing.

To generate a full motor performance characterization data set using the idealized efficiency factors, the user of the database will simply enter the catalogue ID number of the motor and the data set will be automatically generated. The user is then able to copy and paste the performance characterization data set into the conveyor energy modeling tool.

\subsection{Energy Modeling Scenarios}

\subsubsection{Peak Demand; Daily and Yearly Savings Assessments}

The conveyor energy modeling tool was first used to assess and compare the SRM and baseline motor/VFD energy consumption in the selected conveyor system. The ComEd customer provided a list of the structural and operational parameter values for the selected conveyor to input to the tool. The list of values input as conveyor structural parameters is provided in Table 10. Some parameters were not provided by the customer, so NREL assigned a reasonably expected value to those parameters based on assumptions made through other information gathered. Values that were determined directly from the customer response are highlighted accordingly in Table 10. An explanation is provided in circumstances in which a parameter value was assumed by NREL.

For the selected conveyor section, only a single set of idlers made contact with both the forward and return sides of the belt. Therefore, return idler parameters were set to zero in the conveyor energy modeling tool and not included in Table 10. Because this is a candy manufacturing operation, this was expected since return idlers are more typical in higher torque-load applications.

Table 10. Selected Conveyor Structural Parameter Input Values

\begin{tabular}{|c|c|c|c|c|}
\hline Parameter & Symbol & Customer Response & NREL Assumption & Assigned Value \\
\hline Section Length & $\mathrm{L}$ & $\begin{array}{l}\text { "Entire section was powered by } \\
\text { one motor estimated length } 75 \mathrm{ft} \text { " }\end{array}$ & (2: & $75 \mathrm{ft}$ \\
\hline Incline Angle & $\delta$ & "0 degrees" & - & 0 \\
\hline $\begin{array}{l}\text { Guide Friction } \\
\text { Coefficient }\end{array}$ & $\mu$ & $\begin{array}{l}\text { "Contact could not locate } \\
\text { reference box" }\end{array}$ & $\begin{array}{l}\text { Guide boards appear stainless } \\
\text { steel in images of conveyors in } \\
\text { facility and packages are } \\
\text { assumed cardboard }\end{array}$ & 0.35 \\
\hline $\begin{array}{l}\text { Driving Roller } \\
\text { (Pulley) Diameter }\end{array}$ & d & "2 inch diameter" & $\mathrm{C}$ & 2 in \\
\hline Belt Width & $b_{0}$ & $\begin{array}{l}\text { "Belt driving them was } 4 \text { inches } \\
\text { wide, centered in the middle" }\end{array}$ & 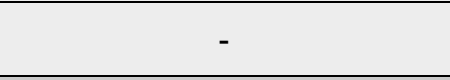 & 4 in \\
\hline Belt Thickness & $t_{b}$ & No response & $\begin{array}{c}\text { Assume } 1 / 2 \mathrm{~cm} \text { guesstimate } \\
\text { from images of conveyors in } \\
\text { facility }\end{array}$ & $0.5 \mathrm{~cm}$ \\
\hline $\begin{array}{l}\text { Belt } \\
\text { Density/Material }\end{array}$ & $\rho b$ & No response & $\begin{array}{l}\text { Assumed natural rubber from } \\
\text { images of conveyors in facility }\end{array}$ & $930 \mathrm{~kg} / \mathrm{m}^{3}$ \\
\hline $\begin{array}{l}\text { Artificial Friction } \\
\text { Factor }\end{array}$ & $f$ & - & $\begin{array}{l}\text { Assumed conveyor installation } \\
\text { is normally aligned }\end{array}$ & 0.03 \\
\hline $\begin{array}{l}\text { Forward Idler } \\
\text { Spacing }\end{array}$ & $\mathrm{XRO}$ & "9 inches" & 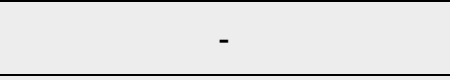 & 9 in \\
\hline $\begin{array}{l}\text { Forward Idler } \\
\text { Width }\end{array}$ & bro & "Rollers were $1 \mathrm{ft}$ wide" & - & $1 \mathrm{ft}$ \\
\hline
\end{tabular}




\begin{tabular}{|l|c|l|c|c|}
\hline Parameter & Symbol & \multicolumn{1}{|c|}{ Customer Response } & NREL Assumption & Assigned Value \\
\hline $\begin{array}{l}\text { Forward Idler Inner } \\
\text { Diameter }\end{array}$ & $\mathrm{d}_{\mathrm{i}-\mathrm{RO}}$ & No response & Assumed $1 \mathrm{inch}$ & $2 \mathrm{in}$ \\
\hline $\begin{array}{l}\text { Forward Idler Outer } \\
\text { Diameter }\end{array}$ & $\mathrm{d}_{\mathrm{o}-\mathrm{RO}}$ & $\begin{array}{l}\text { "Did not have manufacturer } \\
\text { specs, idlers were 2 inch } \\
\text { diameter steel rollers" }\end{array}$ & $\begin{array}{l}\text { Assumed steel is plain } / \mathrm{carbon} \\
\text { steel from images of } \\
\text { conveyors in facility }\end{array}$ & $7850 \mathrm{~kg} / \mathrm{m}^{3}$ \\
\hline $\begin{array}{l}\text { Forward Idler } \\
\text { Density/Material }\end{array}$ & $\rho_{\mathrm{RO} O}$ & No response & $\begin{array}{l}\text { Assumed steel idlers coated in } \\
\text { galvanizing zinc, as is typical }\end{array}$ & $0.02 \mathrm{~mm}$ \\
\hline $\begin{array}{l}\text { Forward Idler } \\
\text { Coating Thickness }\end{array}$ & $\mathrm{t}_{\mathrm{c}-\mathrm{RO}}$ & No response & $\begin{array}{l}\text { Assumed steel idlers coated in } \\
\text { galvanizing zinc, as is typical }\end{array}$ & $5610 \mathrm{~kg} / \mathrm{m}^{3}$ \\
\hline $\begin{array}{l}\text { Forward Idler } \\
\text { Coating } \\
\text { Density/Material }\end{array}$ & $\rho_{\mathrm{c}-\mathrm{RO}}$ & No response & 5 \\
\hline
\end{tabular}

The customer was unable to provide the belt thickness, $t_{b}$, the belt material or density, $\rho_{b}$, the idler inner diameter, $d_{i-R O}$, the idler density, $\rho_{R O}$, or the guide friction coefficient, $\mu$. Images obtained of the facility did not show the selected conveyor section, and so the belt thickness and material, and idler inner diameter and material were assumed based on images of another conveyor section shown. The guide friction coefficient was also assumed based on images of this other conveyor section, which appeared to have steel guide boards. The candy product was stated to be loaded in box packages, and so it was assumed that the box material was cardboard. Therefore, the guide friction coefficient was assigned a reported value of the kinetic friction coefficient between carboard and stainless steel [15]. When selecting the artificial friction factor, it was qualitatively determined that the conveyor installation was likely "normally aligned" based on the conveyors shown in the obtained images.

The operational parameter values specified by the customer are shown in Table 11. The unit mass of the conveyed product material was not provided and instead was calculated from the feed rate and belt speed. The density of the product material, the section width, and the speed of the belt were each reported as constant parameters that did not change throughout operation. Two separate material feed rates were provided for "regular production" and "slow time."

Table 11. Selected Conveyor Operational Parameter Input Values

\begin{tabular}{|l|c|l|c|c|}
\hline Parameter & Symbol & \multicolumn{1}{|c|}{ Customer Response } & Calculation & Assigned Value \\
\hline Belt Speed & $\mathrm{V}$ & $\begin{array}{l}\text { "Belt speed is constant product was } \\
\text { moving approx. 2ft/second" }\end{array}$ & - & $2 \mathrm{ft} / \mathrm{s}$ \\
\hline Section Width & $\mathrm{b}_{1}$ & "Guide board width is constant $1 \mathrm{ft}$ " & - & $1 \mathrm{ft}$ \\
\hline Material Density & $\rho$ & $\begin{array}{l}\text { "Package volume } 4 \times 7 \times 4 \text { inches; } \\
\text { package weight } 504 \mathrm{~g} "\end{array}$ & $\frac{504 \mathrm{~g}}{(4 * 7 * 7) \mathrm{in}^{3}}=$ & $0.157 \mathrm{~g} / \mathrm{cm}^{3}$ \\
\hline $\begin{array}{l}\text { Material Feed } \\
\text { Rate }\end{array}$ & $\mathrm{T}$ & $\begin{array}{l}\text { "Slow time of } 6 \text { boxes per minute; } \\
\text { regular production of } 20 \text { boxes per min" }\end{array}$ & $\begin{array}{c}6 \frac{\text { box }}{\min } * 504 \frac{\mathrm{g}}{\mathrm{box}}= \\
20 \frac{\mathrm{g}}{\min } * 504 \frac{\mathrm{g}}{\mathrm{box}}=\end{array}$ & $3,024 \mathrm{~g} / \mathrm{min}$ \\
\hline
\end{tabular}

The customer did not specify the breakdown of the "regular production" vs. "slow time" operation periods. Therefore, results were calculated for separate 10-hour and 24-hour operation days, with $20 \%$ and $50 \%$ "slow time." The $\mathrm{kWh} /$ day consumption and $\Delta \mathrm{kWh} /$ day savings between the two motor/drive systems in this conveyor system are reported in the following section. Additionally, the power consumption, drive efficiency, torque, and belt speed are reported across the 10 -hour/20\% slow-time operation day. Assuming federal holidays, the yearly energy consumption and savings is also provided for each scenario. 


\subsubsection{Assessment of Energy Sensitivity to Conveyor Parameters}

In order to understand the effect that the conveyor parameters have on power and energy consumption, a sensitivity analysis was conducted. Because it is in the best interest of manufacturers and conveyor customers to design conveyor systems that will minimize energy consumption, it is critical to understand the effect of parameters in the design. The sensitivity analysis, therefore, involves varying the values for each of the conveyor parameters across a reasonable range while holding the other parameters constant. The effect of each parameter on the total energy consumption and savings between the SRM and baseline motor/VFD were compared. For each parameter, three variation curves are also provided where all other parameters are held at $-15 \%$ and $+15 \%$ of, and at the baseline parameter values provided in Tables 10 and 11 (except the artificial friction factor).

For the purposes of the analysis, a single operation period of 12 hours with $20 \%$ slow time was used because the effect of operation time is linear. When analyzing the sensitivity of material feed rate, the feed rate was assumed continuous. Since certain parameters are optional, only the parameters listed in Tables 10 and 11 were included in the sensitivity analysis. Because forward and return idler unit masses are simply summed together in equation 2 , only the parameters associated with the forward idlers were evaluated in the sensitivity analysis as well.

\section{Results and Savings Summary}

\subsection{Peak Demand; Daily and Yearly Savings Results}

Total energy savings were evaluated across a 10-hour operation day and a 24-hour operation day. Material density and belt speed were specified as constant parameters throughout operation; however, two material feed rates were given as "slow time" and "regular production." Because the scheduling of slow time versus regular production was not specified, energy consumption was evaluated using an assumed 20\% slow time and 50\% slow time. The baseline motor and SRM estimated daily energy consumption, as well as the estimated daily energy savings are shown below in Table 12.

Table 12. Total Estimated Daily Conveyor Motor Energy Consumption and Savings by SRM

\begin{tabular}{|c|c|c|}
\hline Baseline Motor/VFD & $20 \%$ Slow Time & $50 \%$ Slow Time \\
\hline 10-hour day & $1.654 \mathrm{kWh} /$ day & $1.649 \mathrm{kWh} /$ day \\
\hline 24-hour day & $3.967 \mathrm{kWh} /$ day & $3.956 \mathrm{kWh} /$ day \\
\hline SRM & $20 \%$ Slow Time & $50 \%$ Slow Time \\
\hline $10-$ hour day & $1.142 \mathrm{kWh} /$ day & $1.138 \mathrm{kWh} /$ day \\
\hline 24-hour day & $2.739 \mathrm{kWh} /$ day & $2.729 \mathrm{kWh} /$ day \\
\hline Savings & $20 \%$ Slow Time & $50 \%$ Slow Time \\
\hline 10-hour day & $0.512 \mathrm{kWh} /$ day & $0.511 \mathrm{kWh} /$ day \\
\hline 24-hour day & $1.228 \mathrm{kWh} /$ day & $1.226 \mathrm{kWh} /$ day \\
\hline
\end{tabular}

The SRM daily energy savings in Table 12 were significant. The baseline motor and VFD averaged 1.65 $\mathrm{kWh}$ across a 10-hour operation day and a total $3.96 \mathrm{kWh} /$ day. The SRM, however, averaged just 1.14 $\mathrm{kWh}$ across 10 -hour operation and total $2.73 \mathrm{kWh} /$ day. This resulted in a $0.51 \mathrm{kWh}$ reduction in energy across a 10-hour operation period and total reduction of $1.23 \mathrm{kWh} /$ day, which constitutes a $31.0 \%$ reduction in total energy consumption. The different slow time and regular operation feed rates were 
found to contribute very little to the overall daily energy savings and consumption from both motor/drives. This was evident by the small discrepancy in daily kWh between $20 \%$ and $50 \%$ slow time.

Yearly savings were estimated by integrating daily energy savings as shown in Table 13, including and excluding weekends. Ten federal holidays were excluded in this integration.

Table 13. Total Estimated Yearly Conveyor Motor Energy Consumption and Savings by SRM

\begin{tabular}{|c|c|c|c|c|c|}
\hline \multicolumn{3}{|c|}{ Excluding Weekends } & \multicolumn{3}{|c|}{ Including Weekends } \\
\hline $\begin{array}{c}\text { Baseline } \\
\text { Motor/VFD }\end{array}$ & $20 \%$ Slow Time & $50 \%$ Slow Time & $\begin{array}{c}\text { Baseline } \\
\text { Motor/VFD }\end{array}$ & $20 \%$ Slow Time & $50 \%$ Slow Time \\
\hline 10-hour day & $415 \mathrm{kWh}$ & 414 kWh & 10-hour day & $587 \mathrm{kWh}$ & $586 \mathrm{kWh}$ \\
\hline 24-hour day & $995 \mathrm{kWh}$ & 992 kWh & 24-hour day & $1408 \mathrm{kWh}$ & $1404 \mathrm{kWh}$ \\
\hline SRM & $20 \%$ Slow Time & $50 \%$ Slow Time & SRM & $20 \%$ Slow Time & $50 \%$ Slow Time \\
\hline 10-hour day & $286 \mathrm{kWh}$ & $285 \mathrm{kWh}$ & 10-hour day & $405 \mathrm{kWh}$ & $404 \mathrm{kWh}$ \\
\hline 24-hour day & $687 \mathrm{kWh}$ & $684 \mathrm{kWh}$ & 24-hour day & $972 \mathrm{kWh}$ & 969 kWh \\
\hline $\begin{array}{l}\text { kWh/year } \\
\text { Savingss }\end{array}$ & $20 \%$ Slow Time & $50 \%$ Slow Time & $\begin{array}{c}\text { kWh/year } \\
\text { Savings }\end{array}$ & $20 \%$ Slow Time & $50 \%$ Slow Time \\
\hline 10-hour day & $128 \mathrm{kWh}$ & $128 \mathrm{kWh}$ & 10-hour day & $182 \mathrm{kWh}$ & 182 kWh-days \\
\hline 24-hour day & $308 \mathrm{kWh}$ & $307 \mathrm{kWh}$ & 24-hour day & $436 \mathrm{kWh}$ & $435 \mathrm{kWh}$ \\
\hline
\end{tabular}

Estimated yearly energy savings were predicted to reach as high as $182 \mathrm{kWh}$-days if using a 10-hour daily operation period, or up to $436 \mathrm{kWh}$-days if operating continuously for 24 hours, when including weekends. Excluding weekends, yearly energy savings for a 10-hour and 24-hour operation period were estimated as high as 128 and $308 \mathrm{kWh}$-days, respectively.

The reason for such significant energy savings is because the conveyor belt speed and torque demand generated a low efficiency in the baseline induction motor and VFD. This speed and torque did not induce efficiencies near the SRM's peak performance; however, they did not induce losses nearly as significant as seen in the baseline motor/drive. The conveyor energy modeling tool output plots of the total daily drive efficiency and consumed power are shown in Figures 17 and 18 for both the baseline and SRM, respectively. Because total operation time did not affect instantaneous efficiency and power consumption, only the 10-hour operation period is shown. 


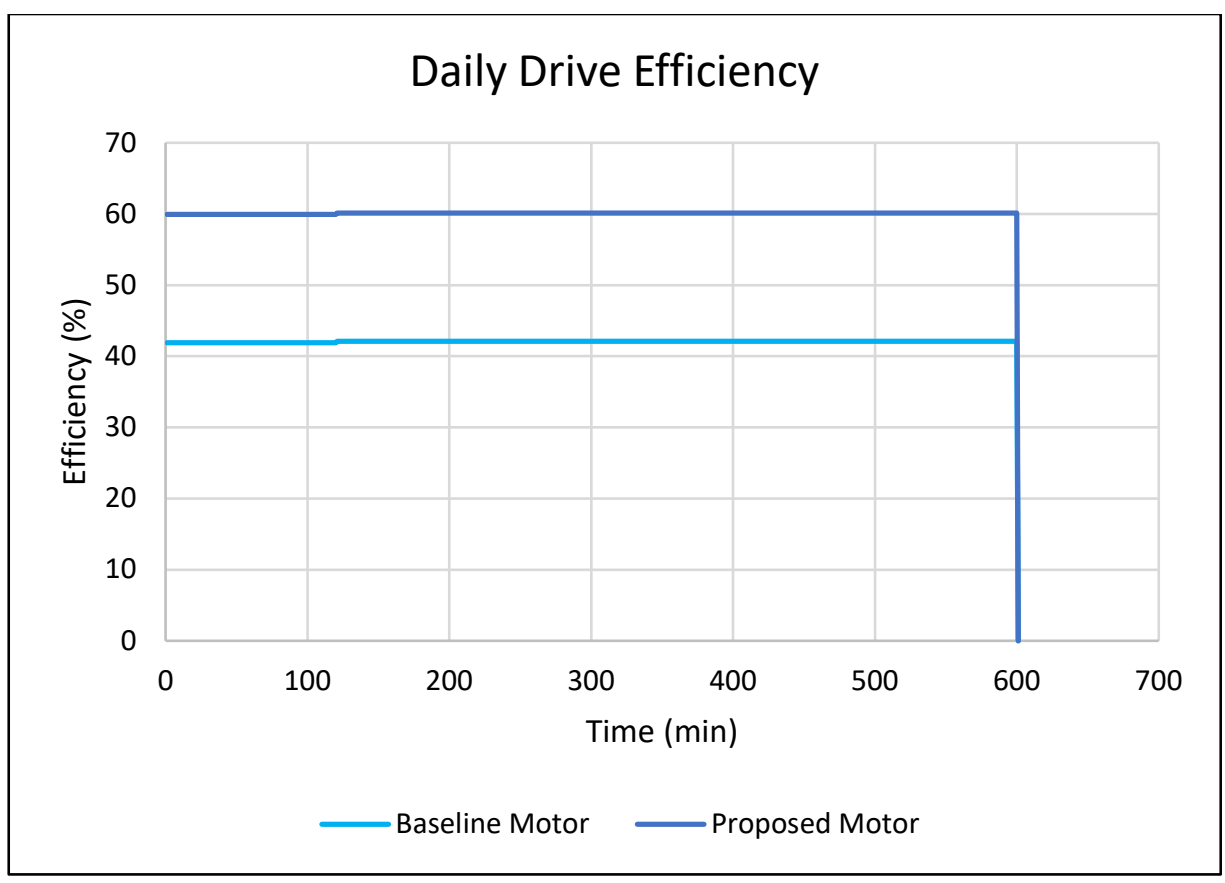

Figure 17. Calculator tool output conveyor drive system efficiency at estimated torque (10-hour operation)

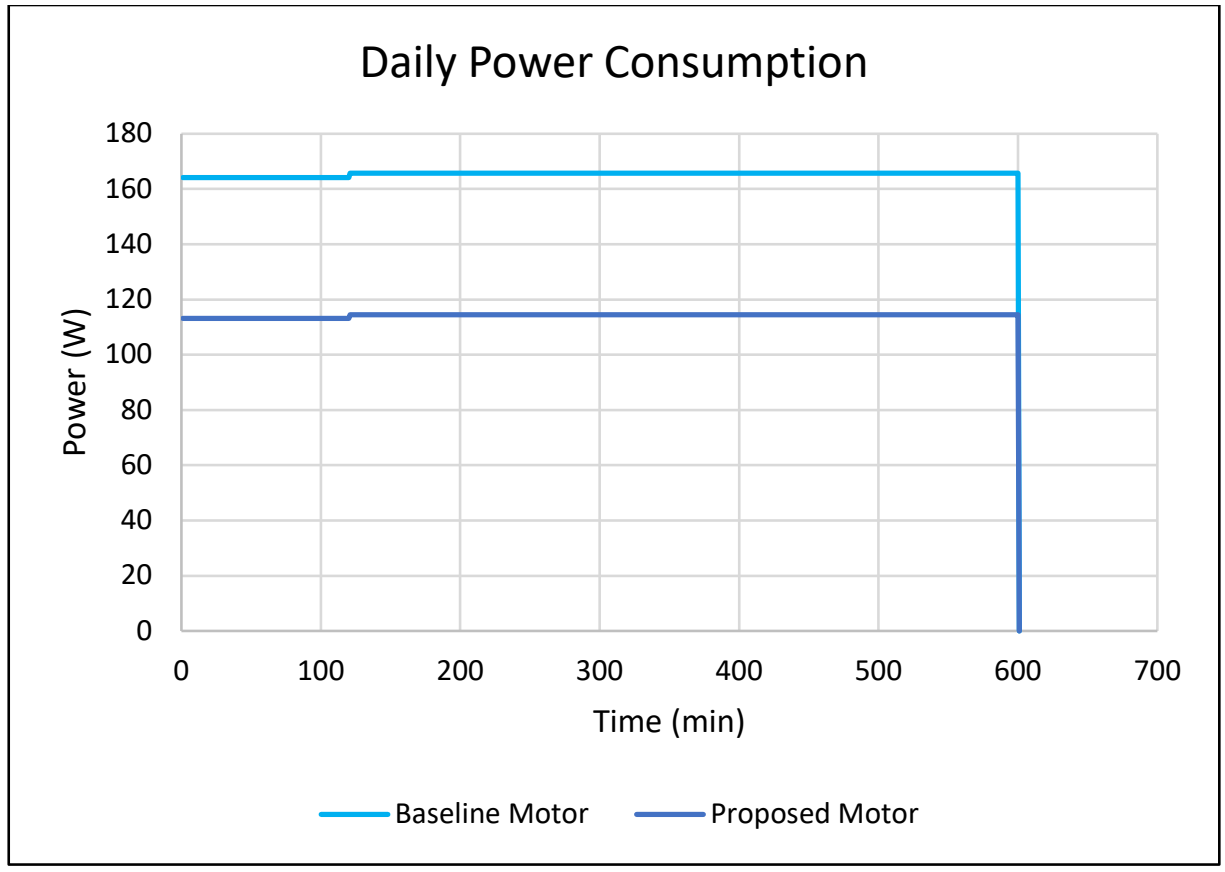

Figure 18. Calculator tool output conveyor estimated daily power consumption (10-hour operation)

Figure 17 shows that the SRM efficiency was far higher than the baseline induction motor and VFD at the estimated torque and belt speed of the conveyor. The efficiencies of each motor/drive were not nearly as high as their peak efficiencies. The SRM's efficiency ranges between $80 \%$ to more than $90 \%$ at its highest speed, as shown in Figure 13. Except at the lowest torques, the SRM did not exhibit efficiencies below 75\% unless operating at speeds below 600 RPM. Because the selected conveyor is operating at such a low speed within the motor/drives' range, the SRM efficiency was relatively low. 
However, the efficiency was not nearly as low as seen in the baseline motor and VFD at this speed and torque. The SRM efficiency was $60 \%$, whereas the induction motor and VFD saw an efficiency of only $42 \%$. These efficiencies constituted an approximately $33.3 \%$ and $49.3 \%$ reduction from the SRM and baseline motor/drive's peak efficiencies, respectively. The speed and torque demand outputs from the conveyor energy calculation tool are shown in below in Figure 19.

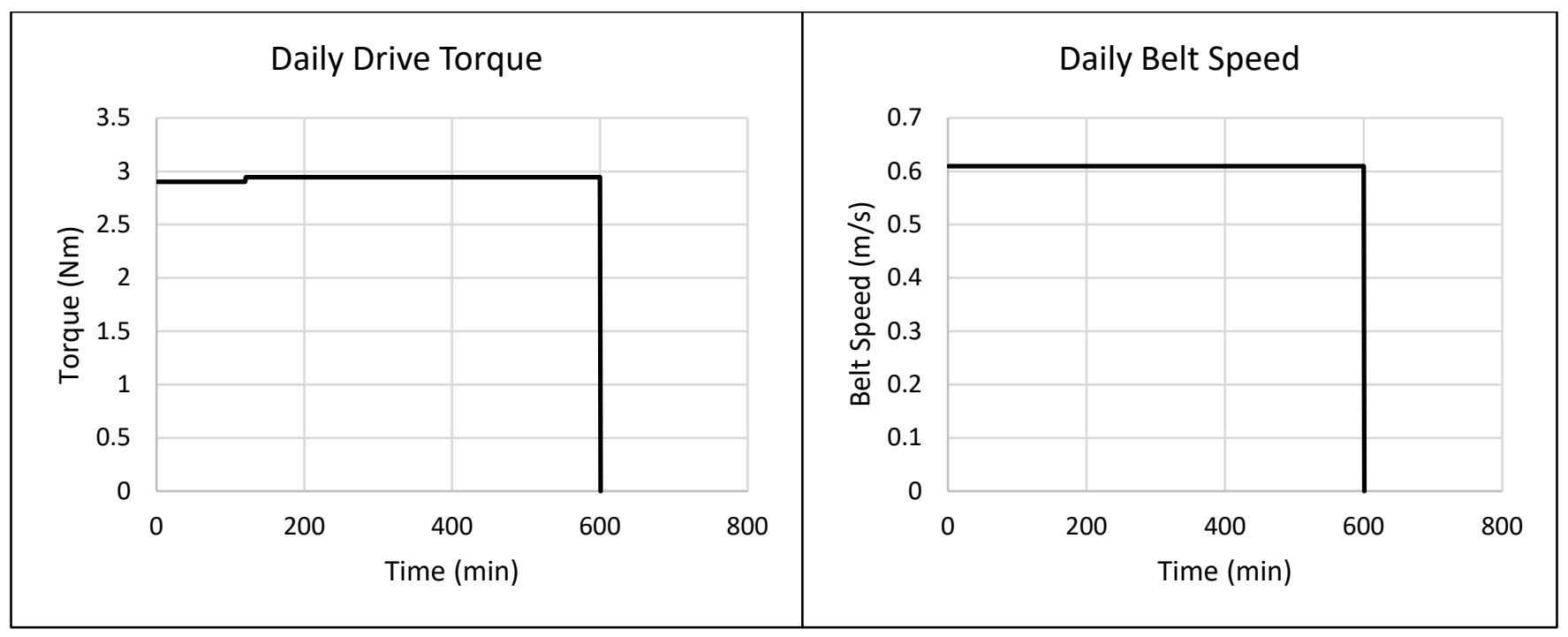

Figure 19. Calculator tool output total conveyor estimated torque demand and belt speed (10-hour operation)

The average torque was estimated at only around $2.9 \mathrm{Nm}$ throughout the operation period. With a 2 -in diameter driving roller, the motor rotational speed was held at a constant 229 RPM. Dynamometer characterization results in Figures 10-11 and Figures 13-14 (Tables 14 and 15 in Appendix B) show that for both motors, this torque and speed was in the lowest range of their operational capability, with the torque load between only $25 \%$ and $50 \%$, and the speed between only 5 and $10 \mathrm{~Hz}$. Due to the excessive losses incurred in the baseline motor/drive at the selected conveyor's speed and torque, the potential SRM savings were much higher than if the conveyor were to operate at higher speeds and loaded with higher torques. A known benefit of the SRM motor is that losses at lower speed and torques are much less significant than in traditional induction motors, and the case of this conveyor presents a strong example of that benefit.

By observing the change in torque across the 10-hour operation period shown in Figure 19, it can be seen that there is only a modest increase following the first two hours, despite the fact that the feed rate is increased by more than $230 \%$ between slow time and regular production. The effect of feed rate can be explained by the torque resistance components output in the conveyor energy calculation tool. Feed rate impacts main resistance (equation 2), secondary resistance (equation 3), and special resistance (equation 5). Because the main resistance is defined as the sum of forces required to pull the masses of the rotating parts of the idlers/pulleys, belt, and conveyed product material, it can be expected that this term would likely dominate the other resistances. The secondary and special resistances are only associated with frictional resistances throughout the conveyor. Therefore, it can be expected that if the mass of the idlers/pulleys and belt is much higher than the conveyed product material, then the feed rate would have less of an impact on the total torque as we are seeing here. During regular operation, the secondary and special resistances were only $0.10 \mathrm{~N}$ and $0.41 \mathrm{~N}$, respectively, whereas the main 
resistance was $115.4 \mathrm{~N}$. During slow time, the secondary and special resistances were nearly negligible at .03 and $.04 \mathrm{~N}$, whereas the main resistance was only reduced to $114.1 \mathrm{~N}$.

In conveyors that operate under highly variable feed rates or belt speeds, it is often typical that the belt and idlers are designed to contribute to most of the total conveyor component mass. If the conveyed material mass is much less than the belt and idler rotating parts, there is less variation in overall torque load. If the conveyed material contributed to the majority of the component mass, torque would vary drastically with any change in belt speed or feed rate. This could force a motor and drive system to operate outside an ideal performance range.

\subsection{Effect of Conveyor Parameters on Energy Consumption and Savings}

In the future, it may be found that some of the assumed conveyor parameters in the selected conveyor system are much different than actual values. Because of this, it was necessary to conduct a sensitivity analysis to gain an understanding of the effect of each parameter on total energy consumption. This was done by varying each of the parameters while holding the other parameters constant. Although the sensitivity analysis here was only conducted using the motor and drive systems evaluated as part of this study, each conveyor parameter can be assumed to contribute a similar effect when coupled with other motors. A user of the conveyor energy calculation tool that wishes to design conveyor systems for optimal efficiency can use the results of this sensitivity analysis as guidance in their selection of conveyor components.

An analysis of the effect on total energy consumption by each conveyor parameter is also necessary to assist the customer in predicting energy consumption and savings of other conveyors in their facility. The 2-HP ABB motor was used with seven other conveyor sections, three of which were paired with an Allen-Bradley VFD. Depending on the conveyor torque load in the sections not containing a VFD, potential savings benefits could be incurred by retrofit of an SRM to those sections as well.

The sensitivity analysis using the conveyor energy modeling tool was first conducted by varying each of the conveyor parameters while holding all other parameters constant. Each parameter and the energy consumption/savings were normalized to the baseline values from the selected conveyor to compare the effect of each parameter. First, the effect of these parameters on the baseline motor/VFD consumption, the SRM consumption, and the energy savings were separately compared. Then, each parameter was varied while holding all other parameters at $15 \%$ below and above their baseline value. Both of these steps in the analysis were conducted under the following conditions:

- Each of the 15 conveyor structural parameters listed in Table 10, and the four operational parameters listed in Table 11, were varied between $-100 \%$ and 100\% from the baseline values provided for the selected conveyor section (also listed in Tables 10 and 11).

- Because the selected conveyor was level to the ground (and so the baseline incline angle was $0^{\circ}$ ), a $100 \%$ deviation from the baseline was specified as a $45^{\circ}$ angle.

- Because energy consumption is calculated by integrating the consumed power over time, the effect of operation time is linear and so was not included in the analysis. Instead, a 12-hour operation period was held constant. 
- A baseline slow time of 20\% was used when varying all parameters, except the material feed rate. When varying the feed rate, it was held constant throughout the operation period as was done with all other operational parameters.

\subsubsection{Parameter Effects Comparison}

The sensitivity analysis results for the selected conveyor section when coupled with the baseline ABB motor and Allen-Bradley VFD are provided in Figure 20. Because not all parameters yield solely an increase or decrease in energy consumption as they are varied in one direction, impact factors were not calculated. Instead, each parameter is listed in the order of inducing the highest to lowest change in overall magnitude in energy consumption. Parameters were varied only to the limits of the operational capability of the motor and drive system, and so certain parameter curves do not span the full range shown. The power consumption is shown as the percent deviation from the 12-hour baseline value, which was $1.985 \mathrm{kWh}$. 

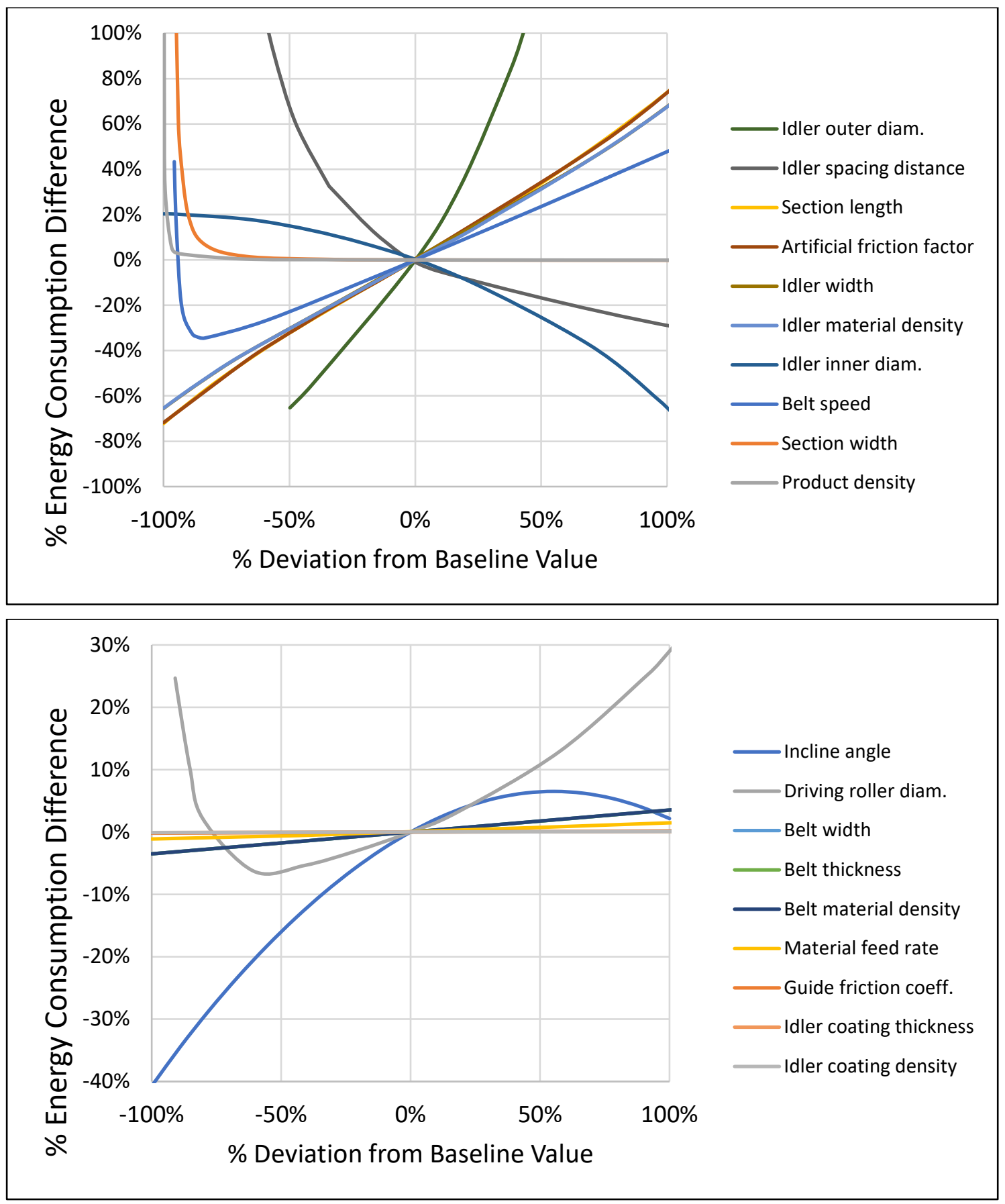

Figure 20. Sensitivity of baseline ABB motor/Allen-Bradley VFD energy consumption to conveyor structural and operational parameters (top: parameters with more impact on energy consumption, bottom: parameters with less impact)

Due to the different performance characteristics of the SRM, the same sensitivity analysis was conducted on the SRM consumption as shown in Figure 21. Again, parameters are listed in the order of inducing the highest to lowest change in magnitude in energy consumption. Parameters were only varied to the limits of the baseline motor/drive for the purposes of comparison and so are not indicative of the 
operational limits of the SRM. A 12-hour operation period using $20 \%$ slow time was used to calculate the baseline energy consumption of $1.371 \mathrm{kWh}$.
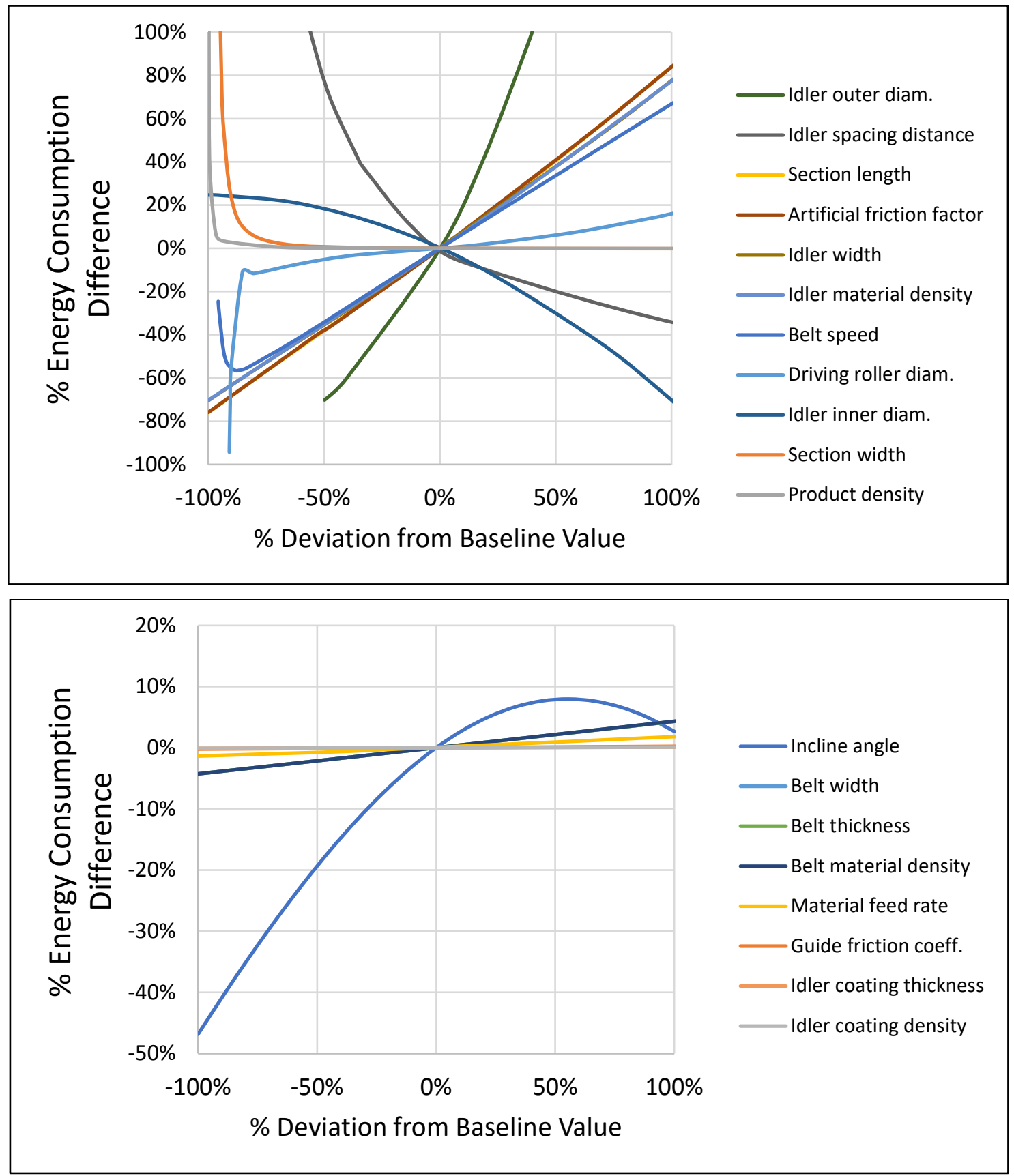

Figure 21. Sensitivity of SRM energy consumption to conveyor structural and operational parameters (top: parameters with more impact on energy consumption, bottom: parameters with less impact)

The overall magnitude in energy consumption of the SRM was significantly less than the induction motor and VFD at the baseline conveyor parameters. This was because these parameters generated a torque demand and rotational velocity that generated much lower energy efficiency in the baseline motor/drive than at higher speeds/torques. If one were to adjust conveyor parameters to increase speed and torque, the efficiency of the baseline would therefore increase more than in the SRM. Because of 
this, one would expect that the difference in energy consumption between the two motors would be reduced. However, because each parameter was varied while all others were held constant, most of these parameters here affected only the torque.

As the torque on the two motors was increased while rotational velocity was held constant at low speed, energy consumption was increased in the baseline motor more than the SRM, which caused energy savings to increase. Similarly, as torque was decreased while holding rotational velocity constant, SRM energy consumption decreased in the SRM at a lower rate than in the induction motor/VFD, causing energy savings to decrease.

The energy savings ( $\triangle \mathrm{kWh}$ ) between the SRM and induction motor/VFD was subjected to the same sensitivity analysis, the results of which are shown in Figure 22. Again, parameters are listed in the order of those that induce the highest to lowest change in magnitude in energy savings. Parameter curves that generated torque loads and rotational velocities outside the operational capability of either the induction motor and VFD or SRM were cut off past those values. A 12-hour operation period using $20 \%$ slow time was used to calculate baseline energy savings of $0.614 \mathrm{kWh}$. 

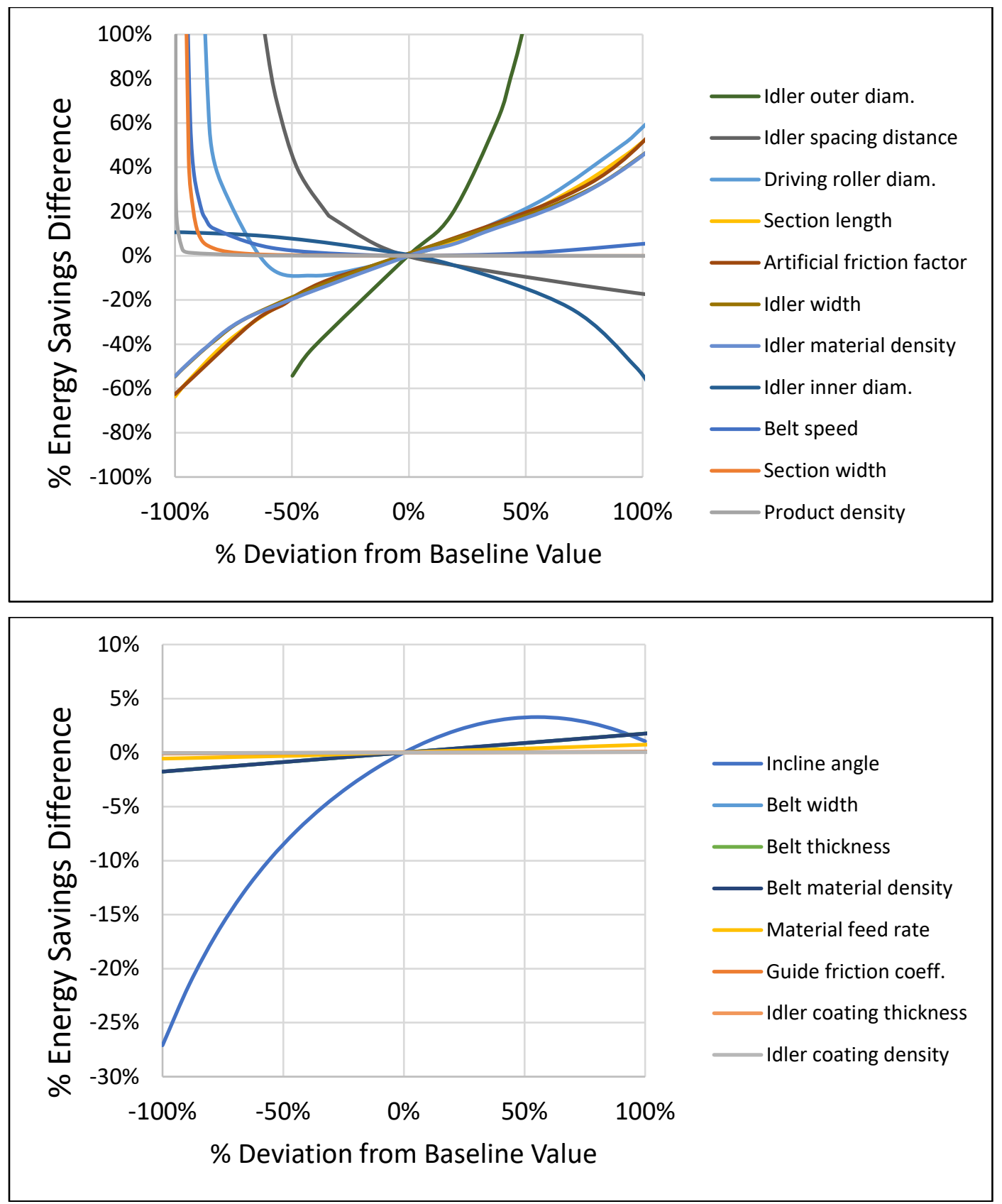

Figure 22. Sensitivity of SRM energy savings to conveyor structural and operational parameters (top: parameters with more impact on energy savings, bottom: parameters with less impact)

Because nearly every conveyor parameter affected the SRM energy consumption less than the baseline motor/drive, the effect on energy savings was largely similar to the effect on consumption. The belt speed and driving roller diameter were the only two parameters that affected energy savings differently. Because near-zero belt speeds generated a positive asymptote in the baseline motor/VFD (Figure 20), and a negative asymptote in the SRM (Figure 21), these values compounded to a larger positive asymptote in savings at near-zero belt speeds (Figure 22).

During SRM dynamometer characterization, the speed-control loop method limited data collection to only the lowest torques at the lowest speeds. Because fewer data points were able to be collected, the 
conveyor calculator tool's curve-fitting method was less accurate at speeds below the lowest dynamometer setpoint. As the belt speed was reduced to near-zero values, an erroneous estimate of energy consumption was exacerbated by this inaccurate curve-fitting. Therefore, the energy consumption and savings at these near-zero values should not be considered reflective of the actual motor/drive systems' performance.

Increase in belt speed also had an effect on torque due to its contribution to the main and secondary resistance. This change in torque, however, was less impactful than the overall effect of the speed increase on total energy consumption. Energy consumption in the SRM increased at a much slower rate with belt speed than in the induction motor and VFD, causing energy savings to increase with respect to belt speed.

Because the driving roller acts as the torque moment arm, its diameter has a more significant impact on torque than the belt speed. Energy savings were therefore more significantly impacted by the driving roller diameter, even though the rotational velocity of the motor is reduced when the diameter is increased. Increase in the driving roller diameter induced a higher increase in energy consumption in the induction motor/VFD than in the SRM. At low driving roller diameters, the rotational velocity of the motor is increased. Again, this increase in speed does not cause SRM energy consumption to increase to the same magnitude as the induction motor and VFD, causing an increase in energy savings.

\subsubsection{Effect of Full Parameter Variation, Discussion}

Because the above results did not show the effect on energy consumption by change in more than one parameter, two more analyses were conducted in which each parameter was varied while holding all other parameters constant at $15 \%$ below, and $15 \%$ above their baseline values. The results of this are shown in the following figures, included with a discussion to describe the effect of each parameter on total energy consumption and savings. Each figure in this section is listed in the order of parameters that contributed the highest to lowest effect on baseline energy consumption as was listed in Figure 20. These figures are organized such that the left columns show the effect on the baseline induction motor/VFD consumption, the middle column shows the effect on the SRM consumption, and the right column shows the effect on energy savings. Some figures show multiple parameters, listed by row. Again, each parameter, including the energy consumption and savings, is displayed as its percent deviation from the baseline conveyor section values. These results are also provided in Appendix $\mathrm{C}$ with respect to the actual $\mathrm{kWh} /$ day consumption/savings and metric values of each parameter.

In each figure below, black lines show the variation in each parameter when all other parameters are held constant at baseline conveyor values (the same as shown in Figures 20, 21, and 22). Dark gray and light gray lines show when all parameters are held constant at $15 \%$ above and below baseline values, respectively. Thin, vertical dotted lines are shown at $15 \%$ below and above the baseline conveyor values listed in each figure. These values are: 1.21 and $3.55 \mathrm{kWh} /$ day for the induction motor/VFD, 0.75 and $2.59 \mathrm{kWh} /$ day for the SRM, and 0.46 and $0.96 \mathrm{kWh} /$ day energy savings. 


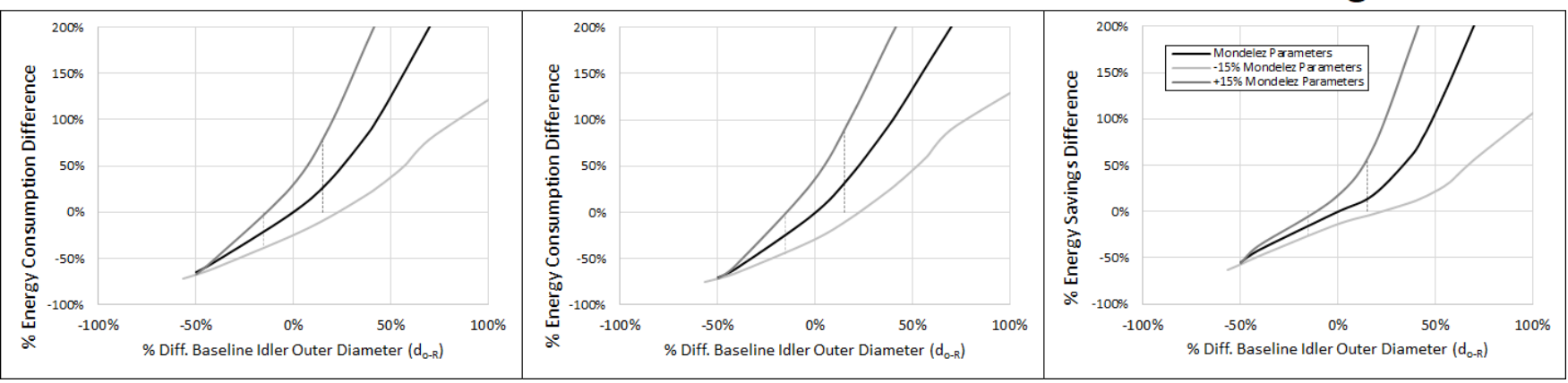

Figure 23. Conveyor energy sensitivity to idler outer diameter $\left(d_{o-R}\right)$

The parameter that exhibited the highest impact on total energy consumption was found to be the outer diameter of the rotating parts of the idlers shown in Figure 23. This was expected because the mass of the conveyed product material was low, and because the belt mass was expected to be low since it did not span the full idler width. The conveyor energy calculator tool output showed that the selected conveyor's idler unit mass was $15.93 \mathrm{~kg} / \mathrm{m}$, whereas the belt unit mass was $0.47 \mathrm{~kg} / \mathrm{m}$ and the product material unit mass was $0.28 \mathrm{~kg} / \mathrm{m}$ during regular operation time. This idler unit mass was equivalent to $95.5 \%$ of the total conveyor section unit mass. At constant density, the mass of the idlers is proportional to the square of the idler outer diameter, and so the unit mass of the idlers increases exponentially with diameter. Because the main resistance is also the dominant resistance contributing to the total torque, energy consumption and savings also increase at an approximately exponential rate with increasing idler outer diameter.

Baseline Motor SRM

Savings

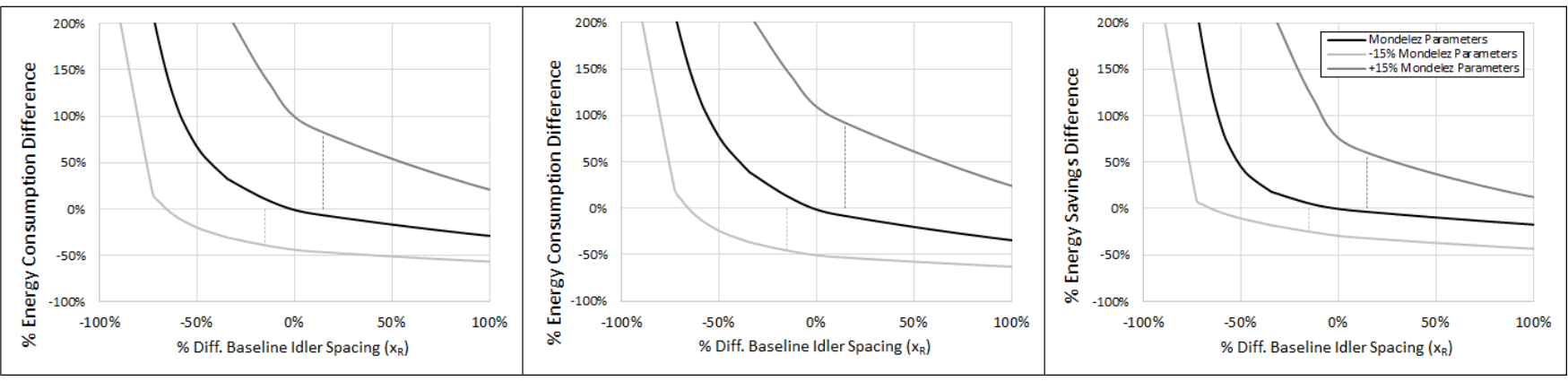

Figure 24. Conveyor energy sensitivity to idler spacing distance $\left(x_{R}\right)$

The parameter that had the second largest effect on energy consumption was the spacing distance between idlers shown in Figure 24. Because the selected conveyor used 2-in. outer-diameter steel idlers, the mass per unit conveyor length of the rotating parts of these idlers was far larger than that of the conveyed product material or the belt. The 4-inch-wide belt did not stretch across the full width of the 1foot-wide idlers and was likely composed of material much less dense than steel. Its unit mass can therefore be assumed to be much lower than that of the rotating parts of the idlers. At constant length, the spacing distance between idlers dictates the number of idlers along the conveyor section, so as the spacing distance is reduced, an increase in idlers drastically increases the torque demand. 
Baseline Motor

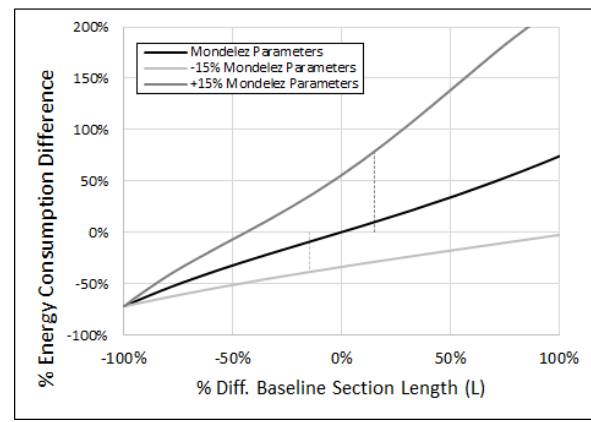

SRM

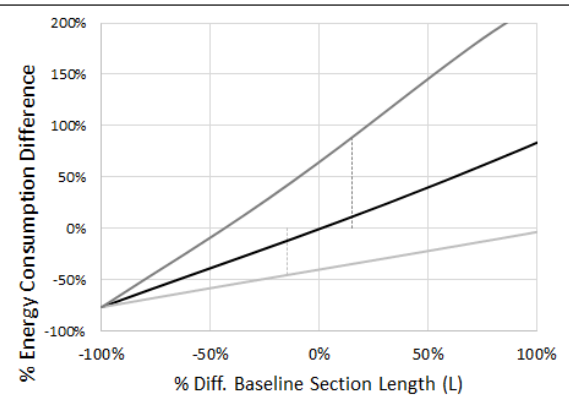

Savings

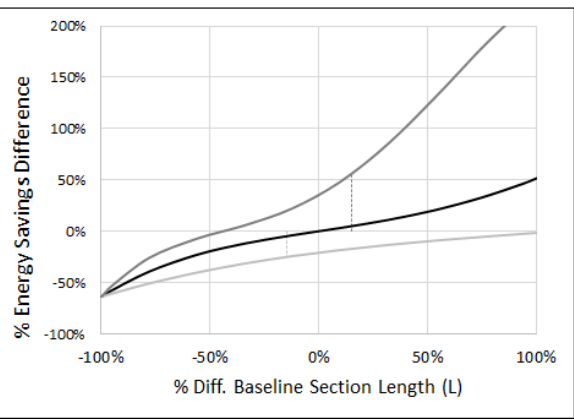

Figure 25. Conveyor energy sensitivity to section length (L)

Section length had the next highest impact, shown in Figure 25. The relationship between energy consumption in both motors and section length was nearly linear, primarily due to the effect of section length on the main resistance. This resistance, as mentioned, is the dominant resistance in the total torque demand. The masses of all structural components are increased proportionally with section length, so this effect was expected.

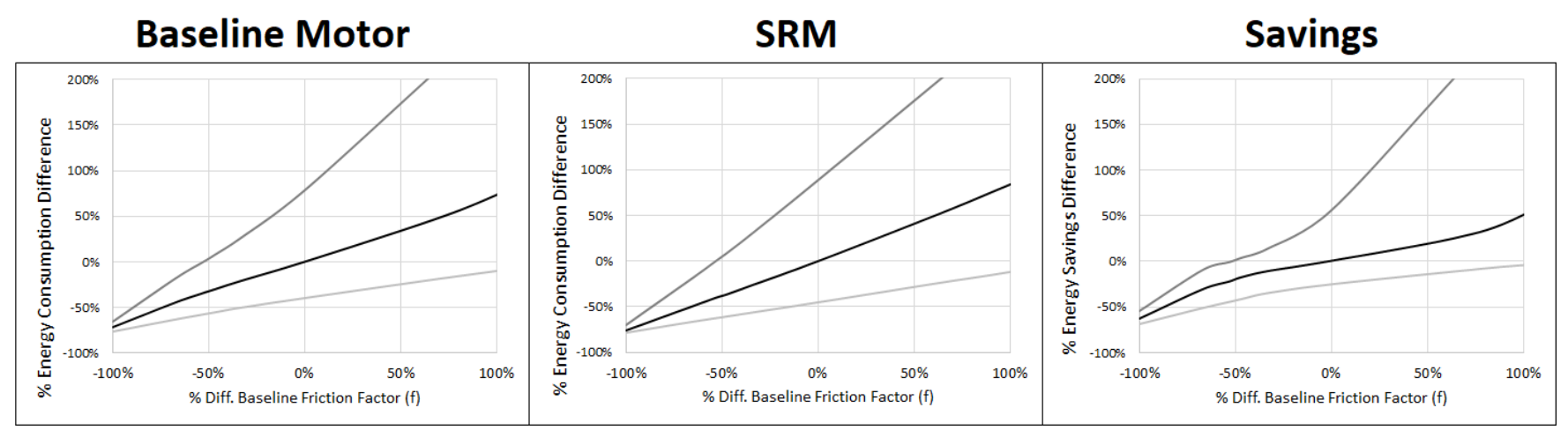

Figure 26. Conveyor energy sensitivity to artificial friction factor (f)

The artificial friction factor (Figure 26) had as much impact on energy consumption as the total section length. It should be noted that artificial friction factor is a discreet value and does not in reality vary linearly, nor to the degree shown here. Qualitative descriptions of the conveyor installation are factored into an algorithm based on other parameters to assign discreet values to the artificial friction factor based on ANSI/ISO 5048 [2], which are only slightly deviated from the baseline value. 
Baseline Motor
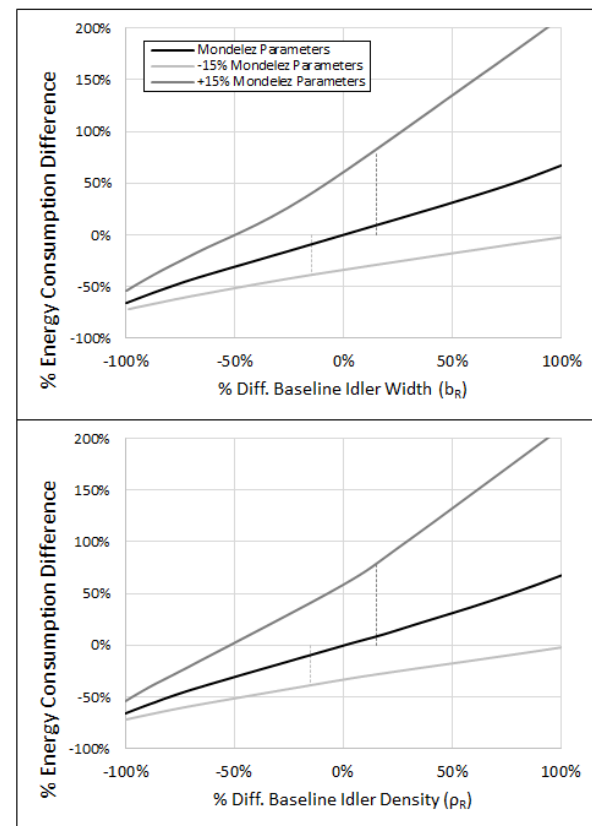

SRM
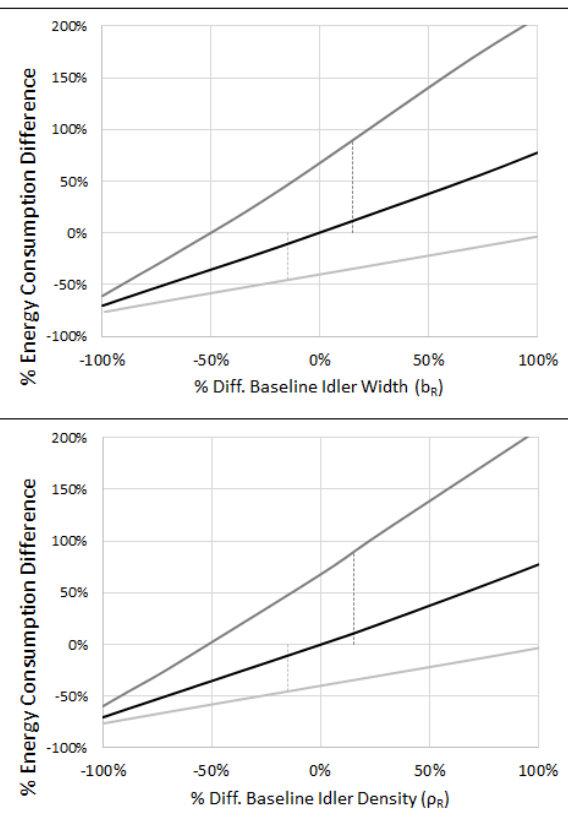

Savings

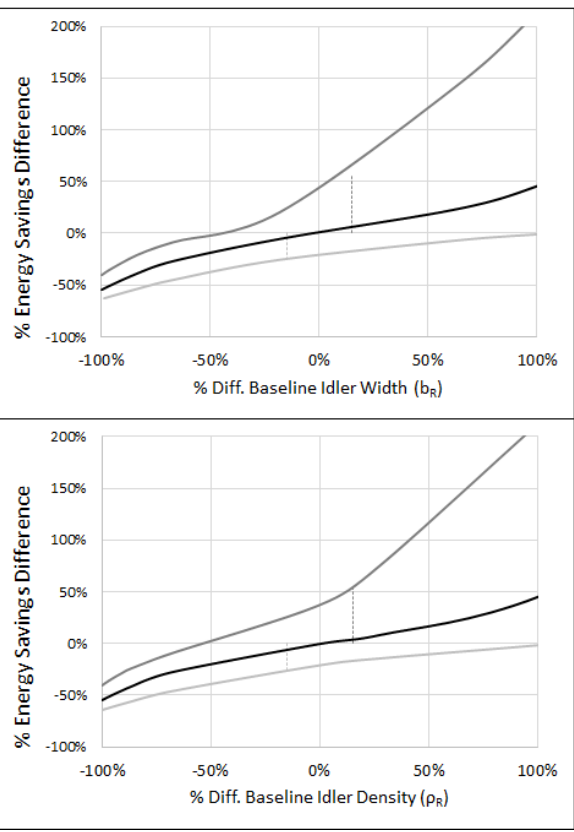

Figure 27. Conveyor energy sensitivity to idler width $\left(b_{R}\right.$, top), and density of the rotating parts $\left(\rho_{R}\right.$, bottom)

The idler width and material density of the rotating parts of the idlers contributed the next highest impact, shown in Figure 27. Both directly impact the idler rotating part mass linearly, which as mentioned, is the largest conveyor component mass contributing to the dominant main resistance.

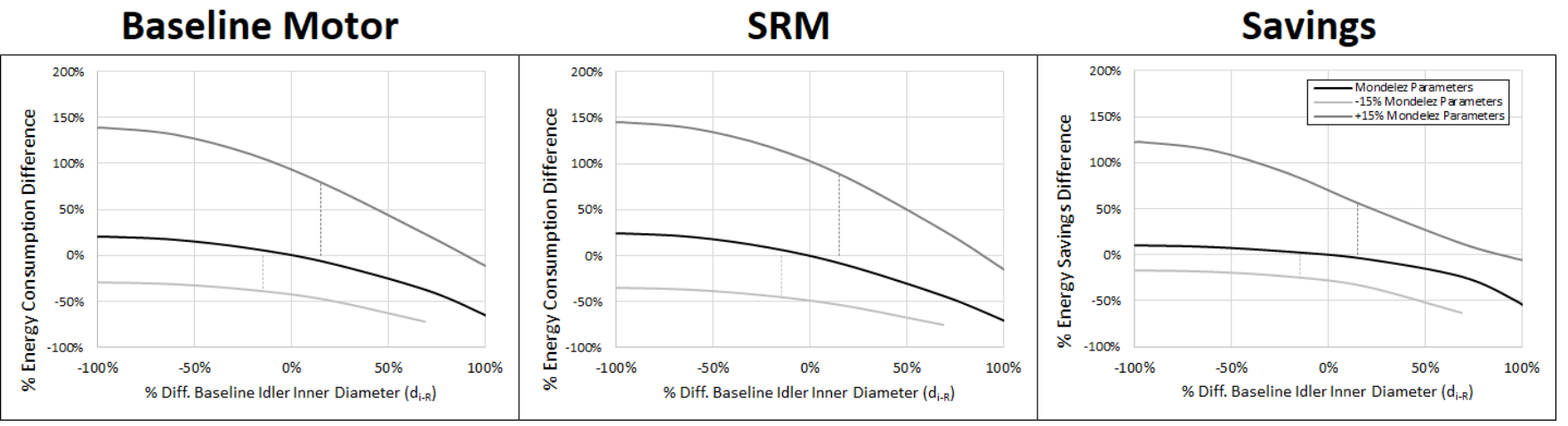

Figure 28. Conveyor energy sensitivity to idler rotating part inner diameter $\left(d_{i-R}\right)$

The inner diameter of the rotating part of the idlers (Figure 28) contributes the next highest impact on energy consumption and savings. The inner diameter has an inverse effect on energy consumption and savings because an increasing inner diameter with a constant outer diameter causes the volume of the rotating part of the idler to approach zero. Reducing the volume of the idlers drastically lowers energy consumption/savings because the idler mass is the largest contributor to the total torque. 
Baseline Motor

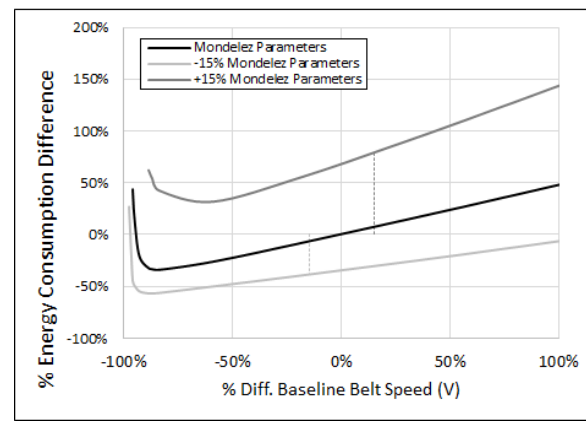

SRM

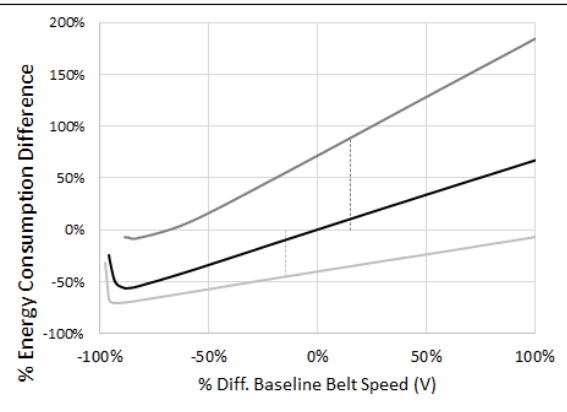

Savings

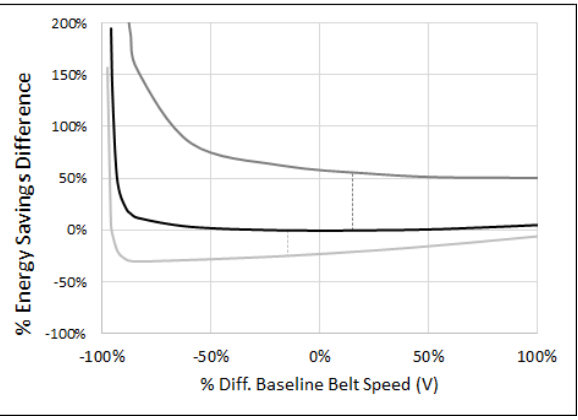

Figure 29. Conveyor energy sensitivity to belt speed (V)

The impact of belt speed (Figure 29) can be primarily attributed to the characterized performance of the motor/drive system. In contributing to the main resistance in equation 2 , the belt speed is used to calculate the unit mass of the conveyed product material. As mentioned, this was significantly lower than the unit masses of the other components in the selected conveyor. As the belt speed is increased, conveyed material fed onto the belt at a constant rate is dispersed less densely across the conveyor length. This lowers the unit mass of the conveyed material and thereby the total main resistance.

The secondary resistance in equation 3 accounts for the force required at the conveyor loading region to accelerate material fed onto the belt to the specified belt speed. This resistance component contributes even less to the overall torque than the main resistance. Therefore, the effect of belt speed on the torque demand is much less than its effect on rotational velocity, which induces more change in energy consumption. As each motor/drive system's rotational velocity was increased, energy consumption increased at a relatively steady rate. As the motor speeds approached zero $(-100 \%$ difference from baseline), the impact on the torque increased. If conveyed product material is fed onto the belt at the same rate while the belt slows to a stop, material will accumulate and cause the unit mass per length to increase drastically. At near-zero speed, product material mass then begins to dominate total torque and causes energy consumption to develop an asymptote.

There were minor differences in the effect of belt speed on energy consumed by the SRM versus the baseline motor/drive. The belt speed had a slightly more significant impact on the SRM power consumption than the baseline motor/drive. Because Figure 29 only shows the percent deviation in power consumption, it should be noted that the actual change in power consumption was actually much less in the SRM than in the baseline motor/VFD (Appendix C). Because the power consumption at the selected conveyor's belt speed was much lower in the SRM than in the baseline motor/drive, the normalized SRM consumption appeared more sensitive to belt speed. 
Baseline Motor

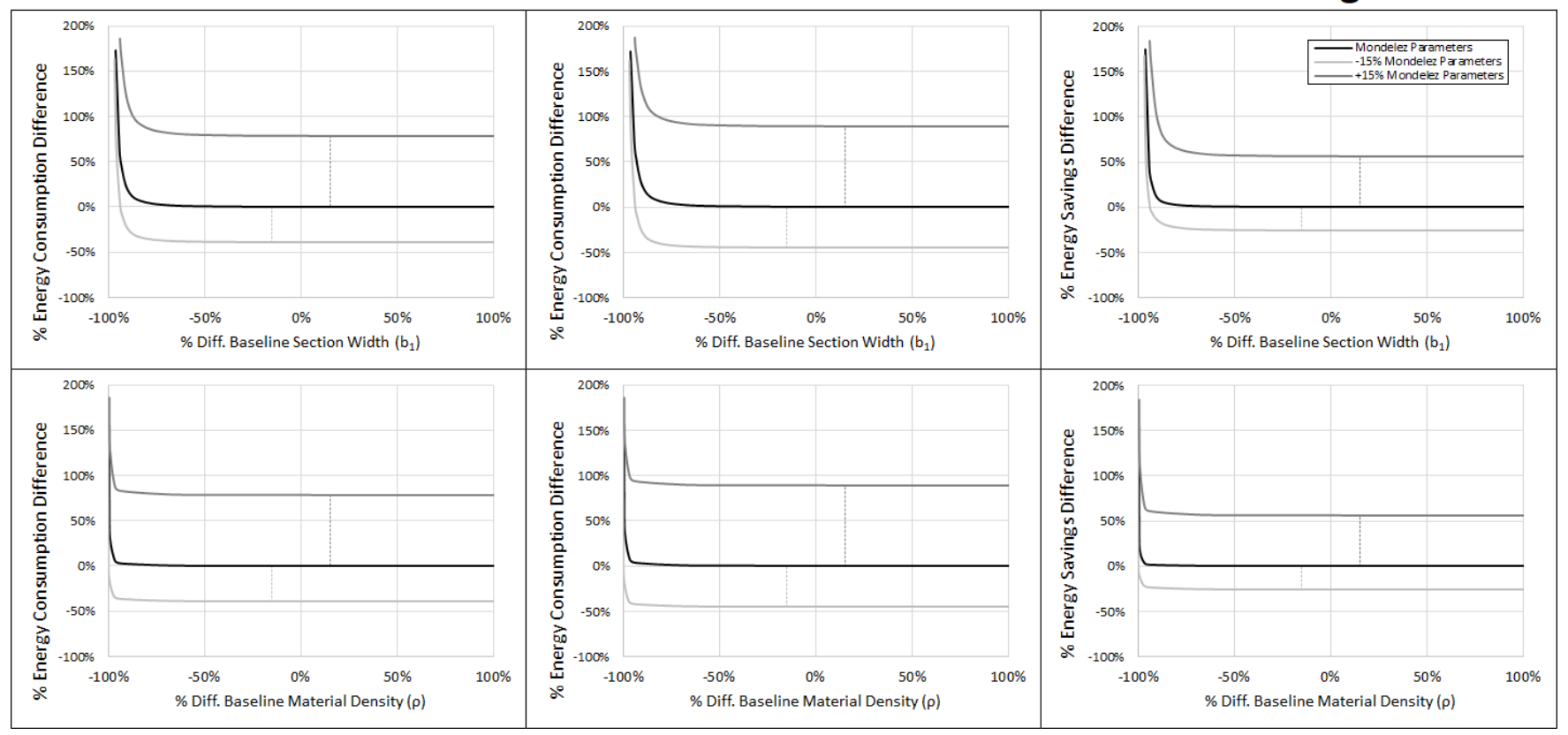

Figure 30. Conveyor energy sensitivity to section guide board width ( $b_{1}$, top), and density of the conveyed product material ( $\rho$, bottom)

Both the conveyor section width and conveyed material density shown in Figure 30 contributed very little to the overall energy consumption, except when those values approached zero. Because the conveyed material mass is dictated by the belt speed and feed rate, material density has no impact on the material mass contribution to the total torque. Likewise, the idler masses and belt mass are calculated using separate "idler width" and "belt width" parameters, and so the section width does not impact the total mass of these components.

These parameters contribute to the force required to feed conveyed material between guide boards as part of the secondary resistance (equation 3), and to the friction force between the product material and guide boards as part of the special resistance (equation 5). By decreasing both these parameters, material is pressed against the guide boards with more force and causing higher friction that adds to the total torque. These frictional resistances are small in comparison to those generated by the mass of the conveyor components. However, they can become large if the product material density and section width are reduced to near-zero values. It should be noted here that the conveyed material used in the selected conveyor consist of rigid boxes that cannot be compacted down to these low densities, and so values here are based on an assumed formless material. 
Baseline Motor

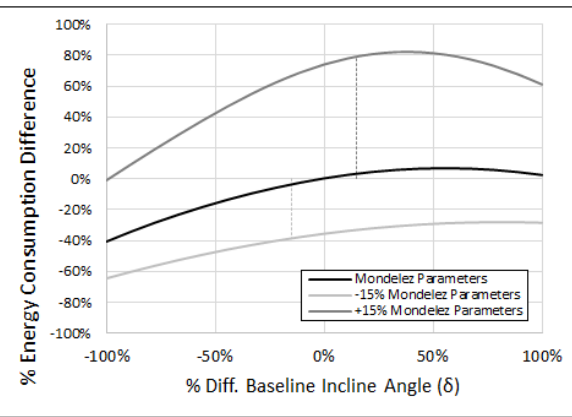

SRM

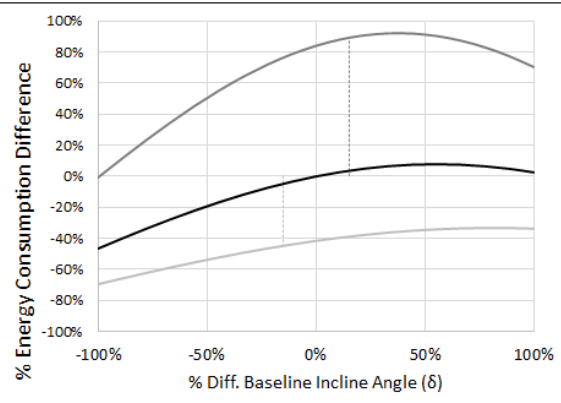

Savings

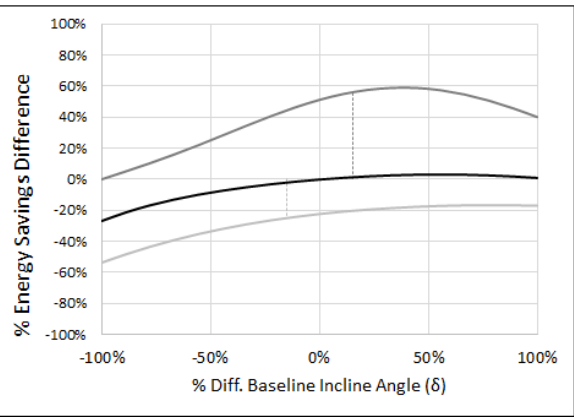

Figure 31. Conveyor energy sensitivity to incline angle (ס)

The incline angle of the conveyor only affects the slope resistance component in equation 4 . This resistance was zero in the baseline conveyor because the incline angle was $0^{\circ}$. If the incline angle is shifted to extreme values, this resistance can have a significant impact on total energy consumption as shown in Figure 31. At negative incline angles, energy consumption was reduced because gravity assists in moving the material, requiring less torque. More torque was required when the incline angle was increased above $0^{\circ}$ because the motor and drive would have to work against gravity to pull the conveyor material uphill. As the torque was increased, energy consumption reached a maximum value at a particular incline angle. Above this angle, the torque load was increased to values that generated improved energy efficiency in both motor/drive systems such that energy consumption was slightly reduced.
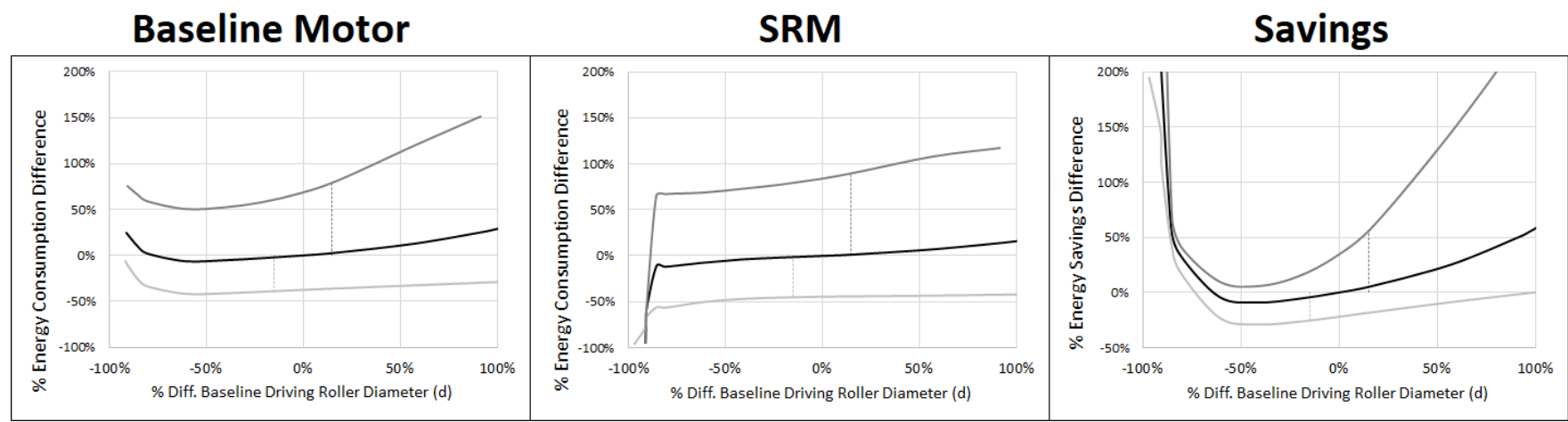

Figure 32. Conveyor energy sensitivity to driving roller diameter (d)

The outer radius of the driving roller is the torque moment arm; therefore, torque demand is calculated from the product of this radius and the sum of the resistances in the conveyor. If this were the sole contribution of this parameter, then one would expect the sensitivity curves shown in Figure 32 to mimic the dynamometer power-torque curves for each motor/drive. However, the rotational velocity is also dependent on the driving roller diameter. Because belt speed is constant, the driving roller diameter inversely affects rotational velocity.

As the driving roller diameter was increased, the torque affected the energy consumption more than the reduction in speed, causing the energy consumption to increase. When the driving roller diameter was reduced below $50 \%$ of its baseline value in the baseline motor/drive, increase in rotational velocity affected energy consumption more than reduction in torque caused by the reduced moment arm. Because it was not possible to collect near-zero speed and torque dynamometer setpoints, the estimated 
motor performance at near-zero roller diameters is less accurate. This is because power and efficiency at these values are estimated from curve fitting to the other data points collected at higher speeds.

The effect on SRM consumption was much more significant than the baseline induction motor due to the drop in power consumption at near-zero diameters. This effect was likely not an accurate representation of this motor's performance because curve-fitting at these values was less accurate in the SRM. The reason that the energy consumption rapidly increased at near-zero driving roller diameters was due to the limited number of dynamometer setpoints able to be collected at low speeds using the speed control loop method. At the lowest speed, the dynamometer was not able to load the SRM to more than two setpoints, which was too few for accurate curve-fitting. Therefore, the energy consumption at these nearzero driving roller diameter values should be considered erroneous and not representative of the motor/drive.

As the driving roller diameter was increased above its baseline value (increasing torque and reducing speed), energy consumption increased in the baseline motor and VFD by much more than in the SRM, causing a drastic increase in savings. This effect provided another example of the benefit of the SRMs at low speeds, where losses in efficiency are far less than in traditional induction motors with VFDs. Here, the effect of reduced rotational velocity and increased torque compounded to affect energy consumption much less in the SRM than in the induction motor and VFD.

Baseline Motor

SRM

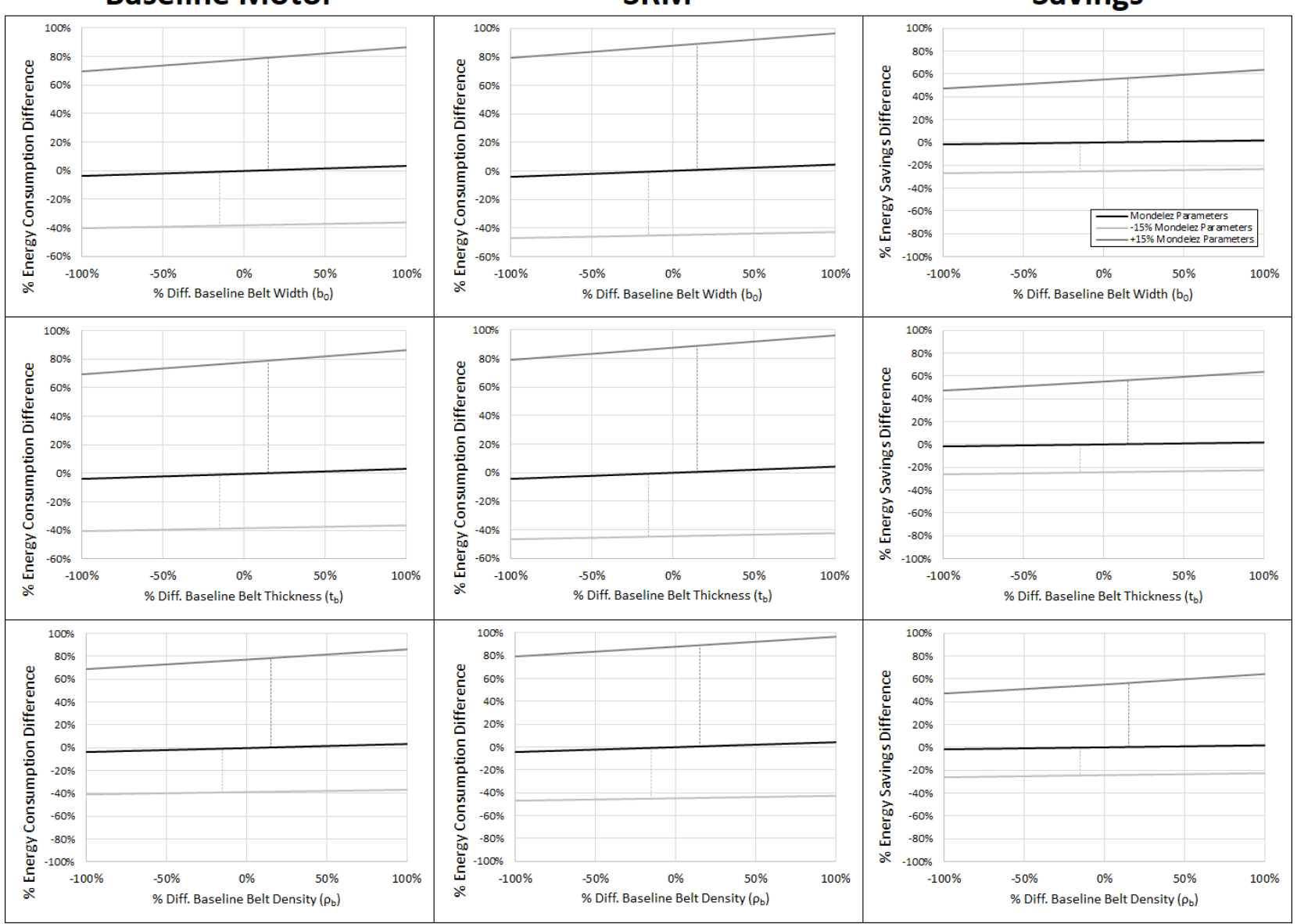

Figure 33. Conveyor energy sensitivity to belt width ( $b_{0}$, top), belt thickness ( $t_{b}$, middle), and belt material density $\left(\rho_{b}\right.$, bottom) 
The belt width, thickness, and material density (Figure 33) all contribute to the belt unit mass, and therefore have the same effect on the main resistance. Because this contribution was small in comparison to the dominant idler unit mass, their contribution to overall power consumption was limited.

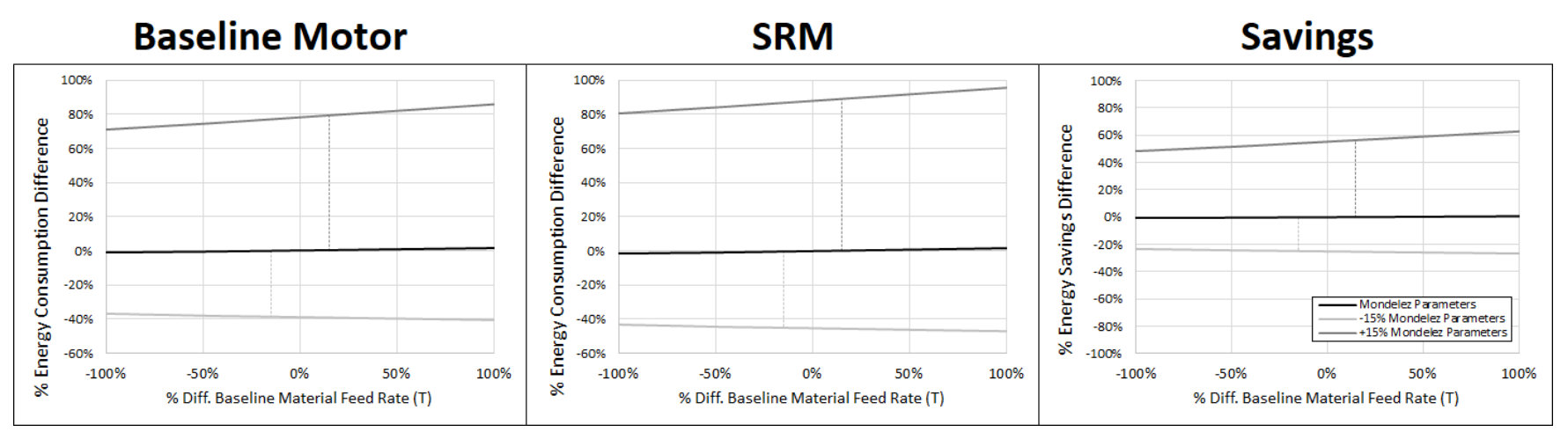

Figure 34. Conveyor energy sensitivity to conveyed material feed rate (T)

As discussed previously, there was only a slight increase in total torque and power consumption induced by the change in feed rate between slow time and regular operation. Therefore, it was expected that little change would be observed in the overall energy consumption when varying feed rate shown in Figure 34. This was due to the effect of feed rate on the unit mass of the conveyed material, which as mentioned, was not significant compared to the contribution of the idler unit mass.

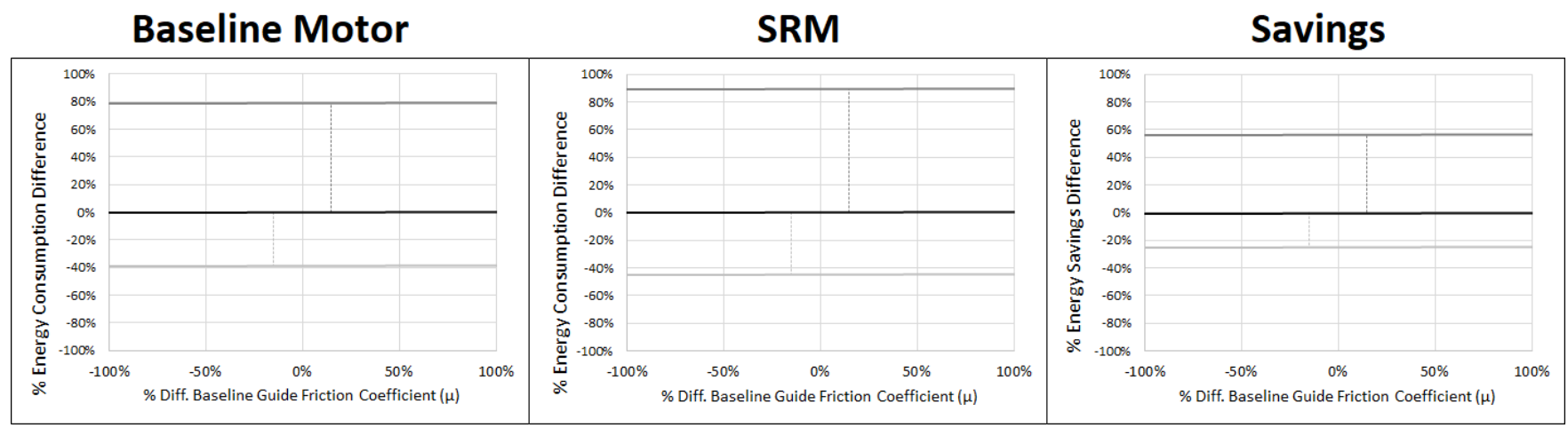

Figure 35. Conveyor energy sensitivity to material-guide board friction coefficient $(\mu)$

The friction coefficient between the conveyed material and guide boards also had little contribution to the overall energy consumption shown in Figure 35. This parameter only impacted the special resistance in equation 5, which was nearly negligible in comparison to the main resistance. 


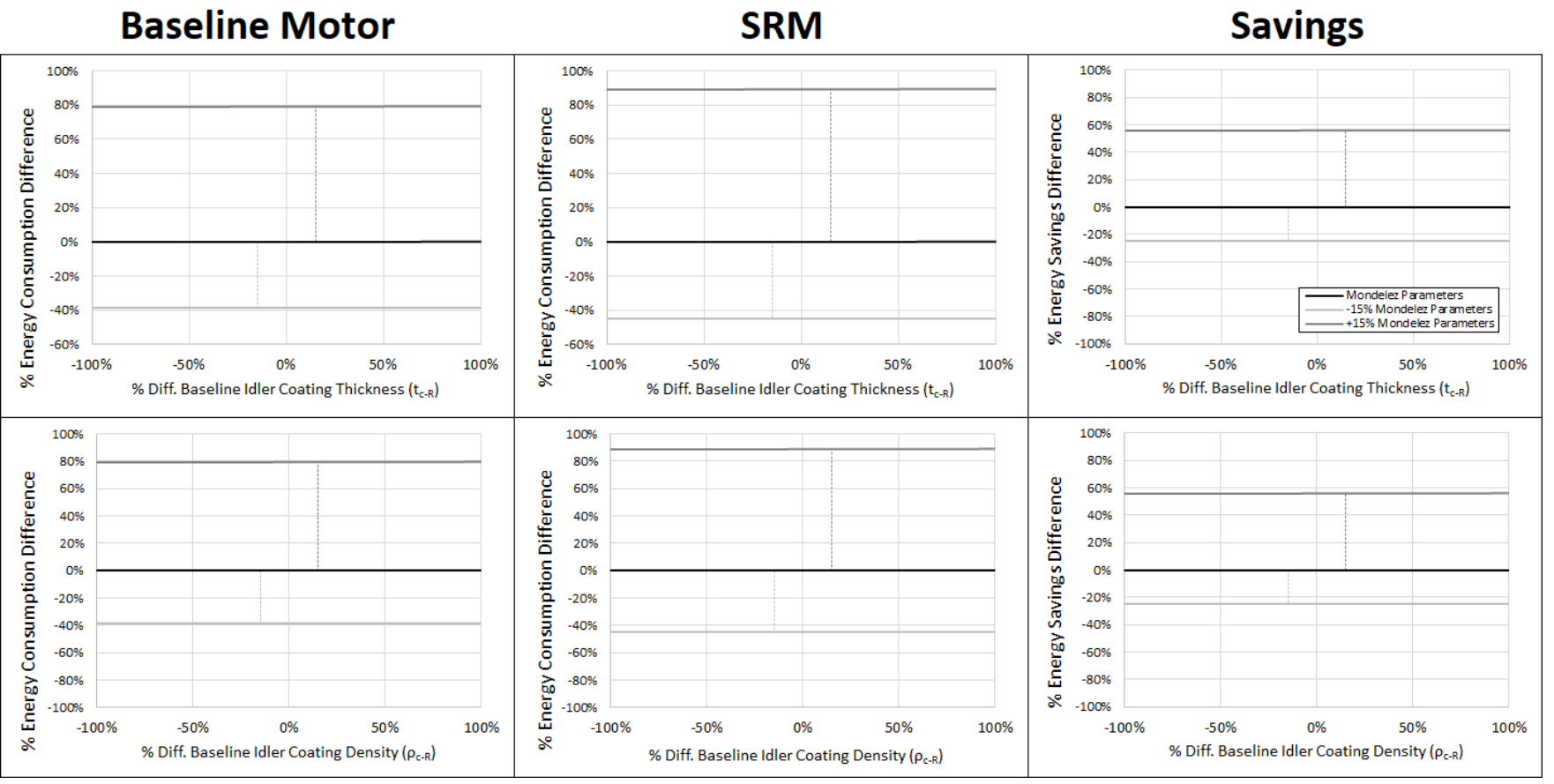

Figure 36. Conveyor energy sensitivity to idler coating thickness $\left(t_{c-R}\right.$, top), and coating material density ( $\rho_{c-R}$, bottom)

In some instances, idler "coatings" can contribute significantly to overall torque if their mass contributes to a significant fraction of the total idler mass, such as if the idler contains a thick rubber layer or geared teeth. In this assessment, it was assumed that the idlers contained only a thin coating of galvanizing zinc, which was negligible in its effect on the total idler mass and thereby the total energy consumption shown in Figure 36.

By increasing all parameters to $15 \%$ above the baseline value of the selected conveyor (dark gray line), the energy consumption was increased by a larger magnitude in both motors/drives than the decrease in energy consumption caused by decreasing all parameters $15 \%$ (light gray line). This was expected because dynamometer characterization showed that efficiency was not linear with respect to torque or rotational velocity. When all parameters were varied proportionally, energy savings continued to increase. This was because consumption increased at a lower rate in the SRM than in the baseline motor and VFD when all parameters were increased proportionally.

\section{Conclusion}

The aim of this project was to estimate the energy savings from using an energy-efficient high rotor pole SRM developed by Turntide Technologies in an industrial conveyor system containing a baseline induction motor and VFD. First, experimental dynamometer characterization was conducted on both the energy-efficient SRM and baseline motor and drive in accordance with ANSI/ASHRAE 222-2018 where applicable [1]. The baseline motor/drive was selected from a conveyor system in one of ComEd's largest industrial customers' facilities. This evaluation was overseen by Advanced Energy, an ISO 17025-accredited laboratory for electric motor and drive efficiency testing. 
A conveyor energy calculator tool was developed to model the torque demand on the motor and drive systems generated by various structural and operational conveyor parameters. The tool estimates torque demand based on equations derived from ANSI/ISO standard 5048-1989 [2]. The calculated torque and rotational velocity are interpolated to each motor and drive system's performance map to estimate efficiency and power consumption. The tool then calculates energy consumption by integrating power across a specified operation profile. Here, performance data from dynamometer characterization was used to evaluate energy consumption in the selected customer's conveyor system. However, the tool is provided with DOE's MotorMaster-Plus database to allow a user to evaluate energy consumption in other conveyors, or design conveyor systems for optimized energy efficiency. Detailed instructions for using the tool are provided in Appendix A.

The selected conveyor section contained a premium-efficiency 2-HP ABB motor with an Allen-Bradley VFD. Therefore, a 1- to 3-HP SRM that operated in the same torque-speed range was compared. Dynamometer characterization revealed the following key observations between the two motor and drive systems:

- The SRM efficiency was higher than the premium-efficiency induction motor and VFD at all characterized torques and rotational velocities by a significant amount.

- At the rated frequency of the baseline motor (1,800 RPM), the efficiency of the SRM was between $90.2 \%$ and $82.8 \%$, whereas the baseline motor/VFD efficiency ranged between $83.8 \%$ and $71.7 \%$, showing a $6.4 \%-18.5 \%$ improvement in efficiency.

- At lower speeds, the SRM efficiency was reduced by a much less significant amount than seen in the induction motor/VFD. The absence of transistor losses, and the use of nontraditional ratios of stator poles to rotor poles in the SRM design can be attributed to these improved efficiencies at lower speeds.

- At a lowered speed of 20-Hz frequency (600 RPM), the efficiency of the SRM was between $81.9 \%$ and $74.0 \%$, whereas the baseline motor and VFD efficiency ranged between $68.9 \%$ and $55.9 \%$, showing a $21.2 \%-34.3 \%$ improvement in efficiency.

The conveyor energy calculator tool was used to evaluate daily energy consumption and savings in the customer's selected conveyor system for multiple operational schedules. Operation days of 10 hours and 24 hours were evaluated using different feed rate schedules throughout the day. Daily energy consumption and savings between the SRM and baseline induction motor/VFD were calculated in each scenario. Yearly consumption and savings were also evaluated, including and excluding weekends. Key observations from this analysis included the following:

- The conveyed product material mass contributed little to the torque demand on the motor and drive. Therefore, material feed rate had a nearly negligible effect on the average power consumed by each motor (baseline: $165 \mathrm{~W}, \mathrm{SRM}$ : $114 \mathrm{~W}$ ) and on the overall energy consumption.

- 10-hour operation days yielded $1.65 \mathrm{kWh}$ /day energy consumption by the baseline induction motor/VFD, and $1.14 \mathrm{kWh} /$ day energy consumption by the SRM, corresponding to 0.51 $\Delta \mathrm{kWh}$ /day savings. This constituted a $31.0 \%$ estimated reduction in energy consumption via retrofit of the SRM to the selected conveyor. 
- 24-hour operation days yielded $3.96 \mathrm{kWh} /$ day energy consumption by the baseline induction motor/VFD, and $2.73 \mathrm{kWh} /$ day energy consumption by the SRM, corresponding to 1.23 $\Delta \mathrm{kWh}$ /day savings.

- Including weekends, energy consumption in the baseline motor and VFD when operated for 10and 24-hour days was 587 and 1,408 kWh/year, respectively. The SRM consumption was 405 and $972 \mathrm{kWh} /$ year, generating yearly savings of 182 and $436 \Delta \mathrm{kWh} / \mathrm{year}$.

- The estimated average torque demand by the selected conveyor was $2.9 \mathrm{Nm}$, and the rotational velocity was 229 RPM. This speed and torque were within the lowest range of speeds and torques in the baseline motor and drive systems' operation range. Due to reduced losses in the SRM at lower speeds and torques compared to traditional induction motor/VFDs, significant savings were calculated for this conveyor configuration.

Because some conveyor parameters were not provided, the customer may need to adjust the calculations performed here in the conveyor energy calculation tool. The customer may also wish to evaluate other conveyor sections within their facility. The calculation tool can be provided to other customers as well to design conveyor systems using structural and/or operational parameters that optimize energy efficiency. Therefore, a sensitivity analysis was conducted to evaluate the effect of each conveyor structural and operational parameter on energy consumption and savings between the two motor and drives. Change in energy consumption and savings was measured as each parameter was varied while holding all other parameters constant at the baseline conveyor values. Then, all parameters were deviated from their baseline values and again held constant while varying each parameter individually. The sensitivity analysis revealed the following observations:

- Parameters that affect the mass of the idlers contribute to the majority of the conveyor torque demand. The mass of the belt, conveyed product material, and the internal frictional resistances throughout the conveyor combined to contribute to only a small fraction of the total torque.

- As all parameters were deviated from the baseline conveyor values in a manner that would increase the energy consumption, that increase was larger in the baseline motor/VFD than in the SRM. Therefore, SRM energy savings increased with change in any parameter that would cause energy consumption to increase. Likewise, as parameters were deviated in a way that would induce a decrease in energy consumption, the reduction in consumption was less in the SRM than the baseline motor/VFD such that savings would decrease with that deviation. 


\section{References}

1. ANSI, A. 2018. Standard Method of Test for Electrical Power Drive Systems. ANSI/ASHRAE.

2. ANSI, I., Continuous mechanical handling equipment - Belt conveyors with carrying idlers - Calculation of operating power and tensile forces. 1989, ISO.

3. The MotorMaster+ Software Tool. 2020, U.S. Department of Energy Office of Energy Efficiency \& Renewable Energy (EERE) Industrial Technologies Program.

4. Burt, C.M., X. Piao, F. Gaudi, B. Busch, and N. Taufik, Electric motor efficiency under variable frequencies and loads. Journal of Irrigation and Drainage Engineering, 2008. 134(2): p. 129-136.

5. Wallbom-Carlson, A., Energy comparison. VFD vs. on-off controlled pumping stations. Scientific impeller, 1998. 136(5): p. 29-32.

6. Coulter, D., J. Ahmed, T. Pistochini, and C. Mande, Software-Controlled Switch Reluctance Motors. 2018, Souther California Edison.

7. Fricke, B. and M. Bhandari, Laboratory Evaluation and Field Demonstration of High Rotor Switched Reluctance Motor Technology, G.S.A.-P.G. Program and D.o.E.-H.I.T.C. Program, Editors. 2019, Oak Ridge National Laboratory.

8. Desai, P.C., M. Krishnamurthy, N. Schofield, and A. Emadi. Switched Reluctance Machines with higher rotor poles than stator poles for improved output torque characteristics. in 2009 35th Annual Conference of IEEE Industrial Electronics. 2009. IEEE.

9. Krishnamurthy, M. and T. Creary, METHOD FOR RELIABLE CONTROL OF HIGH ROTOR POLE SWITCHED RELUCTANCE MACHINE. 2020.

10. Hughes, A. and B. Drury, Electric motors and drives: fundamentals, types and applications. 2019: Newnes.

11. Kraftmakher, Y., Demonstration of Lenz's law with an induction motor. Physics education, 2005. 40(3): p. 281.

12. Bezesky, D.M. and S. Kreitzer. NEMA Application Guide for AC adjustable speed drive systems. in Record of Conference Papers. IEEE incorporated Industry Applications Society. Forty-Eighth Annual Conference. 2001 Petroleum and Chemical Industry Technical Conference (Cat. No. 01CH37265). 2001. IEEE.

13. Rouse, S. and D. Dederer, VARIABLE FREQUENCY DRIVES - Energy Efficiency Reference Guide. 2009, Centre for Energy Advancement through Technological Innovation (CEATI International): Natural Resources Canada.

14. ANSI, N.M.-. Motors and Generators. 2016, ANSI / NEMA.

15. Engineering Toolbox. 2001 2020; Available from: https://www.engineeringtoolbox.com. 


\section{Appendix A. Instructions for Conveyor Modeling Calculation Tool}

This appendix contains detailed instructions for using the conveyor energy modeling calculation tool. The tool is an Excel file that allows the user to modify only certain input cells. The user is able enter parameters and select options from drop-down menus in a group of four sheets within the Excel file. Then, daily energy consumption and savings results are output to a fifth sheet. A sixth optional sheet allows the user to calculate yearly consumption. If the user wants to analyze consumption in an existing motor, an additional Excel file contains a DOE database of 16,359 motors. Instructions for each sheet are provided accordingly in the following sections of this report. The sheets are listed in the Excel files (from left to right) according to:

- Baseline Motor Characterization Inputs (Section A.2)

- Proposed Motor Characterization Inputs (Section A.2)

- Conveyor Structure Inputs (Section A.3)

- Operation Inputs (Section A.4)

- Output (Section A.5)

- Yearly kWh Savings (Section A.6)

- (Supplemental Motor Database) Motor Characterization Inputs (Section A.7)

- (Supplemental Motor Database) Motor Catalogue (Section A.7).

The tool calculates power consumption from conveyor parameters using equations derived from ANSI/ISO standard 5048-1989 [2]. This standard can be used for any belt-type conveyor up to $80 \mathrm{~m}$ in length. However, the modeling tool developed here will not be able to be used for curved conveyor sections. Additionally, to use the derived equations in this tool, the user must be able to make the following assumptions:

- There are no belt cleaners, ploughs, or aprons overhanging the belt; or that friction due to any belt cleaners, ploughs, or aprons can be considered negligibly low

- There is no tilting of the idlers, or that friction due to idler tilt is negligibly low

- Frictional resistances between the material and belt, and material and any guide/skirt boards are relatively the same in the loading/unloading region

- There are no pulleys, or any belt-pulley wrap resistance is negligibly low.

It was desired to estimate tensile forces in a conveyor as accurately as possible while only using parameters that could be realistically obtainable by a user. Therefore, it is not possible to accurately estimate in conveyor sections that do not satisfy these requirements because doing so would require knowledge of obscure parameters. 


\section{A.1 Summary of Equations Used}

A detailed explanation of the calculations used in the modeling tool is available in Section 3.1; however, the equations are also summarized below:

1. The torque is calculated from the sum of internal frictional resistances along the conveyor section:

$$
T_{M}=\frac{d}{2}\left(F_{H}+F_{N}+F_{s t}+F_{S}\right)
$$

where $\mathrm{d}$ is the shaft diameter, $\mathrm{F}_{\mathrm{H}}$ is the "main resistance," $\mathrm{F}_{\mathrm{N}}$ is the "secondary resistance," $\mathrm{F}_{\mathrm{st}}$ is the "slope resistance," and $F_{S}$ is the "special resistance."

2. The main resistance is calculated based on Coulomb's friction law according to:

$$
F_{H}=f L g\left[Q_{R}+2 Q_{B}+\frac{T(t)}{V(t)}\right] \cos (\delta)
$$

where $\mathrm{f}$ is the "artificial friction factor," $\mathrm{L}$ is the section length, $\mathrm{Q}_{\mathrm{R}}$ is the unit mass of the rotating parts of the idlers, $Q_{\text {в }}$ is the unit mass of the belt, $T(t)$ is the feed rate of material (product) onto the belt, $\mathrm{V}(\mathrm{t})$ is the belt speed, and $\delta$ is the belt incline angle $\left(0^{\circ}=\right.$ horizontal). The unit masses are defined as mass per unit length of the conveyor section (affected by idler spacing). The feed rate of material onto the belt is mass per time. The "artificial friction factor" is selected based on qualitative descriptions provided in the "conveyor structure inputs" sheet based on ISO 5048 [2].

3. The secondary resistance is calculated based on:

$$
F_{N}=T(t) V(t)+\frac{T(t)^{2}}{\rho(t) b_{t}(t)^{2}}
$$

where $\rho(t)$ is the material density and $b_{1}(t)$ is the width of the conveyor section or width between guide/skirt boards if any are present.

4. The slope resistance is calculated based on:

$$
F_{s t}=\frac{g L T(t) \sin (\delta)}{V(t)}
$$

where $\mathrm{g}$ is acceleration due to gravity.

5. The special resistance is calculated based on:

$$
F_{S}=\frac{\mu g L T(t)}{\rho(t) b_{1}(t)^{2} V(t)}
$$

where $\mu$ is the kinetic friction coefficient between the material and guide boards. 


\section{A.2 Sheets 1-2: Baseline/Proposed Motor Characterization Inputs Sheet}

The user will be required to enter motor/drive performance data into at least one of the first two sheets listed in the tool, titled "Baseline Motor Char. Inputs" and "Proposed Motor Char. Inputs." If the user wishes to only assess the energy consumed by a single motor, then motor/drive performance data can be entered into either of these sheets. If comparing two different motors, the motor/drive system expected to have a more efficient performance curve should be entered into the "Proposed Motor Char. Inputs" sheet. Otherwise, energy savings may be output as a negative value.

\section{Motor/Drive Performance Data Preparation}

The user should first prepare motor/drive performance data that includes, at minimum:

1. The rotational speed

2. The torque

3. The input power required to maintain that speed and torque

4. The efficiency at each speed and torque.

The user can also provide the output power instead of the efficiency, and efficiency will be calculated automatically. For organizational purposes, the user is also able to enter the frequency (in Hertz), and the percent of the total torque load. These data can be obtained either from the results of dynamometer testing, or by extracting performance curves from manufacturer spec sheets. If the user does not have their own motor performance data, they can select a motor from the supplementary motor database (in the attached Excel file titled "ConveyorMotorEnergyCalculator_MotorDatabase.xlsx"). Instructions for using this database are provided in Section A.7.

The user should ensure that the data are stacked so that the input power and efficiency/output power are aligned by row with their corresponding speed and torque (and frequency, \% torque load). For more accurate results, it is recommended that the user uses more data points than less (preferably at least 4 torque points per speed setting). The tool uses a fourth-degree polynomial line-of-best-fit to curve-fit to motor performance data. This can generate inaccurate results if too few data points are used.

\section{$\underline{\text { Cell Color-Coding }}$}

Each sheet can be navigated by checking through color-coded cells. Only orange and yellow cells can be modified by the user, and all other cells are locked from editing. Orange cells allow the user to enter any numerical value, and yellow cells contain drop-down selections. Blue cells contain information, gray cells indicate outputs, and red cells show alarms generated by errors.

Blacked-out cells indicate that that cell is no longer applicable to the calculation based on other information selected by the user. For example, on this sheet, the user is only able to enter data in either an "input power" column, or an "efficiency" column. If data are entered in one, the other will be blacked out. If both are entered, and the calculated efficiency does not correspond to the entered efficiency, an error alarm is indicated in cell F1. 


\section{Step-by-Step Instructions}

Stepwise instructions for entering data into the "Baseline Motor Char. Inputs" and "Proposed Motor Char. Inputs" is provided below. The layout of the sheet is shown in a snapshot provided in Figure 37.

1. In cell E2, enter the number of rows of data points in your motor/drive performance data. Several rows equivalent to this value will then change from black to orange, available for editing.

2. Select the rotational velocity units for your data from the drop-down menu in cell D4. Copy and paste your column of motor/drive speed values starting in cell D5.

3. Select the torque units for your data from the drop-down menu in cell E4. Copy and paste your column of motor/drive torque values starting in cell E5.

4. Select the input power units for your data from the drop-down menu in cell G4. Copy and paste your column of motor/drive input power values starting in cell G5.

5. If output power data will be entered and efficiency calculated automatically, select the output power units for your data from the drop-down menu in cell F4. Copy and paste your column of motor/drive output power values starting in cell F5. If efficiency will be entered instead of output power, copy, and paste your column of efficiency values starting in cell H5.

6. (Optional) Copy and paste your columns of motor/drive frequency values (in Hertz) and percent torque load values starting in cells B5 and C5, respectively.

7. Check that all data are filled in correctly in all orange cells.

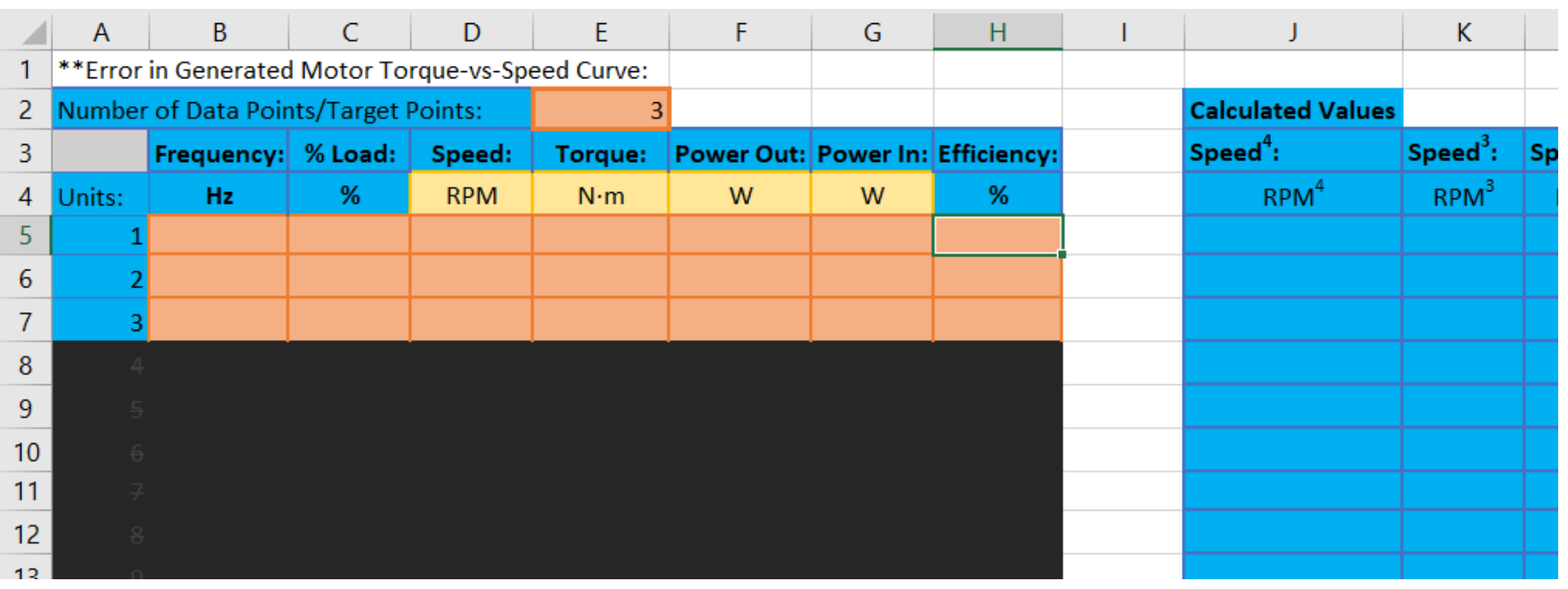

Figure 37. Baseline or proposed motor performance characterization data input sheet

Once all data are entered, blue columns J-Y will be auto-populated with data used to calculate performance regression surfaces. Two fourth-order 2D regression surfaces are generated for both the input power and the efficiency (with respect to rotational velocity and torque). The coefficients of each of these polynomials are generated in columns AA and AE. Other columns are used to calculate discrepancies in order to signal an alarm if data are input erroneously, such as if the input power or efficiency are not continuous with torque or speed. 


\section{A.3 Sheet 3: Conveyor Structural Parameter Inputs Sheet}

Once the user has entered motor/drive system performance data, they will be required to enter conveyor structural data used to estimate the torque demand. Structural parameters are listed by row in the "Conveyor Structure Inputs" sheet. The user will be required enter information in columns C, D, and E for each of the structural parameters listed in column A (unless columns D and E are blacked out). For each parameter, column $\mathrm{F}$ provides a description of, and any instructions specific to entering data for that parameter.

\section{$\underline{\text { Cell Color-Coding }}$}

The "Conveyor Structure Inputs" sheet uses the same color scheme as the previous sheet described in Section A.2, in which the user is only able to enter data or select from drop-down menus in orange and yellow cells. Again, cells that are blacked-out indicate that they are not relevant to the calculation and red cells indicate an alarm. Certain cells are blacked-out based on the selection made from drop-down menus in other cells.

Based on the motor data entered in the previous sheets, alarms are shown with two different shades of red. Light or dark red alarms indicate if an entered value generates a torque that is above, or below the motor/drive system's range. Dark red indicates a torque below the motor's capability and light red indicates a torque above. This could happen if, for example, idlers are over/undersized, or too close together/far apart. A key indicating the meaning of the cell formats is shown in cells G1-H6.

\section{$\underline{\text { General Procedure }}$}

The value for each parameter should be entered into the "Input" cell in column D. Most of the structural parameters are continuous, so any value can be entered. Column E contains drop-down menus in each cell to select the units for each parameter (unless the parameter is unitless).

Column C is titled "Options" and contains drop-down menus that are applicable only to certain parameters. For example, the user can choose to either enter a material density value (by selecting "I Know the Density") or select a material from which to assign a known density (by selecting "Select Based on Material"). Choosing to "Select Based on Material" would black out the density input cells and open a drop-down cell allowing the user to select from a list of common materials. The calculation tool will then assign a density based on the material selected by the user.

\section{$\underline{\text { Selecting Conveyor Parameters }}$}

To obtain this conveyor component and material data, the user is expected to use manufacturers' spec sheets. If unavailable, the user should contact the manufacturer of those components to ensure that the data are as accurate as possible. 


\section{$\underline{\text { Roller/Idler Parameters }}$}

The diameter of the driving roller must be provided, but only the unit mass of the rotating parts of the idler rollers is required. If the forward and return side of the conveyor belt are wrapped around one set of idlers, the user is specified to enter 0 for the return idler unit mass. Typically, the idler manufacturer will provide the mass of the rotating part of the idler on a spec sheet.

If the unit mass is not obtainable, the user can choose to calculate unit mass from dimensions of the idler. The user will then be required to enter inner and outer diameter, material density (either directly or by selecting a material), coating thickness (if any) and coating material density. The user should be aware that this calculation assumes that the rotating part of the idler will be a homogenous cylinder.

\section{$\underline{\text { Belt Parameters }}$}

The user can choose between entering belt unit mass or the belt dimensions and material density. Belt unit mass is also typically reported by manufacturers on provided spec sheets.

\section{Material Friction Parameters}

If the conveyor section has skirt/guide boards, the user must enter the friction factor between the conveyed product material and the skirt/guide board material. Friction factor between two materials can be found through an internet search. Because the material is sliding against the skirt boards, ensure that a kinetic friction factor is used.

One unique parameter is the artificial friction factor in row 12 , which requires the user to select from a drop-down list containing qualitative descriptions of the conveyor system installation. The listed descriptions are used in the ANSI/ISO 5048-1989 standard [2] to assign a value for the artificial friction factor. If the user is unsure how the conveyor system was installed, select the "normally aligned" option.

The layout of the "Conveyor Structure Inputs" sheet is shown below in a snapshot provided in Figure 38. Stepwise instructions for entering data into the sheet is provided below.

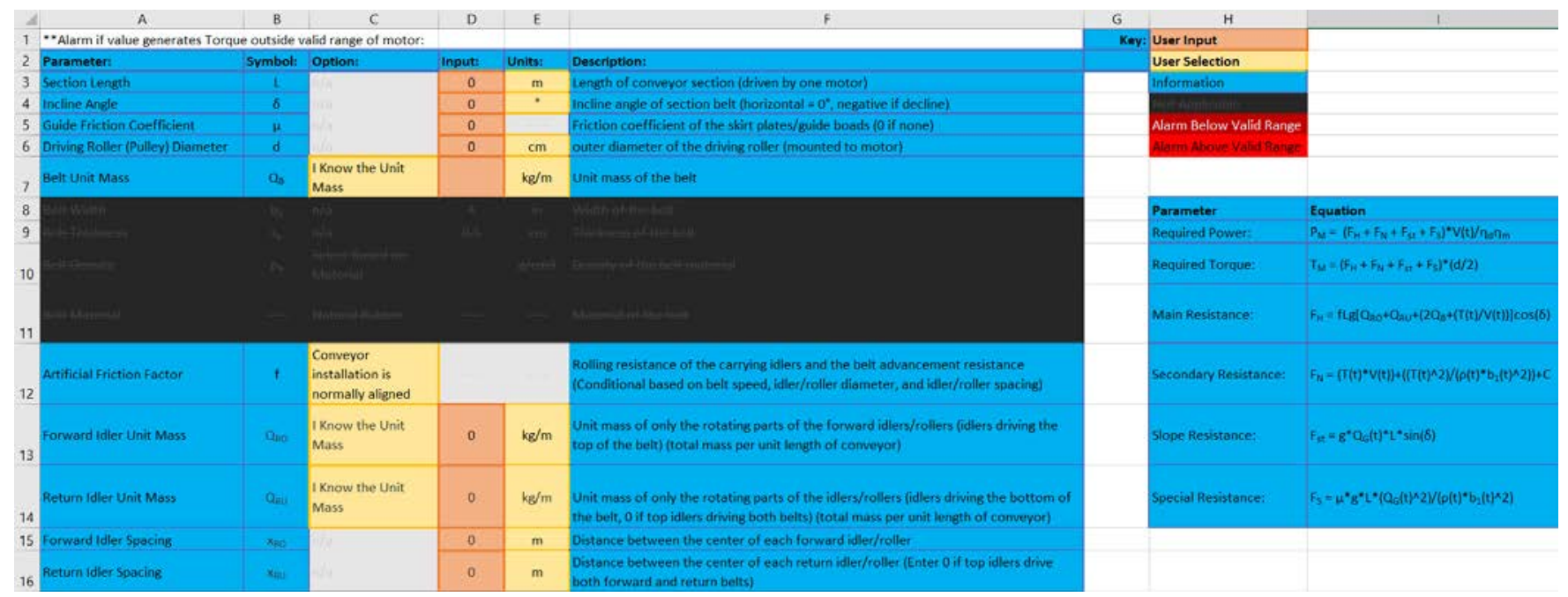

Figure 38. Conveyor structural parameter data input sheet 
1. In cell D3, enter the length of the conveyor section. Ensure that the section is driven by a single motor/drive. In cell E3, select the unit of length.

2. In cell D4, enter the incline or decline angle of the conveyor with 0 degrees/radians as horizontal, using a negative value to indicate a decline. Select the angular units in cell E4.

3. In cell D5, enter the (kinetic) friction coefficient between the guide/skirt boards and the product material. If there are no guide/skirt boards on the conveyor section, or if the product material does not come into contact with the guide/skirt boards, then enter 0 here.

4. In cell D6, enter the outer diameter of the driving roller for the conveyor. This is the roller that is connected to the motor/drive system that is generating torque. Ensure that the thickness of any outer coatings, gratings or teeth between the roller and the belt are included in the outer diameter. Select the units of length in cell E6.

5. If the belt unit mass is known, select "I Know the Unit Mass" in the cell C7 drop-down menu. Then enter the unit mass value and select the units in cells D7 and E7, respectively, and skip to step 6. If the unit mass is unknown, select "Calculate from Belt Parameters" in cell C7 and follow the steps below.

a. In cell D8, enter the width of the belt and then select the units in cell E8.

b. In cell D9, enter the thickness of the belt and select the units in cell E9.

c. If the density of the belt material is known, select "I Know the Density" in the cell C10 drop-down menu. Then enter the density value and select the units in cells D10 and E10. If the density is unknown, select "Select Based on Material" in cell C10 and choose a belt material from the drop-down menu in cell C11.

6. In cell $\mathrm{C} 12$, select a qualitative description of the conveyor setup from the drop-down menu to assign an artificial friction factor. If unknown, select the default first option stating that the "Conveyor installation is normally aligned." If the conveyor is very old or poorly installed and/or the roller bearings are worn, select the second option. If the conveyor is installed properly and uses low-friction materials, choose the third option. The fourth option should only be used if the conveyor is on a decline using a braking motor.

7. If the forward idler unit mass is known, select "I Know the Unit Mass" in the cell C13 dropdown menu. Then enter the unit mass value and select the units in cells D13 and E13, respectively and skip to step 8. If the unit mass is unknown, select "Calculate from Idler Dimensions" in cell C13 and follow the steps below. This will calculate idler unit mass based on the assumption that the rotating portion of the idler is a perfect cylindrical shape of uniform density.

a. In cell D17, enter the width of the idlers and then select the units in cell E17.

b. In cell D19, enter the inner diameter of the rotating section of the idlers and then select the units in cell E19. 
c. In cell D20, enter the outer diameter of the rotating section of the idlers and then select the units in cell E20.

d. If the density of the material used in the rotating part of the idlers is known, select "I Know the Density" in the cell C23 drop-down menu. Then enter the density value and select the units in cells D23 and E23. If the density is unknown, select "Select Based on Material" in cell C23 and choose from a material in the cell C25 drop-down menu.

e. In cell D27, enter " 0 " if there is no coating on the idlers between the belts. Otherwise, enter the thickness in cell D27 and the units in cell E27.

f. If there is no coating on the idlers, or if the density of the coating material is known, select "I Know the Density" in the cell C29 drop-down menu. Then enter the density value (or 0 if there is no coating) and select the units in cells D29 and E29, respectively. If the density is unknown, select "Select Based on Material" in cell C29 and choose from a material in the cell C31 drop-down menu.

8. If the conveyor is driven by only one set of idlers and there are no return idlers, or if there are return idlers and the return idler unit mass is known, select "I Know the Unit Mass" in the cell C14 drop-down menu. If there are no return idlers, then enter "0" into cell D14 and skip to step 9. Otherwise, enter the return idler unit mass value and select the units in cells D14 and E14, respectively and skip to step 9. If the unit mass is unknown, select "Calculate from Idler Dimensions" in cell C14 and follow the steps below.

a. In cell D18, enter the width of the return idlers and then select the units in cell E18.

b. In cell D21, enter the inner diameter of the rotating section of the return idlers and then select the units in cell E21.

c. In cell D22, enter the outer diameter of the rotating section of the return idlers and then select the units in cell E22.

d. If the density of the material used in the rotating part of the return idlers is known, select "I Know the Density" in the cell C24 drop-down menu. Then enter the density value and select the units in cells D24 and E24. If the density is unknown, select "Select Based on Material" in cell C24 and choose from a material in the cell C26 drop-down menu.

e. In cell D28, enter " 0 " if there is no coating on the return idlers between the belts. Otherwise, enter the thickness in cell D28 and the units in cell E28.

f. If there is no coating on the return idlers, or if the density of the coating material is known, select "I Know the Density" in the cell C30 drop-down menu. Then enter the density value (or 0 if there is no coating) and select the units in cells D30 and E30, respectively. If the density is unknown, select "Select Based on Material" in cell C30 and choose from a material in the cell C32 drop-down menu.

9. In cell D15, enter the spacing distance between idlers and then select the units in cell E15. The distance should be measured from the center axis of two adjacent idlers. If return idlers are 
present, do the same for those idlers in cells D16 and E16. Otherwise, the user should enter a value of 0 in cell D16.

Before moving forward, check to ensure that data are entered into all orange cells in column $\mathrm{D}$, and that the correct units are selected for each parameter in column E. All parameters are used to calculate torque demand, so failure to fully enter all data will result in an inaccurate calculation.

\section{A.4 Sheet 4: Conveyor Operational Parameter Inputs Sheet}

The fourth "Operation Inputs" sheet is the last required input sheet. Here, the user sets a conveyor operation schedule for a full operation day. The user must specify several discreet "operation periods" in which operational parameters are held constant. Any time belt speed is altered, or a product is fed at a different rate, for example, a new unique operation period must be assigned. The user specifies the start and end times in columns $\mathrm{C}-\mathrm{E}$ for each operation period.

\section{$\underline{\text { Operational Parameters }}$}

Only four operational parameters are required, including belt speed, conveyed product material density, guide/skirt board width, and either product unit mass or mass feed rate. The unit mass is the mass of conveyed material per belt length, and the feed rate is the mass per time of conveyed material fed onto the belt. Either parameter can be provided and converted to the other based on the belt speed.

Because pneumatic-controlled guides are often used to regulate the product feed, the guide/skirt board width is entered as an operational parameter here.

The user enters parameter values into columns $\mathrm{G}-\mathrm{K}$ for each unique operation period. A description of each parameter is provided in cells M11-O16.

\section{Cell Color-Coding}

Again, users will only be able to enter values in orange and yellow cells. Blacked out cells indicate that the values in that cell are no longer used in the calculation based on a selection made in another cell, and red cells indicate alarms.

Unlike previous sheets which contained one alarm, here three different alarms can be activated in rows 1,2 , and 3 . If a value is entered into any cell that generates a torque above or below the rated capability of the motor, a light or dark red alarm, respectively, will be activated in row 1. Likewise, if a belt speed and/or driving roller diameter is entered that generates a rotational velocity outside the capability of the drive, an alarm will be activated in row 2 .

The row 3 alarm will be activated if the user sets operation period start and end times that overlap, or if the end time of the final period is after 12:00 midnight. Therefore, if choosing a 24-hour operation period, the user should set the first time at 12:00 AM and the final time at 11:59 PM. A cell format key is provided in cells L4-M9. 


\section{$\underline{\text { Step-by-Step Instructions }}$}

The layout of the "Operation Inputs" sheet is shown below in a snapshot provided in Figure 39.

Stepwise instructions for entering data into the sheet is provided below.

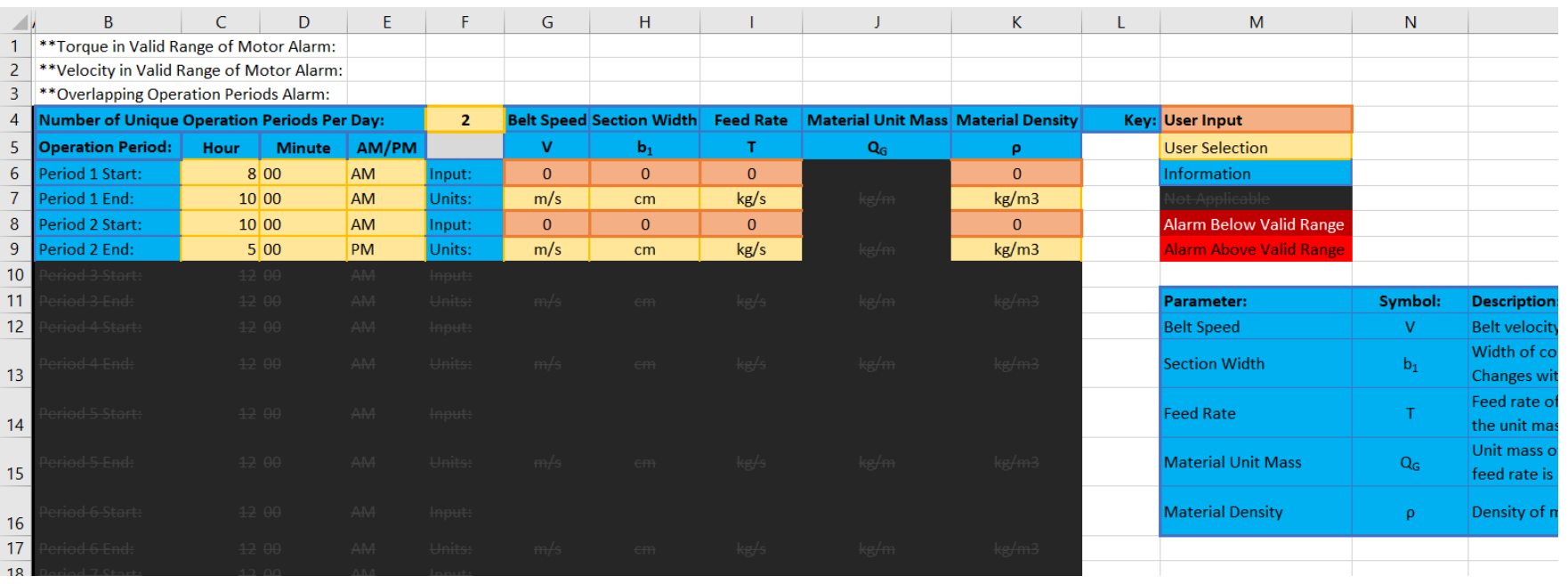

Figure 39. Conveyor operational parameter data input sheet

1. In cell F4, select the number of unique operation periods that will occur in the day. Previously blacked-out, the number of rows will appear corresponding to the number of operation periods entered, allowing the user to enter data.

2. In cells $\mathrm{C} 6$, D6, and E6, select the start time for the first operation period of the day. Select the hour in cell C6, the minute in cell D6, and specify AM or PM in cell E6. If the operation day is 24 hours, enter 12:00 AM.

3. In cells C7, D7, and E7, select the end time for the first operation period. Again, select the hour into cell C7, the minute into cell D7 and specify AM or PM in cell E7.

4. In cell G6, enter the speed of the belt during the first operation period. Select the units of velocity in cell G7.

5. In cell H6, enter the guide/skirt board width during the first operation period. Select units of length in cell $\mathrm{H} 7$.

6. If the user has calculated the product material unit mass, then skip to step 7. Otherwise, enter the product material feed rate during the first operation period into cell I6. Select the units of mass per time in cell $\mathrm{I} 7$.

7. If the user has entered product material feed rate, skip to step 8. Otherwise, enter the product material unit mass during the first operation period into cell J6. Select the units of mass per length in cell $\mathrm{J} 7$.

8. In cell K6, enter the product material density during the first operation period. Select units of length in cell $\mathrm{K} 7$. 
9. Repeat steps 2 through 8 for each subsequent operation period until parameters have been entered for all operation periods. For specific cell numbers, use the same column but add two rows (such that for operation period $n$, add $2 *(n-1)$ rows). If entering a 24-hour operation day, select 11:59 PM as the end time of the last operation period.

Check to ensure that all orange and yellow cells are filled correctly before moving forward. Once data are entered into all sheets according to Sections A.2-A.4, results will be generated in the fifth "Output" sheet. Incorrect results will show if not all cells are fully entered accurately in the previous four sheets.

\section{A.5 Sheet 5: Output Sheet}

The "Output" sheet shows the resultant energy consumption and savings for the specified operation day. The user must ensure that all data have been input correctly into the "Conveyor Structure Inputs" sheet, "Operation Inputs" sheet, and at least one of either the "Baseline Motor Characterization Inputs" or "Proposed Motor Characterization Inputs" sheets for results to be displayed accurately here. Results will be generated from default values (usually 0 for most parameters) if previous sheets are not fully completed.

The total kWh energy consumption is displayed in cells $\mathrm{O} 1$ and $\mathrm{O} 2$ for the baseline and proposed energy-efficient motor/drive systems, respectively. Cell R2 shows the energy savings ( $\Delta \mathrm{kWh} /$ day) if two motor/drives are compared.

Four graphs display the power consumption (in watts), the efficiency, the total torque (in Nm), and belt speed (in $\mathrm{m} / \mathrm{s}$ ) across the operation day. The baseline and proposed motor/drives power consumption and drive efficiency are compared accordingly. The $\mathrm{x}$-axes display the time (in minutes) after the start time of the first operation period. The layout of the output sheet is shown below in a snapshot provided in Figure 41.

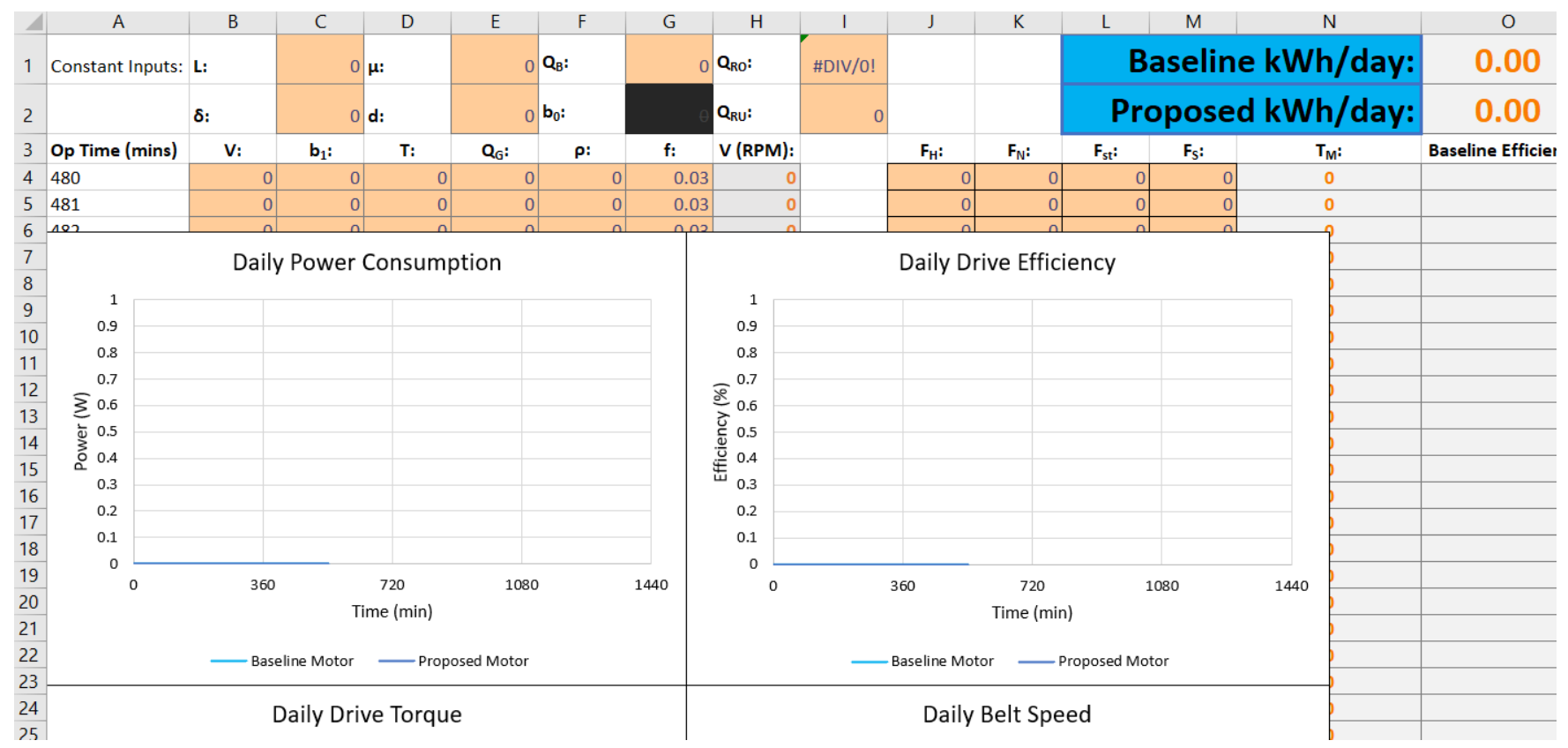

Figure 40. Conveyor energy consumption output sheet 


\section{$\underline{\text { Cell Color-Coding }}$}

No cells in the output sheet can be edited by the user. These cells, however, have their own format structure. Peach-colored cells contain values calculated from conveyor parameter inputs based on the equations shown in Section A.1. Gray cells indicate values calculated via interpolation to the motor/drive performance characterization curve(s).

\section{$\underline{\text { Sheet Layout }}$}

Cells A1-I2 show values entered as constant structural parameters converted to metric base units. Below row 3, variable parameters (also converted to metric base units) and calculations are displayed for each time step. The time steps are shown in column A, beginning with the first operation period start time (in minutes after midnight). Columns B through $\mathrm{F}$ show the converted variable parameters and artificial friction factor. Column H shows the rotational velocity of the motor (in RPM).

Calculated internal frictional resistances (equations 2-5 in Section A.1) are shown in columns J-M, and column $\mathrm{N}$ shows the calculated torque (equation 1). Columns $\mathrm{O}$ and $\mathrm{R}$ show the baseline and proposed motor/drive system efficiencies, respectively, that are interpolated at the calculated rotational velocity and torque. Similarly, the baseline and proposed motor/drive systems' power consumptions are shown in columns $\mathrm{P}$ and $\mathrm{S}$, respectively. Columns $\mathrm{Q}$ and $\mathrm{T}$ show the energy consumption that is integrated to calculate total daily $\mathrm{kWh} /$ day.

\section{A.6 Sheet 6: Optional "Yearly kWh Savings" Sheet}

If the user wishes to estimate yearly energy consumption or savings, an optional sixth "Yearly kWh Savings" sheet is available in the calculator tool. Here the user enters the daily kWh consumption calculated from the "Output" sheet for each unique operation day. The user can go back through the fourth "Operation Inputs" sheet to adjust operational parameters and daily schedules for different unique operation days (make sure to copy and save any graphs from the "Output" sheet prior to re-entering data for different operation days). The user will be able to define a yearly schedule and then enter the energy consumption for each unique operation day to calculate yearly energy consumption and/or savings.

Total yearly kWh consumption is output to cells J18 and J19 for the baseline and proposed motor, respectively. Total yearly $\mathrm{kWh}$ savings are shown in cell J8. The user has the option of entering the average utility rate in cell G6, which can be used to generate an estimated cost savings shown in cell $\mathrm{J} 11$.

\section{$\underline{\text { Regular Operation Week }}$}

First, enter the number of unique operation days in a regular week in cell E6. Unique operation days have either a different schedule and/or different operational parameters than other unique days.

As an example, a week with the same daily operation schedule Monday through Friday, a different schedule on Saturday, and closed on Sunday yields three unique operation days. The user would enter output energy consumption on the Monday-Friday operation day into cells C9 and/or D9. Then the user would enter " 5 " into cell B9 to indicate that the operation day occurred 5 times that week. 
For the Saturday operation day, the user would first readjust the operational schedule and parameters in the "Operation Inputs" sheet. Then the user would enter " 1 " into cell B10 and the output kWh in cells C10 and D10.

The user will also need to specify Sunday as an operation day despite being closed. The number of unique operation days must add up to seven days per week. The user would enter "1" into cell B11 and "0" in cells C11 and D11. The number of unique operation days must add up to seven days per week.

\section{Unique Operation Weeks}

The user is required to enter the number of unique operation weeks in the year in cell E7, such as weeks containing holidays with unique operation schedules. The user will follow the same procedure followed for a regular week for each unique week: First the user will specify the number of unique operation days during the week. Then the user will enter the energy consumed each unique operation day and the occurrence of that operation day.

\section{$\underline{\text { Step-by-Step Instructions }}$}

The layout of the output sheet is shown below in a snapshot provided in Figure 41. Cell formatting is the same as previous sheets and indicated in a key shown in cells K6-K11. Cells will be blacked out corresponding to the number of unique days and weeks specified in cells E6 and E7. If more than seven days are entered in a week in column B, these cells will alarm red. Instructions are provided in cells A1K3. Stepwise instructions for entering data into this sheet are provided below.

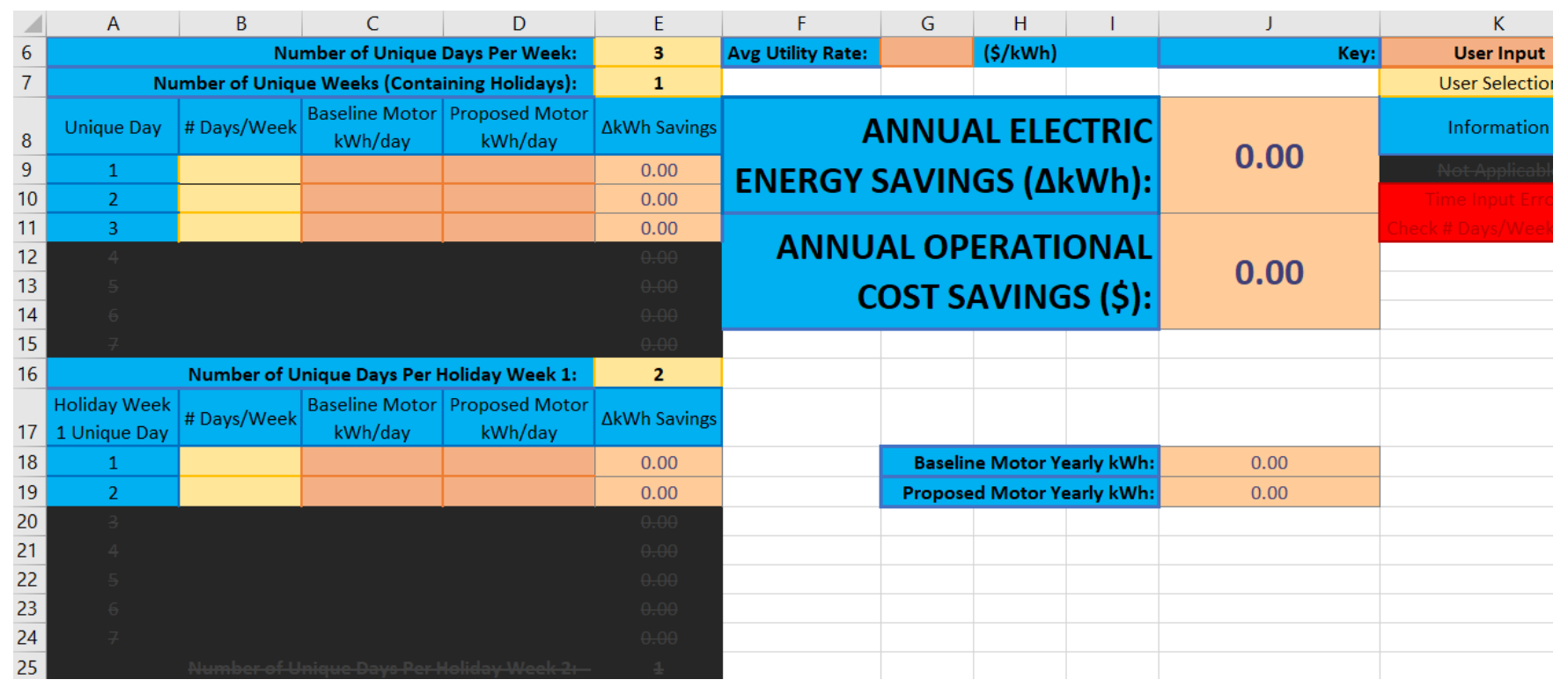

Figure 41. Optional yearly kWh savings calculation sheet

1. In cell E6, select the number of unique operation days that will occur during a regular week. Previously blacked-out, the number of rows corresponding to the number of unique operation days entered will then open to allow the user to enter data. Ensure that days where the conveyor system is not operated are still accounted for as unique operation days. 
2. In cell E7, select the number of unique operation weeks that will occur throughout the year. This includes any weeks containing an operation schedule different from the regular week (such as weeks containing holidays). Previously blacked-out, cells below row 15 will appear to allow the user to enter data for each unique operation week.

3. In cell B9, select the number of days per week in which the first unique operation day occurs (e.g., Monday through Friday $=5$ ). Then enter the baseline and proposed daily kWh consumption values calculated in cells $\mathrm{O} 1$ and $\mathrm{O} 2$ of the "Output" sheet into cells C9 and D9, respectively.

4. Make sure to copy and save any necessary graphs or results data from the "Output" sheet before moving forward. Then, adjust parameters and operation period start and stop times in the "Operation Inputs" sheet for the next unique operation day. Refer to Section A.4 for instructions for entering data in the "Operation Inputs" sheet.

5. Return to the "Yearly kWh Savings" sheet and enter the number of days per week in which the next operation day occurs into the next cell in column B. Then, enter the values calculated in cells $\mathrm{O} 1$ and $\mathrm{O} 2$ of the "Output" sheet into the next cells in columns C and D, respectively.

6. Repeat steps 4 and 5 for all remaining unique operation days occurring during the week. Enter " 0 " $\mathrm{kWh}$ in columns $\mathrm{C}$ and $\mathrm{D}$ cells for any operation day that the conveyor system is not operational.

7. If no additional unique operation weeks were entered, skip to step 12. Otherwise, enter the number of unique days occurring during the first unique week in cell E16, the same as was done in step 1 .

8. In cell B18, select the number of days per week in which the first unique operation day occurs during the first unique operation week. Make sure to copy and save any necessary graphs or results data from the "Output" sheet. Then, adjust parameters and operation period start and stop times in the "Operation Inputs" sheet for the first unique operation day. Then enter the values calculated in cells O1 and O2 of the "Output" sheet into cells C18 and D18 of the "Yearly kWh Savings" sheet, respectively.

9. Repeat steps 4 and 5 for all remaining unique operation days occurring during the first unique operation week. Enter " 0 " $\mathrm{kWh}$ in the columns C and D cells for any operation day that the conveyor system is not operational.

10. Enter data for each subsequent unique operation week starting in row $(9 n+9)$, where $n$ is the number of the unique operation week. First, make sure to copy and save any necessary graphs or results data from the "Output" sheet. Then, adjust parameters and operation period start and stop times in the "Operation Inputs" sheet. Enter the values calculated in cells O1 and O2 of the "Output" sheet into cells C $(9 n+9)$ and $\mathrm{D}(9 n+9)$ of the "Yearly kWh Savings" sheet, respectively. Then select the number of days per week in which the first unique operation day occurs in cell $\mathrm{B}(9 n+9)$.

11. Repeat steps 4 and 5 for all remaining unique operation days occurring during the next unique operation weeks. Enter " 0 " $\mathrm{kWh}$ in the columns C and D cells for any operation day that the conveyor system is not operational. 
12. As an option, the user can enter the average utility rate in cell G6 (converted to $\$ / \mathrm{kWh}$ ). This will generate an output cost savings estimate for the year in cell $\mathrm{J} 11$.

\section{A.7 Supplemental Motor Database}

Provided with the Conveyor Motor Energy Calculator Tool is a supplemental motor database. The database can be used to estimate the performance of a specific motor on the market in a conveyor. This supplemental database is contained in the attached "ConveyorMotorEnergyCalculator_MotorDatabase. xlsx" Excel file. It contains a list of 16,359 motors from 14 manufacturers extracted from the MotorMaster-Plus software tool developed by DOE's Office of Energy Efficiency and Renewable Energy Industrial Technologies Program [3]. Once the user selects a motor from the database, estimated performance characterization data are automatically generated. The user can then copy these data and paste into the "Baseline Motor Char. Inputs" sheet.

The user can browse through available motors based on a list of parameters including:

- Model number

- Rated HP

- Rated RPM

- Rated efficiency

- Part-load efficiencies

- Rated voltage

- Full-load/idle amperage

- Cost

- Weight

- NEMA design

- Rated kW

- Frame design

- Warranty years.

Not all motors listed in the database contain information for every listed parameter. The data contained in this database were also collected from manufacturers' spec sheets and not obtained from standardized performance testing. Therefore, the user should be aware that data contained in this tool may not be indicative of actual performance for all of the motors listed. Manufacturers are required to validate the performance of some, but not all available motors on the market.

\section{VFD Efficiency Estimate}

The database contains performance data only for individual motors without a drive. Therefore, VFD performance at lower speeds is estimated using the idealized efficiency factor. The idealized efficiency factor is used to estimate the overall efficiency of a motor and VFD at a particular rotational velocity. These efficiency factors were calculated by Burt et al. based on the Wallbom-Carlson theory, which accounts for losses in a VFD and losses in a motor that are caused by a VFD [4, 5]. 


\section{$\underline{\text { General Procedure }}$}

Within the database Excel file, there are two sheets titled "Motor Char. Inputs" and "Motor Catalogue." The user will search through the motors listed in the motor catalogue sheet and then select one using a MotorMaster-Plus ID (MM+ ID) number from column A. The user will then enter the MM+ ID into the motor characterization inputs sheet to generate an estimated performance data set for the motor when coupled with a VFD. The user is then able to copy and paste the generated data set into the main conveyor motor energy calculation tool. Instructions for entering performance data into either the "Baseline Motor Characterization Inputs" or "Proposed Motor Characterization Inputs" sheets is described in Section A.2.

A snapshot of the motor catalogue database is shown in Figure 42. Motors are listed by row and motor parameters are listed in columns B-T. To find a motor that satisfies the user's requirements for their conveyor, they can highlight any column to search for a desired value of any parameter.

\begin{tabular}{|c|c|c|c|c|c|c|c|c|c|}
\hline 4 & A & B & $\mathrm{C}$ & $\mathrm{D}$ & $E$ & $\mathrm{~F}$ & G & $\mathrm{H}$ & I \\
\hline 1 & $M M+I D \#$ & Manufacturer & Rated HP & Rated RPM & Rated kW & Model & Frame & NEMA Design & Weigh \\
\hline 2 & 1 & Magnetek & 1 & 1800 & 0 & EPACT & $143 \mathrm{~T}$ & $\mathrm{~B}$ & 40 \\
\hline 3 & 2 & Magnetek & 1.5 & 3600 & 0 & EPACT & $143 \mathrm{~T}$ & B & 36 \\
\hline 4 & 3 & Magnetek & 1.5 & 3600 & 0 & EPACT & $143 \mathrm{~T}$ & B & 36 \\
\hline 5 & 4 & Magnetek & 2 & 3600 & 0 & EPACT & $145 \mathrm{~T}$ & B & 44 \\
\hline 6 & 5 & Magnetek & 2 & 3600 & 0 & EPACT & $145 \mathrm{~T}$ & B & 44 \\
\hline 7 & 6 & Magnetek & 3 & 3600 & 0 & EPACT & $145 \mathrm{~T}$ & B & 43 \\
\hline 8 & 7 & Magnetek & 3 & 3600 & 0 & EPACT & $145 \mathrm{~T}$ & B & 43 \\
\hline 9 & 8 & Magnetek & 2 & 1800 & 0 & EPACT & $145 \mathrm{~T}$ & B & 42 \\
\hline 10 & 9 & Magnetek & 2 & 1800 & 0 & EPACT & $145 \mathrm{~T}$ & B & 42 \\
\hline 11 & 10 & Maunotok & 1 & $12 \mathrm{nn}$ & $n$ & $\mathrm{FD} \Delta \mathrm{CT}$ & $145 \mathrm{~T}$ & $R$ & 20 \\
\hline
\end{tabular}

Figure 42. Supplemental motor database motor catalogue

In the "Motor Char. Inputs" sheet, the user should enter the MM+ ID\# into cell H4. This will automatically generate the motor and VFD's estimated performance data set.

Column B will show the percent full-load, column C shows the rotational speed, column D shows the torque, and column E shows the total system efficiency. A snapshot of the "Motor Char. Inputs" sheet is shown in Figure 43 with an example motor selected. 


\begin{tabular}{|c|c|c|c|c|c|c|c|c|}
\hline 4 & A & B & C & D & $\mathrm{E}$ & $\mathrm{F}$ & G & $\mathrm{H}$ \\
\hline 1 & \multicolumn{6}{|c|}{ Instructions: } & & \\
\hline 2 & \multicolumn{6}{|c|}{ 1. Select a Motor from the "Motor Catalogue" Sheet } & & \\
\hline 3 & \multicolumn{6}{|c|}{ 2. Enter the "MM+ ID\#" Here } & & MM+ ID\# \\
\hline 4 & \multicolumn{6}{|c|}{$\begin{array}{l}\text { 3. Copy and Paste the Below Columns of the Estimated Performance Curve (Grey and Orange } \\
\text { Cells) into the "Motor Char. Inputs" Sheet in the "ConveyorMotorEnergyCalculator" Tool }\end{array}$} & & \\
\hline \multicolumn{9}{|c|}{\begin{tabular}{|l|l|l|l|}
5 & & \\
\end{tabular}} \\
\hline 6 & Percent Rated Frequency (\%) & Load $(\%)$ & Speed (RPM) & Torque $(\mathrm{Nm})$ & Efficiency (\%) & & & \\
\hline 7 & 100 & 100 & 1785 & 3672 & 92.15 & & & \\
\hline 8 & 100 & 75 & 1785 & 2754 & 91.277 & & & \\
\hline 9 & 100 & 50 & 1785 & 1836 & 90.21 & & & \\
\hline 10 & 100 & 25 & 1785 & 918 & 0 & & & \\
\hline 11 & 90 & 100 & 1606.5 & 3672 & 89.775 & & & \\
\hline 12 & 90 & 75 & 1606.5 & 2754 & 88.9245 & & & \\
\hline 13 & 90 & 50 & 1606.5 & 1836 & 87.885 & & & \\
\hline 14 & 90 & 25 & 1606.5 & 918 & 0 & & & \\
\hline 15 & 80 & 100 & 1428 & 3672 & 87.4 & & & \\
\hline 16 & 80 & 75 & 1428 & 2754 & 86.572 & & & \\
\hline 17 & 80 & 50 & 1428 & 1836 & 85.56 & & & \\
\hline 18 & 80 & 25 & 1428 & 918 & 0 & & & \\
\hline 19 & 70 & 100 & 1249.5 & 3672 & 85.5 & & & \\
\hline 20 & 70 & 75 & 1249.5 & 2754 & 84.69 & & & \\
\hline 21 & 70 & 50 & 1249.5 & 1836 & 83.7 & & & \\
\hline 22 & 70 & 25 & 1249.5 & 918 & 0 & & & \\
\hline 23 & 60 & 100 & 1071 & 3672 & 83.125 & & & \\
\hline
\end{tabular}

Figure 43. Supplemental motor database-performance curve data input sheet

\section{Transferring Generated Motor Performance Data}

Motor/drive performance data are always generated with 28 data points for each parameter. Therefore, the user should enter " 28 " as the number of data points/target points in cell E2 in the first two sheets of the main energy calculator tool. When using any motor from the database, ensure that columns $\mathrm{F}$ and $\mathrm{G}$ for "Power In" and "Power Out" are left blank. The calculator tool will calculate energy consumption without populating column B with frequency data, so that column can also be left blank. 


\section{Appendix B. Tabulated Motor/Drive System Performance Characterization Data}

The dynamometer characterization results for the baseline ABB motor and Allen Bradley VFD are provided in Table 14. The uncertainty in each direct measurement is equivalent to the accuracies specified in Table 4. Efficiency was calculated from the ratio of shaft output power (the product of torque and speed) to the electrical input power. This generated a propagated uncertainty of $\pm 0.238 \%$ in efficiency. Plots of the motor/drive efficiency with respect to torque and rotational velocity are shown in Figures 10 and 11.

Table 14. Baseline ABB Motor and Allen-Bradley VFD Performance Characterization Results

\begin{tabular}{|c|c|c|c|c|c|c|c|c|c|c|c|c|}
\hline & $\begin{array}{l}\text { Target } \\
\text { Point }\end{array}$ & $\begin{array}{l}\text { Speed } \\
\text { (RPM) }\end{array}$ & $\begin{array}{l}\text { Torque } \\
(\mathrm{N}-\mathrm{m})\end{array}$ & $\begin{array}{l}\text { \% Full } \\
\text { Load } \\
\text { Torque }\end{array}$ & $\begin{array}{l}\text { Power } \\
\text { Out (W) }\end{array}$ & $\begin{array}{c}\text { System } \\
\text { Efficiency } \\
(\%)\end{array}$ & $\begin{array}{l}\text { Power } \\
\text { In (W) }\end{array}$ & $\begin{array}{l}\text { Current } \\
\text { (A) }\end{array}$ & $\begin{array}{l}\text { Voltage } \\
\text { (V) }\end{array}$ & $\begin{array}{c}\text { Frequency } \\
(\mathrm{Hz})\end{array}$ & $\begin{array}{c}\text { V THD } \\
(\%)\end{array}$ & $\begin{array}{c}\text { I THD } \\
(\%)\end{array}$ \\
\hline \multirow{6}{*}{$60 \mathrm{~Hz}$} & $\begin{array}{l}110 \% \\
\text { Load }\end{array}$ & 1791 & 8.8 & 108.5 & 1652 & 83.8 & 1972 & 3.3 & 459.3 & 60.0 & 3.7 & 64.0 \\
\hline & $\begin{array}{l}100 \% \\
\text { Load }\end{array}$ & 1793 & 8.2 & 100.7 & 1534 & 83.9 & 1827 & 3.1 & 459.3 & 60.0 & 3.6 & 64.7 \\
\hline & $90 \%$ Load & 1794 & 7.4 & 91.2 & 1391 & 84.0 & 1655 & 2.8 & 459.3 & 60.0 & 3.4 & 65.4 \\
\hline & $75 \%$ Load & 1796 & 6.2 & 75.9 & 1158 & 83.8 & 1382 & 2.4 & 459.4 & 60.0 & 3.1 & 66.8 \\
\hline & $50 \%$ Load & 1798 & 4.1 & 50.3 & 768 & 81.3 & 945 & 1.7 & 459.5 & 60.0 & 2.5 & 69.2 \\
\hline & $25 \%$ Load & 1800 & 2.0 & 25.0 & 382 & 71.7 & 533 & 1.0 & 459.5 & 60.0 & 1.9 & 72.1 \\
\hline \multirow{6}{*}{$50 \mathrm{~Hz}$} & $\begin{array}{l}110 \% \\
\text { Load }\end{array}$ & 1501 & 8.9 & 109.2 & 1393 & 82.4 & 1691 & 2.9 & 459.3 & 60.0 & 3.4 & 65.3 \\
\hline & $\begin{array}{l}100 \% \\
\text { Load }\end{array}$ & 1501 & 8.1 & 100.4 & 1281 & 82.3 & 1555 & 2.7 & 459.4 & 60.0 & 3.3 & 65.9 \\
\hline & $90 \%$ Load & 1502 & 7.3 & 90.0 & 1148 & 82.3 & 1396 & 2.4 & 459.4 & 60.0 & 3.1 & 66.7 \\
\hline & $75 \%$ Load & 1503 & 6.2 & 75.8 & 968 & 82.0 & 1181 & 2.1 & 459.4 & 60.0 & 2.8 & 67.8 \\
\hline & $50 \%$ Load & 1504 & 4.1 & 50.5 & 645 & 79.0 & 816 & 1.5 & 459.5 & 60.0 & 2.3 & 70.1 \\
\hline & $25 \%$ Load & 1504 & 2.0 & 25.0 & 320 & 69.3 & 461 & 0.9 & 459.6 & 60.0 & 1.8 & 72.6 \\
\hline \multirow{6}{*}{$40 \mathrm{~Hz}$} & $\begin{array}{l}110 \% \\
\text { Load }\end{array}$ & 1198 & 8.9 & 110.1 & 1121 & 79.9 & 1404 & 2.4 & 459.4 & 60.0 & 3.1 & 66.6 \\
\hline & $\begin{array}{l}100 \% \\
\text { Load }\end{array}$ & 1198 & 8.1 & 100.2 & 1020 & 79.8 & 1277 & 2.2 & 459.4 & 60.0 & 2.9 & 67.3 \\
\hline & $90 \%$ Load & 1199 & 7.3 & 89.6 & 913 & 79.7 & 1144 & 2.0 & 459.4 & 60.0 & 2.8 & 68.0 \\
\hline & $75 \%$ Load & 1199 & 6.2 & 75.9 & 773 & 79.6 & 972 & 1.7 & 459.5 & 60.0 & 2.6 & 69.0 \\
\hline & $50 \%$ Load & 1200 & 4.1 & 51.1 & 521 & 76.7 & 679 & 1.3 & 459.5 & 60.0 & 2.2 & 70.9 \\
\hline & $25 \%$ Load & 1201 & 2.0 & 25.1 & 256 & 66.6 & 384 & 0.8 & 459.6 & 60.0 & 1.6 & 73.2 \\
\hline \multirow{6}{*}{$30 \mathrm{~Hz}$} & $\begin{array}{l}110 \% \\
\text { Load }\end{array}$ & 898 & 8.9 & 109.3 & 834 & 75.8 & 1100 & 2.0 & 459.4 & 60.0 & 2.7 & 68.3 \\
\hline & $\begin{array}{l}100 \% \\
\text { Load }\end{array}$ & 898 & 8.1 & 100.1 & 764 & 76.0 & 1005 & 1.8 & 459.5 & 60.0 & 2.6 & 68.8 \\
\hline & $90 \%$ Load & 899 & 7.4 & 90.6 & 692 & 75.9 & 912 & 1.7 & 459.5 & 60.0 & 2.5 & 69.4 \\
\hline & $75 \%$ Load & 900 & 6.1 & 75.5 & 577 & 75.9 & 761 & 1.4 & 459.5 & 60.0 & 2.3 & 70.3 \\
\hline & $50 \%$ Load & 901 & 4.1 & 50.7 & 388 & 73.3 & 529 & 1.0 & 459.6 & 60.0 & 1.9 & 72.0 \\
\hline & $25 \%$ Load & 902 & 2.0 & 24.9 & 191 & 62.6 & 305 & 0.7 & 459.7 & 60.0 & 1.4 & 73.8 \\
\hline \multirow{2}{*}{$20 \mathrm{~Hz}$} & $\begin{array}{l}110 \% \\
\text { Load }\end{array}$ & 598 & 8.9 & 109.4 & 556 & 68.9 & 807 & 1.5 & 459.5 & 60.0 & 2.3 & 70.1 \\
\hline & $\begin{array}{l}100 \% \\
\text { Load }\end{array}$ & 598 & 8.1 & 100.2 & 509 & 69.0 & 737 & 1.4 & 459.5 & 60.0 & 2.2 & 70.5 \\
\hline
\end{tabular}




\begin{tabular}{|c|c|c|c|c|c|c|c|c|c|c|c|c|}
\hline & $\begin{array}{c}\text { Target } \\
\text { Point }\end{array}$ & $\begin{array}{l}\text { Speed } \\
\text { (RPM) }\end{array}$ & $\begin{array}{c}\text { Torque } \\
(\mathrm{N}-\mathrm{m})\end{array}$ & $\begin{array}{l}\text { \% Full } \\
\text { Load } \\
\text { Torque } \\
\end{array}$ & $\begin{array}{l}\text { Power } \\
\text { Out (W) }\end{array}$ & $\begin{array}{c}\text { System } \\
\text { Efficiency } \\
(\%)\end{array}$ & $\begin{array}{l}\text { Power } \\
\text { In (W) }\end{array}$ & $\begin{array}{l}\text { Current } \\
\text { (A) }\end{array}$ & $\begin{array}{l}\text { Voltage } \\
\text { (V) }\end{array}$ & $\begin{array}{l}\text { Frequency } \\
(\mathrm{Hz})\end{array}$ & $\begin{array}{c}\text { V THD } \\
(\%)\end{array}$ & $\begin{array}{c}\text { I THD } \\
(\%)\end{array}$ \\
\hline & $90 \%$ Load & 597 & 7.4 & 90.7 & 460 & 69.2 & 665 & 1.2 & 459.6 & 60.0 & 2.1 & 71.0 \\
\hline & $75 \%$ Load & 598 & 6.1 & 75.6 & 384 & 69.3 & 554 & 1.1 & 459.6 & 60.0 & 2.0 & 71.8 \\
\hline & $50 \%$ Load & 599 & 4.2 & 51.2 & 261 & 67.0 & 389 & 0.8 & 459.6 & 60.0 & 1.6 & 73.1 \\
\hline & $25 \%$ Load & 601 & 2.0 & 25.1 & 128 & 55.9 & 229 & 0.5 & 459.7 & 60.0 & 1.1 & 73.7 \\
\hline \multirow{6}{*}{$10 \mathrm{~Hz}$} & $\begin{array}{l}110 \% \\
\text { Load }\end{array}$ & 298 & 8.9 & 109.5 & 277 & 53.6 & 517 & 1.0 & 459.6 & 60.0 & 1.9 & 72.0 \\
\hline & $\begin{array}{l}100 \% \\
\text { Load }\end{array}$ & 298 & 8.1 & 100.0 & 253 & 54.1 & 468 & 0.9 & 459.6 & 60.0 & 1.8 & 72.4 \\
\hline & $90 \%$ Load & 299 & 7.4 & 91.0 & 231 & 54.7 & 423 & 0.8 & 459.6 & 60.0 & 1.7 & 72.8 \\
\hline & $75 \%$ Load & 299 & 6.2 & 75.9 & 193 & 55.2 & 350 & 0.7 & 459.7 & 60.0 & 1.5 & 73.5 \\
\hline & $50 \%$ Load & 301 & 4.2 & 51.2 & 131 & 53.2 & 246 & 0.6 & 459.7 & 60.0 & 1.2 & 73.8 \\
\hline & $25 \%$ Load & 302 & 2.1 & 25.8 & 66 & 42.9 & 155 & 0.4 & 459.8 & 60.0 & 0.8 & 70.5 \\
\hline \multirow{6}{*}{$5 \mathrm{~Hz}$} & $\begin{array}{l}110 \% \\
\text { Load }\end{array}$ & 149 & 8.9 & 110.2 & 139 & 36.7 & 379 & 0.8 & 459.6 & 60.0 & 1.6 & 73.2 \\
\hline & $\begin{array}{l}100 \% \\
\text { Load }\end{array}$ & 149 & 8.2 & 100.5 & 127 & 37.3 & 341 & 0.7 & 459.7 & 60.0 & 1.5 & 73.5 \\
\hline & $90 \%$ Load & 149 & 7.4 & 90.8 & 115 & 37.9 & 304 & 0.7 & 459.7 & 60.0 & 1.4 & 73.8 \\
\hline & $75 \%$ Load & 151 & 6.1 & 75.8 & 97 & 39.0 & 249 & 0.6 & 459.7 & 60.0 & 1.2 & 73.8 \\
\hline & $50 \%$ Load & 152 & 4.1 & 50.9 & 66 & 37.8 & 174 & 0.4 & 459.8 & 60.0 & 0.9 & 72.0 \\
\hline & $25 \%$ Load & 153 & 2.1 & 25.5 & 33 & 29.0 & 115 & 0.3 & 459.8 & 60.0 & 0.7 & 66.2 \\
\hline
\end{tabular}

The dynamometer characterization results for the Turntide SRM are provided in Table 15. The uncertainty in each base measurement is equivalent to the accuracies specified in Table 4, which generated a propagated uncertainty of $\pm 0.238 \%$ in efficiency. The dynamometer control method used was not compatible with the SRM at higher torques at the lowest frequencies, so only the lowest torque setpoints were measured at $10 \mathrm{~Hz}$ and $5 \mathrm{~Hz}$. Plots of the performance map with respect to torque and rotational velocity are shown in Figures 13 and 14, respectively. 
Table 15. Energy-Efficient Switch-Reluctance Motor Performance Characterization Results

\begin{tabular}{|c|c|c|c|c|c|c|c|c|c|c|c|c|}
\hline & $\begin{array}{c}\text { Target } \\
\text { Point }\end{array}$ & $\begin{array}{l}\text { Speed } \\
\text { (RPM) }\end{array}$ & $\begin{array}{l}\text { Torque } \\
(\mathrm{N}-\mathrm{m})\end{array}$ & $\begin{array}{l}\text { \% Full } \\
\text { Load } \\
\text { Torque }\end{array}$ & $\begin{array}{l}\text { Power } \\
\text { Out (W) }\end{array}$ & $\begin{array}{c}\text { System } \\
\text { Efficiency } \\
(\%)\end{array}$ & $\begin{array}{l}\text { Power } \\
\text { In (W) }\end{array}$ & $\begin{array}{l}\text { Current } \\
\text { (A) }\end{array}$ & $\begin{array}{l}\text { Voltage } \\
\text { (V) }\end{array}$ & $\begin{array}{l}\text { Frequency } \\
\quad(\mathrm{Hz})\end{array}$ & $\begin{array}{c}\text { V THD } \\
(\%)\end{array}$ & $\begin{array}{c}\text { I } \\
\text { THD } \\
(\%) \\
\end{array}$ \\
\hline \multirow{6}{*}{$60 \mathrm{~Hz}$} & $\begin{array}{l}110 \% \\
\text { Load }\end{array}$ & 1801 & 9.0 & 111.0 & 1699 & 90.2 & 1884 & 3.2 & 460.5 & 60.0 & 3.6 & 63.9 \\
\hline & $\begin{array}{l}100 \% \\
\text { Load }\end{array}$ & 1801 & 8.1 & 99.9 & 1529 & 90.0 & 1698 & 2.9 & 460.5 & 60.0 & 3.4 & 64.8 \\
\hline & $90 \%$ Load & 1801 & 7.3 & 90.1 & 1378 & 89.8 & 1534 & 2.6 & 460.6 & 60.0 & 3.2 & 65.7 \\
\hline & $75 \%$ Load & 1801 & 6.1 & 75.3 & 1152 & 89.3 & 1290 & 2.2 & 460.6 & 60.0 & 2.9 & 67.1 \\
\hline & $50 \%$ Load & 1801 & 4.1 & 50.6 & 775 & 87.1 & 890 & 1.6 & 460.7 & 60.0 & 2.5 & 69.9 \\
\hline & $25 \%$ Load & 1800 & 2.0 & 24.7 & 378 & 82.8 & 457 & 0.9 & 460.9 & 60.0 & 1.8 & 74.6 \\
\hline \multirow{6}{*}{$50 \mathrm{~Hz}$} & $\begin{array}{l}110 \% \\
\text { Load }\end{array}$ & 1501 & 8.9 & 109.7 & 1399 & 89.4 & 1565 & 2.7 & 460.6 & 60.0 & 3.3 & 65.4 \\
\hline & $\begin{array}{l}100 \% \\
\text { Load }\end{array}$ & 1500 & 8.1 & 99.9 & 1274 & 89.2 & 1427 & 2.4 & 460.6 & 60.0 & 3.1 & 66.2 \\
\hline & $90 \%$ Load & 1501 & 7.3 & 90.0 & 1147 & 89.0 & 1290 & 2.2 & 460.6 & 60.0 & 2.9 & 67.1 \\
\hline & $75 \%$ Load & 1501 & 6.1 & 75.2 & 959 & 88.3 & 1087 & 1.9 & 460.7 & 60.0 & 2.7 & 68.4 \\
\hline & $50 \%$ Load & 1501 & 4.1 & 50.6 & 646 & 85.8 & 752 & 1.4 & 460.8 & 60.0 & 2.3 & 71.1 \\
\hline & $25 \%$ Load & 1501 & 2.0 & 24.8 & 316 & 81.7 & 387 & 0.8 & 460.9 & 60.0 & 1.7 & 75.8 \\
\hline \multirow{6}{*}{$40 \mathrm{~Hz}$} & $\begin{array}{l}110 \% \\
\text { Load }\end{array}$ & 1201 & 8.9 & 109.9 & 1121 & 88.1 & 1273 & 2.2 & 460.6 & 60.0 & 2.9 & 67.2 \\
\hline & $\begin{array}{l}100 \% \\
\text { Load }\end{array}$ & 1200 & 8.1 & 100.0 & 1019 & 87.9 & 1160 & 2.0 & 460.7 & 60.0 & 2.8 & 67.9 \\
\hline & $90 \%$ Load & 1200 & 7.3 & 90.0 & 918 & 87.6 & 1048 & 1.9 & 460.7 & 60.0 & 2.7 & 68.7 \\
\hline & $75 \%$ Load & 1201 & 6.1 & 75.3 & 768 & 87.0 & 883 & 1.6 & 460.8 & 60.0 & 2.4 & 69.9 \\
\hline & $50 \%$ Load & 1200 & 4.1 & 50.7 & 516 & 85.2 & 606 & 1.1 & 460.8 & 60.0 & 2.1 & 72.5 \\
\hline & $25 \%$ Load & 1200 & 2.0 & 24.9 & 254 & 80.3 & 316 & 0.6 & 460.9 & 60.0 & 1.5 & 77.4 \\
\hline \multirow{6}{*}{$30 \mathrm{~Hz}$} & $\begin{array}{l}110 \% \\
\text { Load }\end{array}$ & 901 & 8.9 & 109.9 & 841 & 86.0 & 978 & 1.7 & 460.7 & 60.0 & 2.6 & 69.2 \\
\hline & $\begin{array}{l}100 \% \\
\text { Load }\end{array}$ & 901 & 8.1 & 99.9 & 765 & 85.9 & 890 & 1.6 & 460.7 & 60.0 & 2.5 & 69.8 \\
\hline & 90\% Load & 901 & 7.3 & 90.1 & 689 & 85.7 & 804 & 1.5 & 460.8 & 60.0 & 2.3 & 70.6 \\
\hline & $75 \%$ Load & 901 & 6.1 & 75.3 & 576 & 85.1 & 677 & 1.2 & 460.8 & 60.0 & 2.2 & 71.8 \\
\hline & $50 \%$ Load & 901 & 4.1 & 50.7 & 388 & 83.5 & 465 & 0.9 & 460.9 & 60.0 & 1.8 & 74.4 \\
\hline & $25 \%$ Load & 902 & 2.0 & 24.7 & 190 & 78.1 & 243 & 0.5 & 461.0 & 60.0 & 1.2 & 79.2 \\
\hline \multirow{6}{*}{$20 \mathrm{~Hz}$} & $\begin{array}{l}110 \% \\
\text { Load }\end{array}$ & 601 & 8.9 & 109.8 & 561 & 81.9 & 685 & 1.3 & 460.8 & 60.0 & 2.2 & 71.7 \\
\hline & $\begin{array}{l}100 \% \\
\text { Load }\end{array}$ & 601 & 8.1 & 99.8 & 510 & 81.8 & 623 & 1.2 & 460.8 & 60.0 & 2.1 & 72.4 \\
\hline & $90 \%$ Load & 601 & 7.3 & 90.1 & 461 & 81.6 & 564 & 1.1 & 460.8 & 60.0 & 2.0 & 73.0 \\
\hline & $75 \%$ Load & 601 & 6.1 & 75.3 & 385 & 81.1 & 474 & 0.9 & 460.9 & 60.0 & 1.8 & 74.3 \\
\hline & $50 \%$ Load & 602 & 4.2 & 51.1 & 261 & 80.0 & 327 & 0.7 & 460.9 & 60.0 & 1.5 & 77.2 \\
\hline & $25 \%$ Load & 599 & 2.0 & 24.6 & 125 & 74.0 & 169 & 0.4 & 461.0 & 60.0 & 1.0 & 81.4 \\
\hline \multirow{3}{*}{$10 \mathrm{~Hz}$} & $75 \%$ Load & 301 & 6.1 & 74.8 & 191 & 71.8 & 266 & 0.6 & 460.9 & 60.0 & 1.3 & 78.6 \\
\hline & $50 \%$ Load & 301 & 4.1 & 50.8 & 130 & 69.6 & 186 & 0.4 & 461.0 & 60.0 & 1.0 & 80.8 \\
\hline & $25 \%$ Load & 302 & 2.0 & 24.6 & 63 & 59.6 & 106 & 0.2 & 461.1 & 60.0 & 0.8 & 83.5 \\
\hline \multirow{2}{*}{$5 \mathrm{~Hz}$} & $50 \%$ Load & 160 & 3.7 & 45.9 & 62 & 57.3 & 109 & 0.3 & 460.6 & 60.0 & 0.8 & 83.5 \\
\hline & $25 \%$ Load & 152 & 2.0 & 24.8 & 32 & 48.3 & 66 & 0.2 & 461.1 & 60.0 & 0.6 & 85.5 \\
\hline
\end{tabular}




\section{Appendix C. Sensitivity Analysis Full Result Data}

The "sensitivity" analysis shown in Section 4.2 involved varying each conveyor structural and operational parameter while holding all other parameters constant at $15 \%$ below, at, and 15\% above the baseline conveyor values provided in Tables 10 and 11 . The results of this analysis were only provided with the percent deviation in each parameter between $100 \%$ below and $100 \%$ above their baseline values (or between 0 and double the baseline). Likewise, the estimated energy consumption and savings were also only provided as percent deviations from the values calculated from the baseline conveyor parameter values. Therefore, the results of the same sensitivity analysis are shown below in Figures 4447 with respect to metric values for each parameter on the $\mathrm{x}$-axes, and with respect to $\mathrm{kWh} /$ day consumption and savings on the y-axes.

The energy consumption and savings were calculated across the full operational range of both the induction motor/VFD and SRM, and so a wider range in variation of each parameter is shown here than was shown in Section 4.2. Therefore, the $\mathrm{x}$-axis is shown in a logarithmic format for some parameters. These parameters were varied only based on the extent to which both motor/drives were capable of operating at the calculated torques and rotational velocities. So, in some cases, the energy consumption and savings were still calculated at unrealistic parameter values. Again, black lines show the resultant energy consumption and savings from baseline customer conveyor parameters and dark and light gray lines show the consumption and savings from 15\% deviations above, and below baseline conveyor parameters, respectively. Thin vertical dotted lines show the locations of baseline parameter values and $15 \%$ deviations above and below those values. 


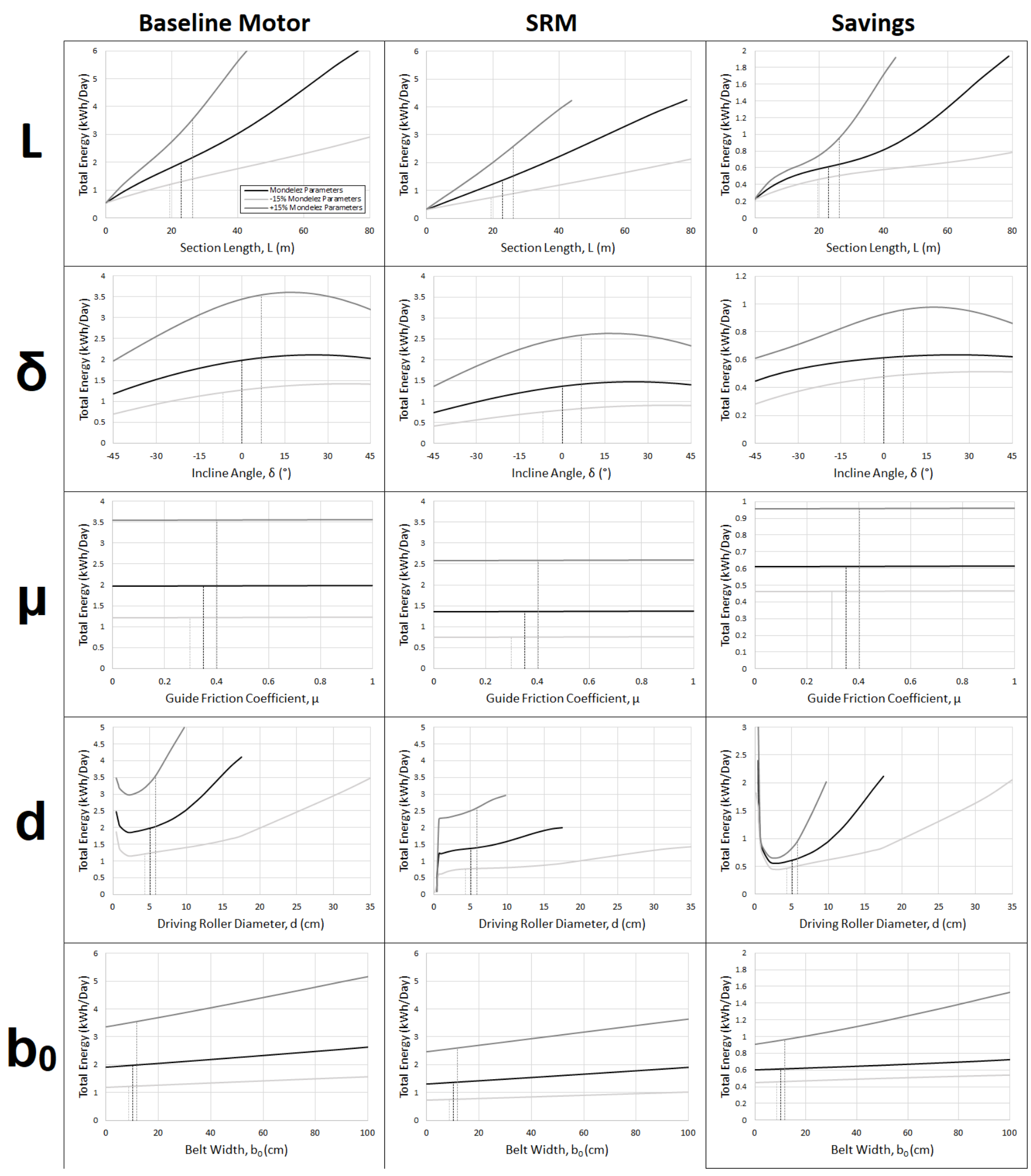

Figure 44. Sensitivity of motor/drive system energy consumption and savings to variation in conveyor structural parameters: section length $(L)$, incline angle $(\delta)$, guide friction coefficient $(\mu)$, driving roller diameter (d), and belt width ( $\left.b_{0}\right)$ 


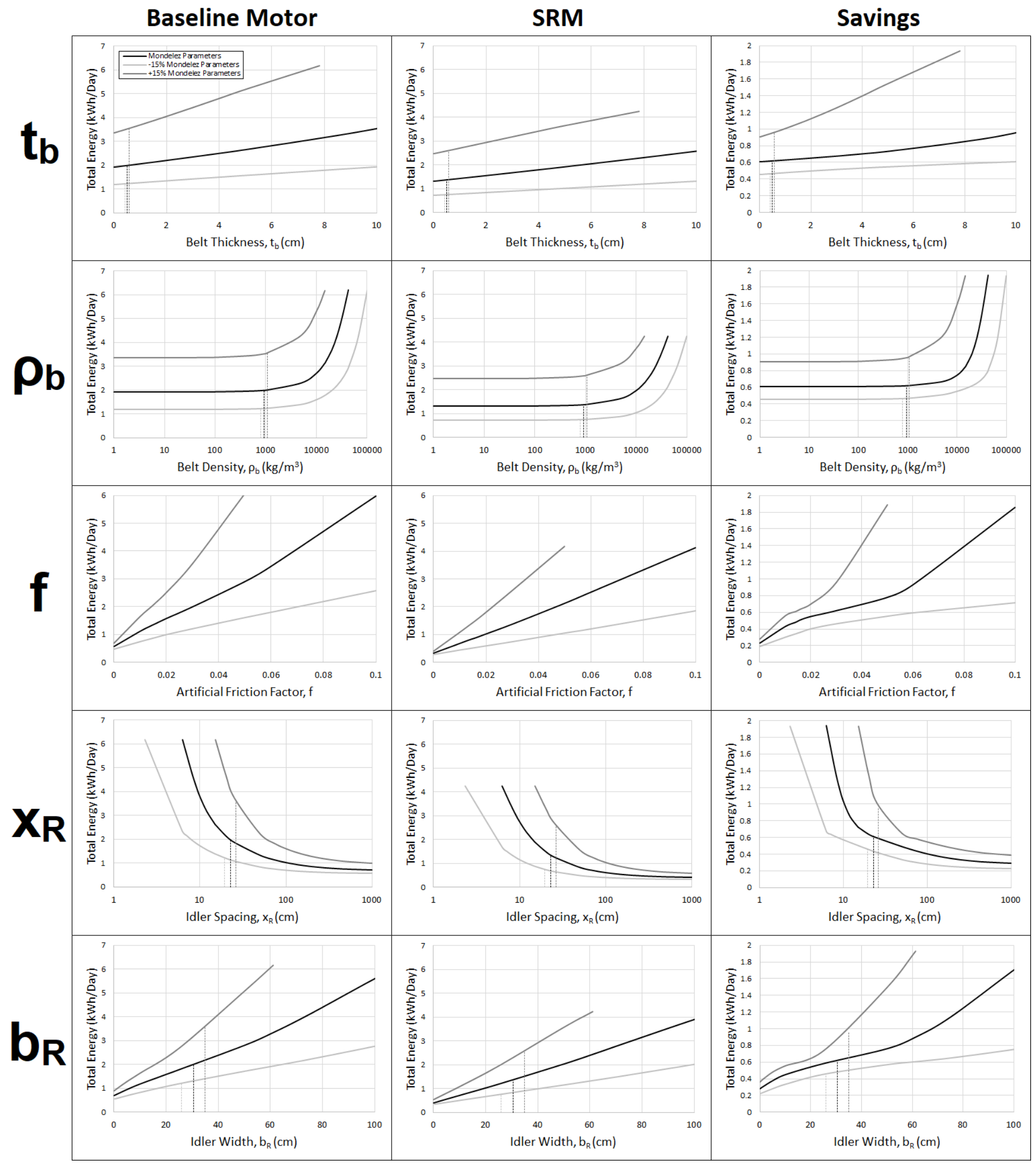

Figure 45. Sensitivity of motor/drive system energy consumption and savings to variation in conveyor structural parameters: belt thickness $\left(t_{b}\right)$, belt density $\left(\rho_{b}\right)$, artificial friction factor $(f)$, idler spacing $\left(x_{R}\right)$, and idler width $\left(b_{R}\right)$ 


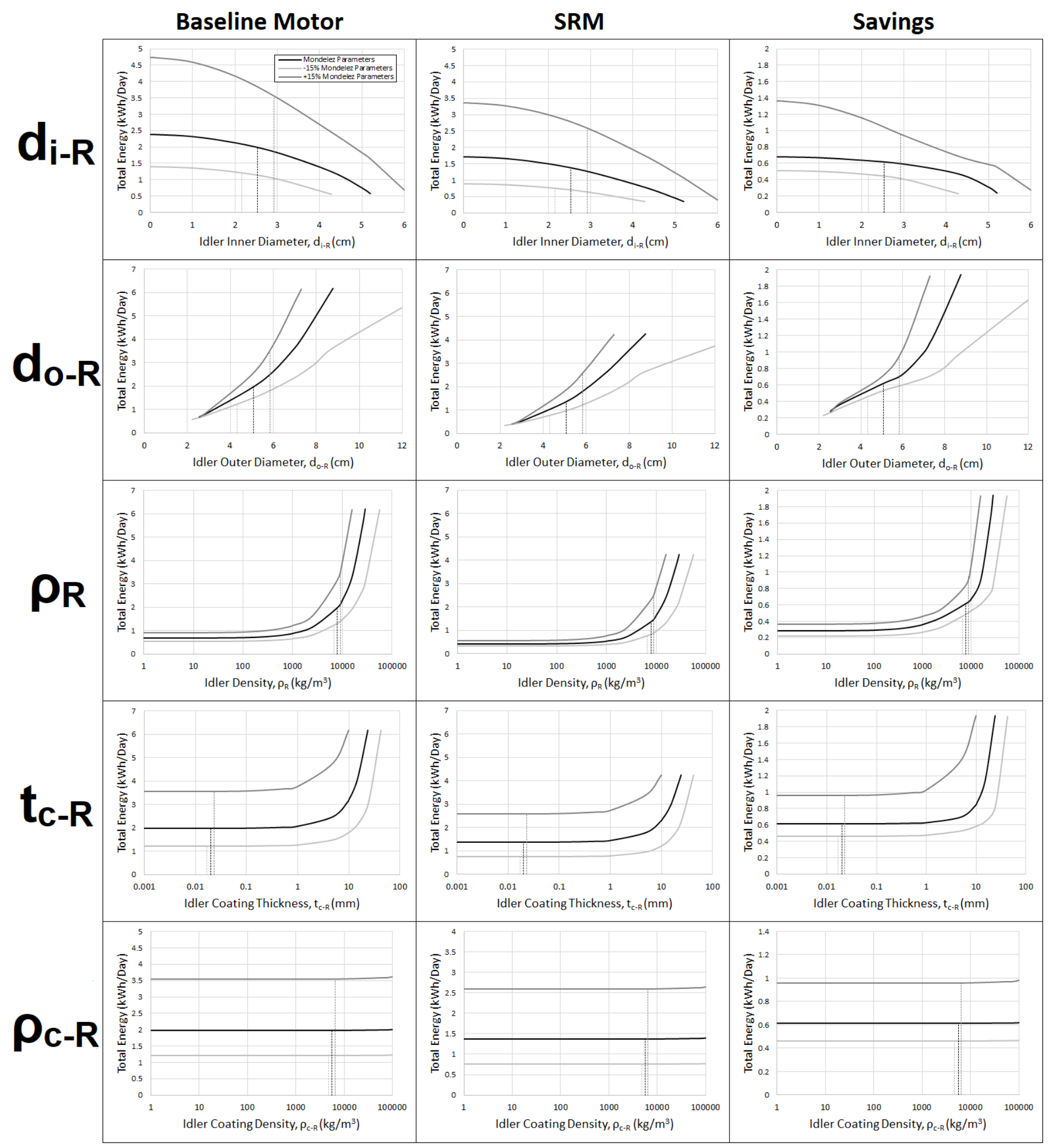

Figure 46. Sensitivity of motor/drive system energy consumption and savings to variation in conveyor structural parameters: idler rotating part inner diameter $\left(d_{i-R}\right)$, outer diameter $\left(d_{o-R}\right)$, idler rotating part material density $\left(\rho_{R}\right)$, idler coating thickness $\left(t_{c-R}\right)$, and idler coating density $\left(\rho_{c-R}\right)$ 


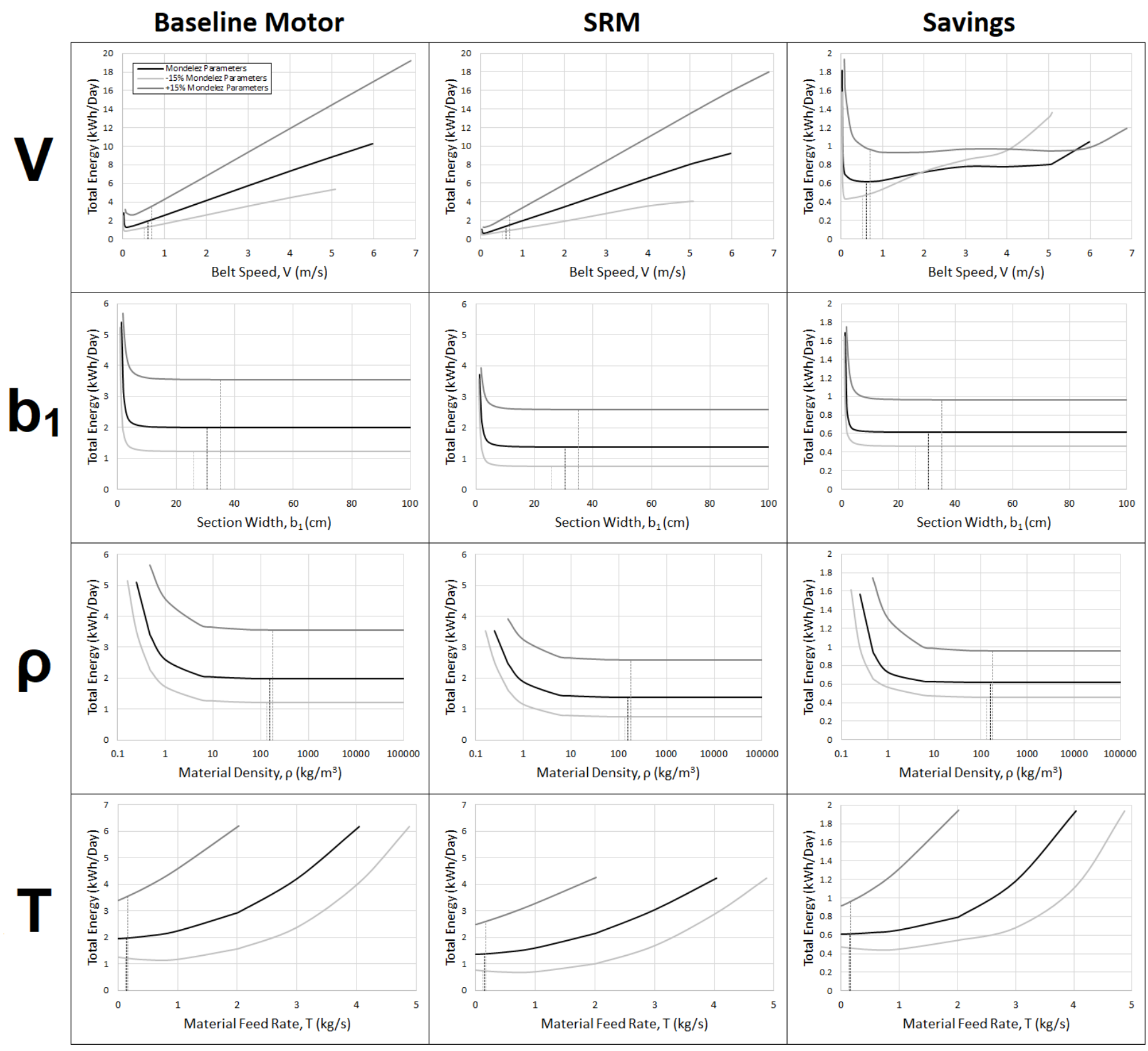

Figure 47. Sensitivity of motor/drive system energy consumption and savings to variation in conveyor operational parameters: belt speed $(V)$, section width $\left(b_{1}\right)$, conveyed product material density $\left(\rho_{R}\right)$, material mass feed rate $(T)$ 